\title{
Capturing the essence and the coalescence of presence within the community of inquiry of an online graduate course in multicultural diversity
}

\author{
Katherina C. Muller \\ West Virginia University
}

Follow this and additional works at: https://researchrepository.wvu.edu/etd

\footnotetext{
Recommended Citation

Muller, Katherina C., "Capturing the essence and the coalescence of presence within the community of inquiry of an online graduate course in multicultural diversity" (2009). Graduate Theses, Dissertations, and Problem Reports. 2929.

https://researchrepository.wvu.edu/etd/2929

This Dissertation is protected by copyright and/or related rights. It has been brought to you by the The Research Repository @ WVU with permission from the rights-holder(s). You are free to use this Dissertation in any way that is permitted by the copyright and related rights legislation that applies to your use. For other uses you must obtain permission from the rights-holder(s) directly, unless additional rights are indicated by a Creative Commons license in the record and/ or on the work itself. This Dissertation has been accepted for inclusion in WVU Graduate Theses, Dissertations, and Problem Reports collection by an authorized administrator of The Research Repository @ WVU. For more information, please contact researchrepository@mail.wvu.edu.
} 
Capturing the Essence and the Coalescence of Presence within the Community of Inquiry of an Online Graduate Course in Multicultural Diversity

Katherina C. Muller

Dissertation submitted to the College of Human Resources and Education

at West Virginia University in partial fulfillment of the requirements

for the degree of

Doctor of Education

in

Curriculum and Instruction

\author{
Ardeth Deay, Ph.D. Chair \\ Jim Rye, Ph.D. \\ Charline BarnesRowland, Ed.D. \\ Pat Obenauf, Ed.D. \\ Douglas Smith, Ph.D., Litt.D. \\ College of Human Resources and Education
}

\author{
Morgantown, West Virginia \\ 2009
}

Key Words: Community of Inquiry, Cognitive, Social and Teacher Presence, Asynchronous, Discourse Analysis, Multicultural, Diversity

Copyright 2009 Katherina C. Muller 


\title{
ABSTRACT \\ Capturing the Essence and the Coalescence of Presence within the Community of Inquiry of an Online Graduate Course in Multicultural Diversity
}

\author{
Katherina C. Muller
}

In this study, students who are preservice and inservice teachers participated in an asynchronous online graduate course in multicultural diversity during the fall of 2008 . Their emails, threaded discussions, cross-cultural community interactions, and final reflections were examined and analyzed revealing their perceptions of their experiences in this course. The main relevance of the study was to provide insight and new understandings of learning online.

The Community of Inquiry provided the framework within which these insights and understandings were drawn. Four archived course components were analyzed: emails, threaded discussions, cross-cultural community interactions, and final reflections. A coalescence of presence was found throughout. Themes of transformation emerged from the threaded discussions, cross-cultural community interactions, and final reflections. Although most of the participant perceptions of learning online were positive, some downsides were voiced, namely, difficulties with technology and preference for face to face (f2f) instruction.

The study addressed the overarching question: How do teachers' perceptions of and experiences in an online graduate course on diversity education evolve over time? Themes which emerged from the email section included technology issues, assignment and grade expectations, and life challenges. Threaded discussions, cross-cultural community interactions, and final reflections revealed themes of transformation. Early in the course, participant posts and responses were peppered with statements of disbelief, e.g. "I didn't know..." and "I can't believe..." By the end of the course, the statements had evolved to "I now know..." and "I now believe..." as the participants examined and analyzed their core beliefs. 


\section{DEDICATION}

I dedicate this dissertation to Ardeth Deay and all educators who have made it their mission in life to promote equity, social justice, and democracy for all. 


\section{ACKNOWLEDGMENTS}

First and foremost, I am thankful to Ardeth Deay for her patience and steadfastness in her mentoring of me through this daunting project. Without her resolve I honestly would never have

finished. I also wish to thank the members of my doctoral committee, Jim Rye, Charline Barnes, Pat Obenauf, and Doug Smith, all of whom were chosen for the special talents they brought to the table and their unwavering support of my work. Additionally, heartfelt thanks go to the members of my family who supported me without any doubt of my ability to finish this dissertation. Special thanks go to my parents for their unconditional love and the immigrant stories that served as the inspiration for my career and life's work. Special thanks also go to my son, Nicholas, for sending me back into the school system after a long hiatus in the corporate world. Finally, extra special thanks go to my husband, Rich, for his unwavering support. 
Revolutionary changes in technology, the global marketplace and significant social, political and environmental issues dramatically affect what students today must know. The challenge to educators and parents is to provide instruction that is not only relevant and engaging but that also includes the world-class rigor necessary to prepare students to get a job in a culturally diverse, technologically complex and economically competitive world.

http://wvde.state.wv.us/global21/overview.html

\section{GLOBAL21}

West Virginia Department of Education 


\section{TABLE OF CONTENTS}

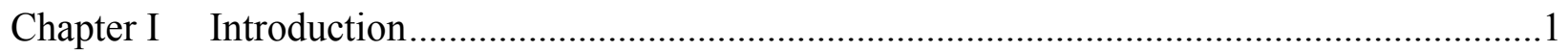

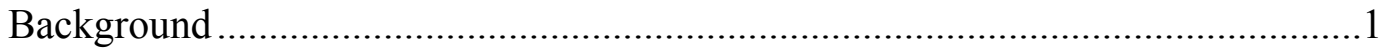

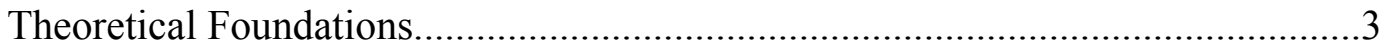

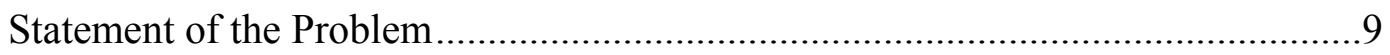

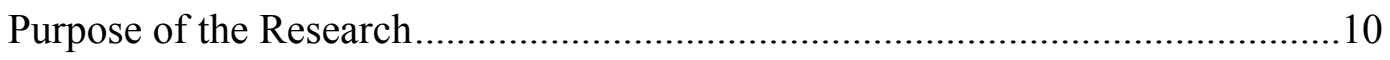

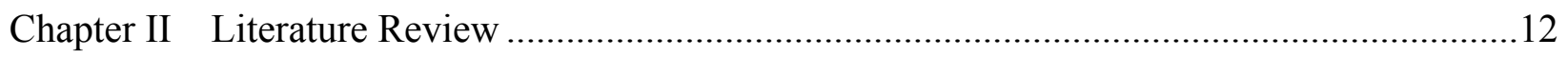

Literature Focus on Learning Online ................................................................12

Literature Focus on the Community of Inquiry ................................................17

Literature Focus on Multicultural Education........................................................24

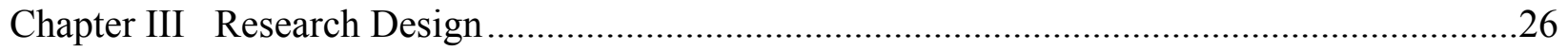

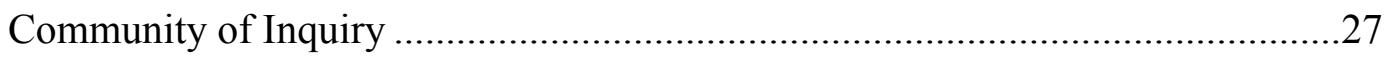

Description of the Population …………………………........................................

Selection of the Participants......................................................................................

Data Collection and Analysis.................................................................................

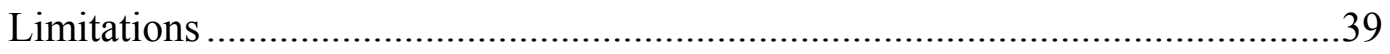

Chapter IV Results ....................................................................................................

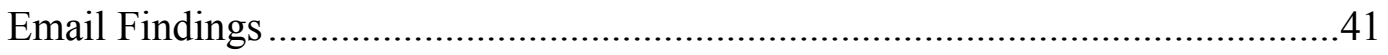

Threaded Discussion Findings ................................................................................49

Cross Cultural Community Interaction Findings ....................................................96

Final Reflection Findings.................................................................................102

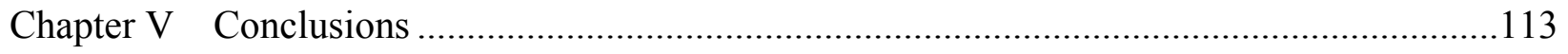

Responses to Research Questions ................................................................113

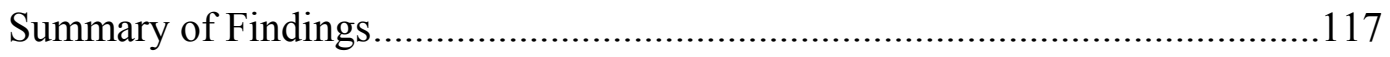

Implications for Future Practice.....................................................................119 
Recommendations for Future Research ........................................................1 $10 \square$

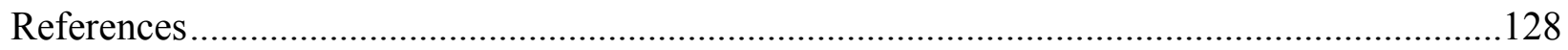

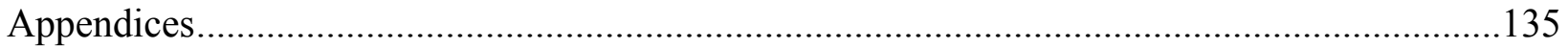

Figure 1: Model of a Community of Inquiry ..............................................135

Table 1: Community of Inquiry Model of Practical Inquiry..........................136

Appendix A: Course Welcome Letter......................................................137

Appendix B: Course Syllabus................................................................139

Table 2: Demographic Data .................................................................. 146

Table 3: Threaded Discussion Posts Sorted by Role .......................................147

Table 4: Threaded Discussion Posts Sorted by Presence and Category ............148

Figure 2: Threaded Discussion Categories of Presence over Time ....................149

Figure 3: Emails Sent by Students to Instructor over Time............................150

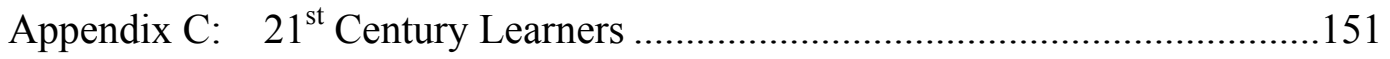




\section{CHAPTER I \\ INTRODUCTION \\ Background}

Learning online is and continues to be a growing phenomenon worldwide. Research confirms the importance of technology and cultural competence in the classroom. Today's education and political focus on student achievement and teacher accountability underscores not only the obvious ethical and moral ramifications of equitably educating every child, but the legal consequences as well. Teachers in schools today and in the future must be able to negotiate technology and the diverse terrain of the multicultural classroom because not only will they, their students, and their schools, be left behind, but the United States of America as well. Year after year, statistics continue to show the volatility of America's stance in the education arena as other countries jockey for position (Darling-Hammond et al, 2009). The domino effect is clear if we continue to follow this downward trajectory and ignore what the statistics are telling us about our children and our schools (Bushaw \& Gallup, 2008). Much of the burden lies solely on the shoulders of the teachers and the teachers of teachers to raise the bar and indeed make sure that no child is left behind as the rest of the world soars by academically (Organization for Economic Cooperation and Development, 2007).

Online graduate courses on diversity in the classroom are one powerful approach to tackling the challenges today's teachers face as they stride into their increasingly diverse classrooms in the fall of every school year. The potent multicultural curriculum and the ease of online instruction play a transformational role in the lives of the teachers who participate in such courses. Discourse analysis can show how lives are changed as teachers weave in and out of multicultural theory and practice throughout the online course environment. Today's fast-paced volatile global environment calls for immediate attention to bringing students and teachers up to 
speed on technology and multicultural issues. "The fierce urgency of now" (Obama, 2007) couldn't be clearer.

Christensen, Horn, and Johnson (2008) in their book, Disrupting Class: How Disruptive Innovation will Change the Way the World Learns give their perspective on school reform and the future by going back to the future of innovation in the business world. By examining lessons learned by companies such as Apple, Microsoft, Toyota, Sony, and IBM, the authors write of a time when Drucker, Covey, and Peters ruled and individual employees were valued for the talents they brought to the table. In making the leap to the current school system, the authors propose that transformation can occur by espousing a "student-centric approach based on customization to address the needs of each individual student" (p. 12). This "student-centric" approach drawing on intrinsic motivation leads to their prediction that this method will grow and transform school as we know it. Based on their research, the authors predict that "by 2014, online courses will constitute $25 \%$ of all high school course offerings.... Half of high school courses will be delivered online by 2019" (p. 118). They believe that the impact of this growth and "volume of online instruction will finally support the development of student-centric online technology" (p. 119).

As indicated by Christensen, Horn, and Johnson (2008) above, online learning has been and continues to be a growing phenomenon. Garrison, in his seminal work on the Community of Inquiry (CoI) model (2000), examines and analyzes an important aspect of this online revolution, namely, the online course itself. The CoI model has demonstrated its ability to withstand the sands of time as more and more research is built upon it. A Google search on January 28, 2009 revealed that Garrison's foundational article, "Critical inquiry in a text-based environment: Computer Conferencing in Higher Education" (2000) has been cited more than 500 times to date. 
In his search for how learning occurs in the online course, Garrison has found that three elements are required: social, cognitive, and teaching. These three elements come together in the form of three interlocking circles (see Figure 1, p. 135). Each circle represents what Garrison calls a presence and each circle intersection represents the coalescence of two adjacent presences. Supporting discourse represents the coalescence of social presence and cognitive presence, selecting content represents the coalescence of teaching presence and cognitive presence and setting climate represents the coalescence of social and teaching presence. The three presence and the intersections of the three presences all coalesce in the center of the model to form the educational experience.

The purpose of this research is to capture the essence of this coalescence of these three presences by looking at the perceptions and experiences of the students in an online graduate course on diversity. The framework of the Community of Inquiry will guide the content analysis of the archived threaded discussions, cross-cultural community interactions papers, course emails and final reflective papers.

\section{Theoretical Foundations}

The theoretical foundations of the educational experience can be viewed from a number of perspectives. In What is Called Thinking? (1968) Heidegger muses on the phenomenon of learning. He metaphorically describes the learner as an apprentice to a carpenter and his relationship to the subject of his work (wood). The essence of this relationship to the wood is inextricably connected to the presence of a teacher (the carpenter). He explores this teacherlearner juxtaposition by deconstructing why teaching is more difficult than learning. "Teaching is more difficult than learning because what teaching calls for is this: to let learn. The real teacher, in fact, lets nothing else be learned than - learning" (p. 15). 
Heidegger also uses the metaphor of a path as a way of thinking and questioning, a path which has its own route and form. He brings in the idea of crossroads and trivium: three areas studied independently yet already interconnected - three paths fusing into one. Heidegger speaks of pursuing this trivium (grammar, rhetoric, and dialectic) one by one (Heidegger, 1999). Heidegger presents the relationship between teacher and student as homologous, meaning that the teacher and student are egalitarian by nature. The teacher provides the student with the spiritual fodder necessary for molding and fashioning in harmony with some intangible form (Heidegger, 1999).

Like Heidegger, Vygotsky also uses metaphors to describe the types of processes and relationships now being revisited and applied to learning online years later. In the 1962 edition of Thought and Language, his words liken the connection of a person to humanity as a paradox, a river and its branches as it combines and separates the unique elements of its existence similar to the ebb and flow of the presences of the Community of Inquiry in today's online classes. In the afterword of Mind in Society (1978) editors Vera John-Steiner and Ellen Souberman write, "Vygotsky presents a sophisticated argument demonstrating that language, the very means by which reflection and elaboration of experience takes place, is a highly personal and at the same time a profoundly social human process" (p. 126). They describe how Vygotsky views the internalization and personalization of social language (two facets of cognition), initially separate then merged afterward: "Up to a certain point in time the two follow different lines, independently of each other...At a certain point these lines meet, whereupon thought becomes verbal and speech rational" (p. 44). John-Steiner and Souberman contend that what Vygotsky shows here is the usefulness of thinking of these associated purposes not as individual or unique but as a coalescence of two distinct elements - social and cognitive. "The particulars 
of human social existence are reflected in human cognition: an individual has the capacity to externalize and share with other members of her social group her understanding of their shared experience" (p. 132). This process can be viewed as similar to the coalescence of the social and cognitive elements of the Community of Inquiry in an online course.

Vygotsky's zone of proximal development further adds to the theoretical underpinnings of the Community of Inquiry Model in that social skills and information become internalized as subject matter is meticulously and specifically taught by a highly qualified and skilled teacher. The overarching principles of his cognitive theory include "the transformation of an interpersonal (social) process to an intrapersonal one; the stages of internalization; and the role of experienced learners" (p. 131). He describes the zone of proximal development as "the distance between the ... actual development level as determined by independent problem solving and the level of potential development as determined through problem solving under adult guidance or in collaboration with more capable peers" (p. 131). Vygotsky perceived the educational experience to be an overwhelmingly social process in which language performed a large part in both the teaching and cognitive arenas. Through the process of scaffolding, teachers could invariably coach their students from their stage of development to the next level. These concepts mirror Paolo Freire's ideas about tailoring pedagogy to place and space, in other words, to where his students are coming from culturally and historically (Freire, 1970).

Vygotsky and Luria (Vygotsky's apprentice) delved into research in which they studied the cognitive results of ongoing social adjustments and the influence of the educational experience (Luria, 1976). Vygostky was troubled by a world that in many ways was similar to the diverse and multicultural world we live in today. In Mind in Society (1978) editors JohnSteiner \& Souberman write that Vygotsky spent much time thinking about the "social and 
educational transformations brought about by the October Revolution. Similar concerns occupy many contemporary educators in countries undergoing rapid modernization and urbanization" (p.130). Jonathan Kozol is one of these contemporary educators who voices similar themes of mass education and social structure gone awry in his 2005 book, The Shame of the Nation: The Restoration of Apartheid Schooling in America.

At the same time as Vygotsky was writing halfway around the world another great thinker, John Dewey, was pondering the state of society and education. Dewey's work contributed important foundational support to the emerging technological society of today. Taking on the rugged individualism concept of his time Dewey worked to change the current view from all for one to one for all, "emphasiz(ing) the crucial importance of the collaborative group and shared activities and experiences in creating social intelligence" (Gutek, 2001, p.

304). In his third edition of Historical and Philosophical Foundations of Education, Gutek (2001) describes Dewey's ideas:

In the interactive episode between the person and the environment, thinking occurs and from it learning takes place. When the person encounters an obstacle or impediment to activity, a problematic situation arises. For Dewey, life itself was problematic. Interaction with the environment alters both the individual and the society so that new problems arise. It is by resolving these problems that thinking occurs and human growth, or progress, takes place. (p. 313)

Dewey's focus on this interactive nature of life led him to create the following stages based on his version of the scientific method also known as the "complete act of thought" (Gutek, 2001, p.

313). Dewey's five stages follow:

1. The person encounters something different, a new experience or deviant particular that stops the flow of ongoing activity. It is in the context of this new element that the person finds herself or himself in a problematic situation ... used educationally when a student or group of students encounters a problem needing to be solved.

2. For the person to solve the problem, the element that is blocking activity must be located and defined. The question needs to be asked, "What is causing the problem?" 
Once a definition is posed, the person can begin to locate and solve the problem. In the educational situation, the ability to define the problem correctly is an important skill. The definitional phase of problem solving, if correctly done, will point the learner to the resources needed to solve the problem.

3. After the problem has been located and defined, it is then possible to gather information, do research, and consult previous experience that will shed light on the problem and point to its resolution... In this stage, the teacher functions as a resource person who facilitates students' research activities.

4. Now comes the conjectural stage, in which tentative hypotheses of possible action are structured. The person or group reflects on the possible actions and mentally explores the consequences of each... In the educational situation, the goal is to develop reflective attitudes that contribute to planning skills.

5. The last stage involves acting on the tentative hypothesis that is likely to resolve the problem by affecting the projected and desired consequences. If the problem is solved, the procedures of the complete act of thought have been followed correctly. If it is not resolved, the process needs to be reexamined to identify mistakes that may have interfered with its solution. If the problem is solved, the person resumes activity and adds the particular problem-solving episode to her or his network of experience. In the educational situation, the final step of the problem-solving sequence is of crucial importance. Unlike many conventional school situations where problem solving stays strictly academic, Dewey's process requires action.... For Dewey, the complete act of thought, or problem solving according to the scientific method, is the proper way to think and also the most effective strategy for teaching and learning. (Gutek, 2001, p. 314)

Dewey's view of the United States as a giant collective made up of smaller groups in terms of race, ethnicity and gender all working for the good of the whole, freely and collaboratively, fits in with his scientific method. For Dewey, democracy was "a way of life, a culture, free of those absolutes that blocked truly experimental inquiry....The social setting was to be free of coercive and authoritarian persons who would jeopardize freedom of thought, inquiry, and experimentation" (Gutek, 2001, p. 316). Through the scientific method and free social interactions, Dewey believed that people could exercise "reflective inquiry and practical intelligence" (Gutek, 2001, p. 317). Garrison (2002) would draw heavily from Dewey’s 
practical inquiry model in the development of the cognitive presence of the community of inquiry.

While Dewey was contemplating the problematic nature of life, Jacob Riis was taking on the problematic slums of New York. The concept of assimilation was gaining popularity among the Northern and Western Europeans who had already settled in the United States as the new wave of immigrants began to flood in from Southern, Central, and Eastern Europe. Riis's (1890/1957) groundbreaking expose on the squalid conditions these newcomers faced and endured reached the ears of Theodore Roosevelt bringing attention to the multicultural "problem" the country was facing. World War I and II exacerbated the situation as tensions rose in response to the events that took place. Additionally, racial tensions escalated within the United States among African Americans and Whites until the civil rights movement of the 1960's began addressing the issues.

Multicultural education evolved out of this melee and continues to grow and change, defying definition. James Banks (2006) writes,

Multicultural education includes but is much more comprehensive than ethnic studies or curriculum reform related to ethnicity and culture. It focuses on modifying the total school environment so that students from diverse ethnic and cultural groups will experience equal educational opportunities. Educators must reform their total educational environments in order to implement powerful multicultural education and give all students an equal opportunity to learn. (p. 63)

Based on the seminal works of these philosophers, it is clear that many of the global perspectives and the foundation of the Community of Inquiry emanate from the philosophies and experiences of these unique individuals. 


\section{Statement of the Problem}

The problem faced by today's teachers that will be addressed in this research is two-fold: increasing diversity in the classroom and online learning. In order to step up to the role of $21^{\text {st }}$ century teachers, teachers must themselves be life-long learners. In order to teach their technology-savvy students, they must be technology-savvy as well. In order to teach the increasingly diverse students they find in their classrooms, they must themselves understand the many cultures of our global society and know how to teach its children.

Online learning is a relatively new way of learning and teaching that has increased in usage in higher education over the past decade. Because it is a new method of learning and teaching, ongoing research seeks to define and refine current theory and practice. Three areas that invite ongoing research are: identifying evidence of higher order thinking and learning in online courses (cognitive presence); identifying evidence of teaching presence online and its impact on higher order thinking and learning; and identifying evidence of social presence and its impact on student learning.

The asynchronous environment of online courses allows for a convenience that face to face (f2f) classes do not provide, namely, anywhere, anytime access to learning. Time to compose coherent, well-thought out answers adds to the quality of the online dialogue that f2f classrooms may not always afford due to the constraints of allotted time to cover vast amounts of material. The asynchronous environment allows for all voices to be heard. Additionally, the online course casts a wide global net potentially allowing for students from around the world the choice to participate in real time (synchronously) or when time permits (asynchronously). This unique advantage grants geography-bound, monocultural students in particular, the opportunity to not only experience a course with multicultural content but also allows them to interact with 
others who may have uniquely different backgrounds from their own (Karpova, Correia, \& Baran, 2008). The weaving of multicultural theory and practice in the context of the online environment provides a powerful vehicle for transformation of self and view of the world.

\section{Purpose of the Research}

The purpose of this research is to explore student perceptions about learning online. In order to better understand how $20^{\text {th }}$ century educated professors can prepare themselves and their student teachers so they can teach preK-12 students in 2018 (Rubin, 2008), this research study looked to Akyol and Garrison's recent research study, "The Development of a Community of Inquiry over Time in an Online Course: Understanding the Progression and Integration of Social, Cognitive and Teaching Presence" (2008). The purpose of their study was to look at how students perceive learning online. In their study, Akyol and Garrison used the Community of Inquiry framework as the tool through which they examined asynchronous threaded discussions. They categorized several discussion postings via transcript analysis "in order to understand the progression and integration of each of the Community of Inquiry presences" (p. 3).

Similarly, my study examined how student perceptions of and experiences with learning online within the context of an online graduate course on diversity changed over time. Analysis of computer-mediated communication using the CoI framework aided in teasing out and organizing these perceptions and experiences.

Taking into account the content and mode of transmission of this online course on diversity education and today's local, national, and global state of affairs, my study explores the perceptions and experiences of these participants in regard to learning online and multicultural issues. This examination of the perceptions and experiences of the students will be conducted through content analysis of archived course materials. Consequently, the main question which 
directs this research study is: How do teachers' perceptions of and experiences in an online graduate course on diversity education evolve over time?

Other questions guiding the research are:

1. What light do the threaded discussions shed on the perceptions and experiences of teachers in an online graduate course on diversity education?

2. What do the emails reveal about the perceptions and experiences of the teachers?

3. What do the cross-cultural interactions reveal about their perceptions and experiences?

4. What do the reflections reveal about the perceptions and experiences of the teachers? 


\section{CHAPTER II}

\section{LITERATURE REVIEW}

This chapter primarily discusses the current research in the field that relates to the online educational experience in general and then focuses more specifically on the Community of Inquiry (Garrison, Anderson, \& Archer, 2000). Multicultural education literature will be examined in the context within which it is presented, namely, as the content found in the online graduate course upon which this interpretive, descriptive case study research is based.

\section{Literature Focus on Learning Online}

Online education is a growing phenomenon. The Sloan Consortium, in their sixth annual report on the state of online learning among higher education institutions in the United States released in November, 2008, tells us exactly how large this phenomenon has become based on responses from over 2500 colleges and universities. The numbers speak for themselves:

- Over 3.9 million students were taking at least one online course during the fall 2007 term. A 12 percent increase over the number reported the previous year.

- The 12.9 percent growth rate for online enrollments far exceeds the 1.2 percent growth of the overall higher education student population.

- Over twenty percent of all U.S. higher education students were taking at least one online course in the fall of 2007. (Allen \& Seaman, 2008, p. 4)

These same institutions believe that the economy will not have a negative impact on enrollment in online courses. Quite the contrary, unemployment and underemployment may, in fact, bring more students to the online courses of these institutions. Public institutions especially believe that "online education is critical to their long-term strategy" (Allen \& Seaman, 2008, p. 
11). The steady growth in online enrollments seems to be discipline-wide with the lone exception of engineering.

Bender, in her book, Discussion-based Online Teaching to Enhance Student Learning (2003), describes the theoretical and practical implications of learning in the online environment by applying theories on how people learn, how to manage online discussions, and how to teach in this new online environment by effectively connecting with students to produce exemplary outcomes.

Hiltz and Goldman add to this research in their edited collection of articles on asynchronous learning networks in their book, Learning Together Online (2005). In addition to their own co-authored articles, they include articles by other well known experts in the field of online learning such as J. B. Arbaugh, Raquel Benbunan-Fich, Karen Swan, and Peter Shea. Articles define asynchronous learning networks, compare the effectiveness of face to face (f2f) to online courses, discuss quantitative, qualitative and mixed methods research methods in online research, examine contextual factors, students, faculty and technology, and make suggestions for moving forward.

Maurino (2007), in her analysis of 37 current studies on critical thinking and deep learning in online threaded discussions, explains that "threaded discussion forums have been a popular topic for the past few years in distance education research ....and have only recently been considered as a potential vehicle for the development of critical thinking skills and deep learning" (p. 242). 19 of the studies were graduate courses and 12 of the 19 were education courses (p. 243). One of the prevalent themes of her synthesis of the research consisted of the contrary nature of the various studies. For example, participation quantity and quality was reported from one end of the continuum to the other; some reported low participation and low 
quality while others reported high participation and high quality; others reported mixed results (p. 244). However, the one theme that came up time and time again was that "deep learning does NOT happen spontaneously and that when it does happen, it is difficult to measure" (p. 246).

Arbaugh and Rau (2007) explored the effects of course subject, organization, and student conduct on the students' perceptions about their knowledge acquisition and fulfillment in online MBA courses in their two-year study. The importance of this research lies in the focus on discipline-specific outcomes, student perceptions of learning and satisfaction, and instructor characteristics. Arbaugh and Rau (2007) believed "there is a lack of knowledge regarding the extent to which effective online teaching and learning practices are discipline-specific" (p. 63) and hence were interested in understanding how students' perceptions of learning online is influenced by the course subject. Furthermore, they wanted to see if attributes of course subject in combination with learning online produced significant results. They found that "there were significant differences in perceived student learning” (p. 73) between courses. Moreover, they found the following concerns:

- Using finance as a referent discipline, (they) found statistically significant differences in the mean course outcomes (students' perceived learning and satisfaction with delivery medium) associated with thirteen business disciplines.

- Although most of these disciplinary differences ceased to be significant predictors of student perceived learning as structural and behavioral characteristics were incorporated into the model, these differences remained significant predictors of perceived delivery medium satisfaction.

- Some structural and behavioral characteristics were significant predictors of course outcomes, but in opposite directions: 
o Media variety was a positive predictor of delivery medium satisfaction but a negative predictor of perceived learning.

o Learner-learner interaction positively predicted perceived learning but negatively predicted delivery medium satisfaction.

- These findings suggest that instructors of online graduate courses must manage tradeoffs in balancing students' learning with their perceptions of the internet as a course delivery medium. (p. 63)

- This finding raises the question of whether instructors should focus on interacting with students, pushing them to interact more with each other, or being somewhere in the middle, and suggests the need for additional research on appropriate types and levels of participant interaction in online MBA courses. (p. 80)

- This raises the questions of whether there are characteristics of these subject areas that better lend themselves to interaction than other disciplines. Alternatively, these findings may reflect that these courses have been structured in such a way to encourage a higher level of interaction. (p. 80)

Limitations in their study include single institution, generalizability to programs which are completely online due to participants also being enrolled in $\mathrm{f} 2 \mathrm{f}$ classes at the same time vs. online classes alone, generalizability to undergraduate online programs, and lack of fully f2f classes of same courses to compare to. Yet, in spite of these noted limitations, other research studies have not found any reportable differences between $\mathrm{f} 2 \mathrm{f}$ and online graduate courses in regard to learning outcomes; these studies include a 51 journal meta-analysis by Zhao, et al., (2005) on articles published after 1998, a meta-analysis by Stizman, et al., (2006), and others (Baugher, Varnelli, \& Weisbord, 2003; Alavi et al., 1997; Arbaugh, 2000; Clouse \& Evans, 
2003; Dellana et al., 2000; McLaren, 2004). This research adds credence to Clark’s (1994) argument that "delivery medium does not matter; it is the method within the medium that matters for delivering education" (p. 25).

The following implications of Arbaugh and Rau's (2007) study of the effects of discipline, structure and behavior on course outcomes add to the literature review of this study:

- For researchers, disciplinary effects in online learning merit further study.....At minimum, (the) findings suggest that disciplinary effects should be one of the contextual factors used to extend Garrison and collegues' (2000) CoI model.

- Another issue for online learning researchers is whether disciplinary, instructor, and course structural characteristics are sufficient for predicting student satisfaction with virtual learning environments.

- A third implication of (the) study is the need for researchers to consider program/degree level and institutional effects more thoroughly in future studies....There likely are institutional factors that were not considered in either study that create differing contexts for the role and importance of participant interaction in the respective institutions' virtual learning environments.

- Lastly...instructor experience in conducting online courses was a significant predictor of satisfaction with the delivery medium .... and was a significant predictor of perceived learning.

- Behavioral effects are most significantly associated with perceived learning, whereas disciplinary and course structural effects are most significantly associated with satisfaction with the internet as an educational delivery medium. (p. 83-85) 
A detailed look at the Community of Inquiry model and how it fits into the understanding of learning online will be described in the next section.

\section{Literature Focus on the Community of Inquiry}

A recent review of the literature by Garrison and Arbaugh (2007) indicates that the Community of Inquiry (CoI) model has been attracting attention since it first appeared in The Internet and Higher Education in the year 2000. Garrison, Anderson, and Archer (2000) introduced the Community of Inquiry model in their precedent-setting research article, "Critical Inquiry in a Text-Based Environment: Computer Conferencing in Higher Education.” Their purpose was to "provide conceptual order and a tool for the use of computer-mediated communication (CMC) and computer conferencing in supporting an educational experience" ( $\mathrm{p}$. 87). Based on the community of inquiry concept and model, and broken down into what they describe as "three elements essential to an educational transaction" (p. 89), they explore the parameters of cognitive, social and teaching presence in the online environment. During their initial research analysis of the online transcripts several themes emerged. They then incorporated these themes into their community of inquiry model to be used as guides or indicators to facilitate the identification of presence within the online transcripts. This template could then be used by researchers and educators to analyze online transcripts in order to understand what is going on in the online course environment. Both researcher and educator could then use this information to identify and optimize online instruction, i.e., to see what is working and what is not working (Garrison, et al., 2000, p. 89).

The CoI model consists of three elements. Figure 1 in the appendix (p. 135) shows the three concentric circles that comprise the CoI model, namely, cognitive presence, social 
presence, and teaching presence. At the locus of the three presences is the educational experience. Table 1 in the appendix (p. 136) lists the three presences and their corresponding categories and indicators which provide a coding template for analyzing and understanding computer mediated communication. The following description of the three presences and their relationship to the $\mathrm{CoI}$ is noted.

\section{Cognitive Presence}

Garrison, Anderson, and Archer (2000) define cognitive presence as "the extent to which the participants in any particular configuration of a community of inquiry are able to construct meaning through sustained communication" (p. 89). The degree, construction, and maintenance of cognitive presence within the community of inquiry will be affected to some extent by the amount of scaffolding provided or not provided to foster communication. "Cognitive presence is a vital element in critical thinking, a process and outcome that is frequently presented as the ostensible goal of all higher education" (Garrison, et al., 2000, p. 92).

Garrison, Anderson, and Archer (2000) built on the research about cognitive presence from the work of Newman, Johnson, Cochrane, and Webb (1996) who studied "deep and surface approaches to learning and thinking in face-to-face and computer-supported group learning context" (p. 58). The findings of Newman et al., (1996), support Garrison, Anderson, and Archer's "theoretical position regarding the potential for facilitating deep and meaningful learning in a computer conference environment" (p. 65).

Another study supporting Garrison, Anderson, and Archer's early research is that of Gunawardena, Lowe, and Anderson (1997) about knowledge construction in a computerconferencing context which "through a grounded theory analysis of the transcripts" (p. 398) produced an interaction model of CMC similar to Garrison's (1991) model focusing on the 
critical thinking process. The Gunawardena, Lowe, and Anderson (1997) model contained "five phases of negotiation and knowledge co-construction: sharing/comparing, dissonance, negotiation, co-construction, testing, and application" (p. 398).

Important to this early foundation of online cognitive presence research are studies that yielded other results. These results are important because they provide information about what is not working in the online course. Replication by Kanuka and Anderson (1998) of Gunawardena, Lowe, and Anderson's (1997) research yielded slightly different results which they hypothesized were due to lack of teacher presence in the computer conference they investigated. Outcomes of a study by Bullen (1998) "of the facilitation of critical thinking within a formal education context supported by computer conferencing" (Bullen, 1998, p. 29) reported methodological issues that would need to be addressed by subsequent research.

Garrison, Anderson, and Archer (2000) offer explanation of methodological challenges challenges that they and others would continue to wrestle with in their ongoing research (Garrison, 2007; Garrison et al., 2006; Arbaugh, 2005; Fahy, 2001).

All these studies have faced methodological challenges in creating and applying valid indicators that reflect the quality and extent of deep and meaningful approaches to learning facilitated in a computer-conferencing environment. The challenge is to choose indicators that are specific enough to be meaningful, but still broad enough to be usable in the actual analysis of transcripts. Furthermore, these indicators must be parsimoniously categorized within the main elements of a community of inquiry such that coherence and meaning are apparent. (p. 94)

To meet the challenge initially, Garrison, Anderson, and Archer (2000) chose to use a generic model of critical thinking originally designed by Garrison (1991). The practical inquiry model consists of a multi-phase process which begins with a triggering event, followed by perception, deliberation, conception, and warranted action. It has its origins in Dewey's (1933) understanding of practical inquiry which consisted of pre-reflection, reflection, and post- 
reflection. It is based on experience. Garrison, Anderson, and Archer (2000) describe how they

use this model within the cognitive presence part of the community of inquiry model:

- The first category of cognitive presence represented in the model is a state of dissonance or feeling of unease resulting from an experience. This category is described as that of a triggering event or communication.

- The second category is that of exploration in a search for information, knowledge and alternatives that might help to make sense of the situation or problem. This category is described as that of searching for clarification and attempting to orient one's attention.

- The third category is integrating the information and knowledge into a coherent idea or concept. The description here is looking for insights and gaining some understanding of the acquired information and knowledge.

- The fourth category is the resolution of the issue or problem. This category is described as an application of an idea or hypothesis. The success of the application and whether the idea is confirmed will determine whether the process of inquiry continues. (p. 98)

From these four categories came the current four categories utilized in the cognitive presence part of the Community of Inquiry: triggering event, exploration, integration, and resolution.

\section{Social Presence}

Garrison, Anderson, and Archer (2000) define social presence as "the ability of participants in a community of inquiry to project themselves socially and emotionally, as "real" people (i.e. their full personality), through the medium of communication being used" (p. 94). Three categories make up the social presence element of the community of inquiry model: emotional expression, open communication, and group cohesion. Each category has a matching indicator or guide to help researchers, instructors or readers of research identify the category. For example, emoticons are an indicator or example of emotional expression; risk taking free expression is an indicator or example of open communication; encouraging collaboration is an indicator or example of group cohesion. Visual cues (being able to see your instructor and classmates) are an important aspect of social presence that has been absent from many online 
environments. Emoticons (e.g. smiley faces made with colons, semi-colons and right parenthesis), exclamation points, the use of capitol letters to accent specific words or groups of words, addressing peers by their name, thanking them, sharing personal stories, etc. are all examples of ways in which online participants signal emotion or give evidence of social presence (Kuehn, 1993; Walther, 1994). Garrison, Anderson, and Archer (2000) sum up:

Individuals must feel comfortable in relating to each other... Such an educational community is nurtured within the broader social-emotional environment of the communicative transaction. We hypothesize that high levels of social presence with accompanying high degrees of commitment and participation are necessary for the development of higher-order thinking skills and collaborative work. (p. 95).

Without social presence, cognitive presence by itself is not enough to sustain a community of learners (Garrison, Anderson, and Archer, 2000).

\section{Cognitive and Social Presence}

Garrison (1997) and Gunawardena (1995) agree that cognitive presence "is more easily sustained when a significant degree of social presence has been established....Socio-emotional interaction and support are important and sometimes essential in realizing meaningful and worthwhile educational outcomes" (Garrison, et al, p. 96). Fabro and Garrison (1998) "found social presence to be crucial in establishing a critical community of learners" (p. 44). Garrison, Anderson, and Archer (2000) explain that this is done through "a collaborative process where critical reflection and discourse are encouraged and practiced" (p. 168). Schrage (1995) defines the "act of collaboration (as) an act of shared creation and/or discovery" (p. 18). Garrison, Anderson, and Archer (2000) explain how inextricably collaboration is tied to learning:

Collaboration must draw learners into a shared experience for the purposes of constructing and confirming meaning. Realizing understanding and creating knowledge is a collaborative process... Reaching beyond transmission of information and establishing a collaborative community of inquiry is essential if students are to make any sense of the often incomprehensible avalanche of information characterizing much of the 
educational process and society today. The educational process is largely concerned with being initiated, not only into the common body of knowledge (i.e., public knowledge), but also into the meta-cognitive processes and culture of a discipline or field of study. Here is where collaboration and critical discourse is essential. Collaborative inquiry provides for a qualitative dimension beyond acquiring specific content of a discipline. (p. 96)

Clearly, in order for learning to take place, a coalescence of social and cognitive presence must take place. Garrison, Anderson, and Archer (2000) explain why they believe these presences must coalesce to create an optimal learning environment within the community of inquiry:

An awareness of the critical thinking and inquiry dynamic is an essential metacognitive ability that encourages students to approach a problem strategically and actively seek out sources of knowledge, discover biases, sift through the increasingly large quantities of information now available, and formulate and defend their own intellectual positions....It is essential that the process be done in an interactive and social environment....There is clearly a need to understand how we can create a critical community of inquiry and support worthwhile educational outcomes using mediated communication technologies such as computer conferencing.... When social presence is combined with appropriate teaching presence, the result can be a high level of cognitive presence leading to fruitful critical inquiry. (p. 97)

The role of teaching presence will be examined in the next section.

\section{Teaching Presence}

The glue that holds the community of inquiry together is teaching presence (Garrison, Anderson, and Archer (2000). Teaching presence consists of more than simple instructor dialogue. In the community of inquiry, teaching presence is far more dynamic and entails instructional design and organization, facilitation of discourse, and direct instruction. Although sustainable teaching presence presents its own unique challenges in an asynchronous text-based communication environment, the research and experiences of Garrison, Anderson, and Archer (2000) "suggest that teaching presence can be created and sustained in computer-conferencing environments despite the absence of non-verbal and paralinguistic cues" (p. 99). Tagg and Dickenson (1995) found that "student activity is influenced by tutor behavior" (p. 45), namely, 
that brief comments from the instructor boosted learner involvement. Teaching presence, whether found in the threaded discussions, emails or within the curriculum itself, is an important part of the learning experience within the Community of Inquiry.

\section{A Complex Process}

A current literature review on online learner participation by Stefan Hrastinski (2008) found that the "research is dominated by low-level conceptions of online participation, which relies on frequency counts as measures of participation" (p. 1758). He did find that some researchers "aim to study more complex dimensions of participation, such as whether participants feel they are taking part and are engaged in dialogues, reflected by using a combination of perceived and actual measures of participation" (p. 1759). In his conclusion, he suggests that research be directed at the more "complex dimensions" of online learner participation, such as "doing, communicating, thinking, feeling, and belonging" (p. 1759). Based on his literature review, Hrastinski (2009) suggests in a follow up article, "A Theory of Online Learning as Online Participation" that online learner participation is "a complex process of taking part and maintaining relations with others; supported by physical and psychological tools; not synonymous with talking or writing; and supported by all kinds of engaging activities" (p. 79). Hrastinski contends that participation and learning are inextricably linked and cannot be separated. He concludes with the simple suggestion that "if we want to enhance online learning, we need to enhance online learner participation" (p. 81). Enhancing online student participation requires more than compelling students to post more. It entails creating a socially and cognitively supportive community of inquiry with teacher presence. This can be achieved through the coalescence of cognitive, social and teaching presence which will consequently foster the optimal education experience. 


\section{Literature Focus on Multicultural Education}

Multicultural education has many perspectives. This section of the literature review will focus on the texts found in the online course beginning with a definition of multicultural education by James A. Banks, followed by Christine Bennett, Gary Howard, Sonia Nieto, and James Loewen.

James A. Banks defines multicultural education in his Handbook of Research on Multicultural Education (Banks \& Banks, 2004) as "a field of study designed to increase educational equity for all students that incorporates, for this purpose, content, concepts, principles, theories, and paradigms from history, the social and behavioral sciences, and particularly from ethnic studies and women's studies" (p. xii). He considers multicultural education a "metadiscipline" (p. xii). In his book Cultural Diversity and Education (2006), Banks adds another perspective about the myriad of terms and views that inundate the field:

A wide range of concepts are used to describe programs and practices related to ethnic, cultural, and racial diversity in Western societies. The proliferation of concepts in part reflects the ideological conflicts in multicultural education and the emergent status of educational reform related to ethnic and cultural diversity. Concepts related to diversity must be better clarified before pluralistic educational reforms and research can be more effectively designed and implemented. (p. 85)

Christine L. Bennett, in her book, Comprehensive Multicultural Education: Theory and Practice (2007), provides a broad framework in which she connects multicultural education to global education. The first sentence in the preface of her book speaks to the importance of this topic: "Today, more than ever before, we are in urgent need of national and global citizens who 
possess multicultural competence, and who are committed to the achievement of worldwide social justice and economic equity as a foundation for lasting peace on the planet." (p. v)

Gary R. Howard, in his book, We Can't Teach What We Don't Know: White Teachers, Multiracial Schools (2006), recounts forty years of multicultural education and social justice through personal narratives and historical events. James A. Banks writes in the series foreword of the enormity of the growing multicultural force we are facing in our future:

The nation's deepening ethnic texture, interracial tension and conflict, and the increasing percentage of students who speak a first language other than English make multicultural education imperative in the $21^{\text {st }}$ century. The U.S. Census Bureau (2000) estimates that people of color made up $28 \%$ of the nation's population in 2000 and predicts that they will make up 38\% in 2025 and 50\% in 2050 (El Nasser, 2004). (p. viii)

James W. Loewen, in his revised edition of, Lies My Teacher Told Me: Everything Your American History Textbook Got Wrong (2007), explores, researches, and decries the eighteen leading high school American history texts found in our schools today. Starting with Columbus and ending with the Iraq War that continues to this day, he unearths the lies and lays down groundwork for examining the truth. He dedicates his book to "all American history teachers who teach against their textbooks" (p. v). Loewen reminds us that in order to look to the future, we must examine the past or our fate will be to repeat our mistakes. 


\section{CHAPTER III}

\section{RESEARCH DESIGN}

The aim of this study was to capture the essence and the coalescence of presence within the Community of Inquiry of an online graduate course in diversity by looking at the participants' perceptions of and experiences with learning online. The Community of Inquiry served as a framework within which participant perceptions were organized. Archived course transcript data were categorized, coded and analyzed within the parameters of the Community of Inquiry framework via content analysis. Because learning online is a relatively new phenomenon, a qualitative design approach was chosen to shine light upon the rich descriptions emanating from the participants' voices captured within the archived documents of the online course. The main objective of the investigation and analysis of these archived course documents was to answer the overarching research question: How do teachers' perceptions and experiences in an online graduate course on diversity education evolve over time?

Concurrent with the analysis of the archived course documents within the framework of the CoI, an open minded approach was kept in play in order to capture the essence of the participants' perceptions in this case study. Stake (2000) defines case study as "a choice of what is to be studied" (p. 435). A case is a "specific, unique, bounded system" (Stake, 2000, p. 436). It has set features of time, space, and components, meaning, the case took place during a specific period of time, in a specific place, with a specific amount of participants (Merriam, 2002). Patton (2002) adds that "well-constructed case studies are holistic and context sensitive, two of the primary strategic themes of qualitative inquiry...Cases can be individuals, groups, (or) cultures" (p. 447). This case focused on 21 participants in an online course during the fall of 2008. 
Qualitative research methods were employed via interpretive, descriptive research. Descriptive research vividly depicts the perceptions and experiences of the participants. In a report prepared by the Institute for Higher Education Policy (1999) for the American Federation of Teachers and the National Education Association, two of the four research approaches found in a meta analysis of the research on the effectiveness of distance learning used descriptive research and case study to disseminate their findings.

Maurino (2007), in her review of current literature on critical thinking when learning online, found a predominance of graduate level education courses. Her research indicated that even though the methodology varied, "content analysis of class transcripts, discussion threads, or listservs was a popular method" (p. 14). This method was found in 22 of the 37 studies she examined, serving as a vehicle to analyze student responses. The student responses were frequently classified by quality and quantity. A number of studies used Bloom's Taxonomy (Bloom, 1956) or the Practical Inquiry Model (Garrison, Anderson \& Archer, 2000).

\section{Community of Inquiry}

Garrison's 2007 review of the Community of Inquiry discusses crucial information about methodology, qualitative transcript analysis and coding protocol. His research found that the CoI framework "has provided a useful tool and approach to studying online learning" (p. 64). The methodology so far has employed an exploratory qualitative approach to provide "insights for the purposes of constructing meaningful propositions to be explored in further research" (Garrison, Cleveland-Innes, Koole, \& Kappelman, 2006, p. 6). Additionally, a great deal of the research can be portrayed as "interpretivist" due to efforts to comprehend interface via text analysis (Miles \& Huberman, 1994). Garrison (2006) believes that comprehending and 
elucidating the multifaceted nature of online conferencing and educational discourse is still in the early phases noting that "the goal is descriptive, not predictive" (p. 2).

\section{Cognitive Presence}

The three presences of the CoI model consist of the cognitive presence, the social presence, and the teaching presence. According to Garrison, et al, (2000), the "concept of the cognitive presence is grounded in the literature on critical thinking and operationalized within a model of practical inquiry" (see Table 1, p. 136). This model of practical inquiry, which comprises the cognitive presence, consists of four categories: triggering event, exploration, integration, and resolution.

\begin{tabular}{|lll|}
\hline \multicolumn{2}{|l|}{ Community of Inquiry Elements, Categories, and Examples of Indicators } \\
\hline Elements & Categories & Indicators (examples of) \\
\hline Cognitive Presence & Triggering Event & Sense of puzzlement \\
\hline & Exploration & Information exchange \\
\hline & Integration & Connecting ideas \\
\hline & Resolution & Apply new ideas \\
\hline
\end{tabular}

Indicators which help in classifying the category further delineate the categories. A sense of puzzlement would be an example of a triggering event; information exchange is an example of exploration; connecting ideas is an example of integration, and applying new ideas is an example of resolution. These indicators serve as a guide to the researcher, instructor, or reader, to narrow down where the participants are in their learning journey.

\section{Social Presence}

Social presence refers to the ability of the participant to project his personality and sense of "self" in the online course. The three categories that make up social presence are emotional expression, open communication, and group cohesion. 


\begin{tabular}{|lll|}
\hline \multicolumn{2}{|l|}{ Community of Inquiry Elements, Categories, and Examples of Indicators } \\
\hline Elements & Categories & Indicators (examples of) \\
\hline Social Presence & Emotional Expression & Emotions \\
\hline & Open Communication & Free expression \\
\hline & Group Cohesion & Encouraging collaboration \\
\hline
\end{tabular}

Indicators further delineate these categories: emoticons are an example of emotional expression; risk-taking expression is an example of open communication; and encouraging collaboration is an example of group cohesion. As in the cognitive presence element, these indicators help guide the researcher, instructor, and reader, in their journey of understanding participant perceptions and experiences.

\section{Teaching Presence}

Teaching presence is defined as "the design, facilitation, and direction of cognitive and social processes for the purpose of realizing personally meaningful and educationally worthwhile learning outcomes" (Anderson, Rourke, Garrison, \& Archer, 2001, p. 2). Categories within teaching presence include design and organization, facilitating discourse, and direct instruction.

\begin{tabular}{|lll|}
\hline Community of Inquiry Elements, Categories, and Examples of Indicators \\
\hline Elements & Categories & Indicators (examples of) \\
\hline Teaching Presence & Design \& Organization & Setting curriculum \& methods \\
\hline & Facilitating Discourse & Sharing personal meaning \\
\hline & Direct Instruction & Focusing discussion \\
\hline
\end{tabular}

Indicators associated with each of these categories are: setting curriculum and methods; sharing personal meaning; and focusing discussion. As in the cognitive and social presence elements, teaching presence indicators help serve as guides to types of teaching presence found in the archived course documents. 
Together, these three elements and their indicators provided the researcher with a tool and a framework within which to analyze the contents of the archived course documents, namely, the threaded discussions, emails, cross-cultural interactions, and final reflections. Results of the findings are discussed in Chapter 4 of this document.

\section{Description of the Population}

The population of this study consists of students in an online graduate course on diversity (see syllabus in Appendix B, p. 139) during the fall of 2008. The students were taking this course for one or more of the following reasons: to complete a master's degree or to acquire initial or additional certification. Twenty-eight students signed up for this course initially. Five students dropped shortly after the course began; one student dropped after 6 weeks and one student did not complete the course assignments. Twenty-one students completed this course. The analysis in this research study will focus on the twenty-one students who completed the course. Of the twenty-one students, seventeen students were female and four students were male. Students have been assigned numbers 1-21 in order to protect their identity and maintain anonymity in accordance with IRB guidelines.

\section{Selection of the Participants}

The participants were selected from the most recently completed online graduate education course in diversity in order to have the most current archived information available for research into the perceptions and experiences of students in the online learning environment.

\section{Description of the participants}

The participants are students who were enrolled in an online graduate class on diversity (see syllabus in Appendix B, p. 139) in the fall of 2008. Per IRB requirements, names have been 
changed to provide anonymity to the participants. Participants are described and organized by gender, ethnicity, age range, and experience in education in the following table:

DEMOGRAPHIC DATA: WHO ARE THE PARTICIPANTS IN THIS STUDY?

\begin{tabular}{|c|c|c|c|c|}
\hline $\begin{array}{c}\text { ROLE IN } \\
\text { PROGRAM }\end{array}$ & GENDER & RACE & $\begin{array}{c}\text { AGE } \\
\text { BRACKETS }\end{array}$ & $\begin{array}{l}\text { EDUCATION } \\
\text { EXPERIENCE }\end{array}$ \\
\hline 1 ELEMENTARY & $\mathrm{F}$ & $\mathrm{W}$ & $31-40$ & 12 \\
\hline 2 ELEMENTARY & $\mathrm{F}$ & $\mathrm{W}$ & $20-30$ & 2 \\
\hline 3 ELEMENTARY & M & W & $20-30$ & 4 \\
\hline 4 ELEMENTARY & $\mathrm{F}$ & W & $20-30$ & 1 \\
\hline 5 ELEMENTARY & $\mathrm{F}$ & $\mathrm{W}$ & $20-30$ & 3 \\
\hline 6 ELEMENTARY & $\mathrm{F}$ & W & $20-30$ & 0 \\
\hline 7 ELEMENTARY & $\mathrm{F}$ & W & $20-30$ & 2 \\
\hline 8 ELEMENTARY & $\mathrm{F}$ & W & $20-30$ & 6 \\
\hline 9 ELEMENTARY & $\mathrm{F}$ & W & $31-40$ & 7 \\
\hline 10 SECONDARY & M & W & $20-30$ & 0 \\
\hline 11 SECONDARY & $\mathrm{F}$ & Latina & $31-40$ & 10 \\
\hline 12 SECONDARY & $\mathrm{F}$ & $\mathrm{W}$ & $20-30$ & 0 \\
\hline 13 SECONDARY & $\mathrm{F}$ & W & $20-30$ & 1 \\
\hline 14 SECONDARY & $\mathrm{F}$ & W & $20-30$ & 2 \\
\hline 15 SECONDARY & $\mathrm{F}$ & Asian & $20-30$ & 4 \\
\hline 16 SECONDARY & $\mathrm{F}$ & W & $20-30$ & 0 \\
\hline 17 SECONDARY & $\mathrm{F}$ & $\mathrm{W}$ & $20-30$ & 2 \\
\hline 18 HIGHER ED & M & W & $20-30$ & 0 \\
\hline 19 HIGHER ED & $\mathrm{F}$ & W & $31-40$ & 10 \\
\hline 20 HIGHER ED & $\mathrm{F}$ & W & $20-30$ & 5 \\
\hline 21 HIGHER ED & $\mathrm{M}$ & $\mathrm{W}$ & $41-50$ & 2 \\
\hline
\end{tabular}


The demographic data of the above chart show that there were four male and 17 female participants in this study. Two of the males and three of the females had no education experience and were in the 20-30 age brackets; all five were Caucasian. On the other end of the spectrum, there are four females who have seven or more years of education experience; of these, two are elementary school teachers, one is a secondary school teacher and another teaches in higher education. Three are Caucasian and one is Latina. All four are in the 31-40 age brackets. Twelve participants have anywhere from one to six years of education experience. Eleven are Caucasian and one is Asian. Six are elementary school teachers of which five are female and one is male. The four secondary school teachers are all female; three are Caucasian and one is Asian. Eleven of the twelve participants are in the 20-30 age brackets. One of these eleven females teaches in higher education. Lastly, one of the twelve participants is a male who teaches in higher education and falls into the 41-50 age brackets.

Herewith follows a description of each of the 21 participants beginning with the elementary education students, then the secondary students, ending with the higher education students. Nine elementary education participants were participants in this study:

Participant 1 is currently in the elementary education master's program. She needs another master's degree and additional certification for her current fourth grade teaching position. She has been teaching English for ten years at the college level and most recently, two years at the sophomore high school level. In addition to her current fourth grade teaching position, she is also the intermediate school remedial specialist. Participant 1 is married and has a seven-year-old daughter. 
Participant 2 is currently seeking a master's in elementary education for which this course is part of the requirements. She has a bachelor's degree in elementary education K-6. She is in her third year of teaching and is currently teaching third grade. She is married.

Participant 3 is in the elementary education master's program for which this course is required. He has a B.S. in Psychology and completed an undergraduate degree in elementary education in July of 2006. He has worked as a child protective service worker for one year and as a case manager for children with severe emotional disabilities for two years. He is currently a third grade teacher, is thirty years old, married, and has a three year old child.

Participant 4 is currently in the master's program for elementary education for which this course is a requirement. She has been a police officer for eight years and has worked in the juvenile hall of one of the largest metropolitan areas in the U.S. She is married with four children and is currently expecting another child.

Participant 5 is currently in the master's program for elementary education. She has a B.A. in music performance and a master's in special education. She has been a substitute teacher in numerous settings for three years and has taught at the higher education level. She has worked full time in a hospital for children. She is married with four children.

Participant 6 is currently in a master's program in elementary education where this course is a requirement. She received her B.S. in May of 2007. She will be student teaching in the spring. She is currently a Cadet in the Air Force ROTC program.

Participant 7 is currently in the master's program for elementary education and is taking this course because it is required. She graduated in August of 2006 with a degree in early childhood and elementary education. She is currently a substitute teacher and an assistant coach for a girl's high school basketball team. 
Participant 8 is currently in the master's program for elementary education and is taking this course because it is required. She has a B.S. in elementary education and graduated in May of 2003. She has five years of teaching experience, three years of which were in Raleigh, North Carolina. She is in her third year of teaching third grade. She is married.

Participant 9 is currently working on a master's in elementary education and is taking this class as part of the requirements to earn a master's degree with initial certification to teach. She has a B.A. in music education. She has been teaching for seven years: three years of high school vocal music and piano and four at elementary general music and choir. She is married and has four daughters ages five, four, three and two.

The following eight secondary education students were participants in this study:

Participant 10 is currently in the secondary education master's program for social studies education for which this course is a major requirement. He received a B.A. in history in 2006 and is twenty-four years old.

Participant 11 is currently in the master's program for secondary education and foreign languages. This course is a requirement to complete her masters. She currently teaches Spanish and is originally from Argentina. She has been in the U.S. for eleven years, has a husband and two daughters.

Participant 12 is currently in the secondary education history master's program for which this course is a major requirement. She has a Regents B.A. in business administration and currently works full time as a retail manager. She is thirty years old and married.

Participant 13 is currently in the secondary education master's program. She has a B.A. in education specializing in biology and general science. She is currently a substitute teacher. 
Participant14 is currently in the curriculum and instruction master's program specializing in social studies. She has an undergraduate degree in education for grades 5-12. She is currently working at a school for blind children and a Montessori daycare. Last year she worked at a school for autistic children. She is twenty-five years old.

Participant 15 is working on a master's degree in secondary education. This course is in the secondary education curriculum. She has a B.A. in English language and literature and public administration. She was born in South Korea and has lived in the United States for seven years. She has worked as a substitute for four years. She is married.

Participant 16 is in the second year of a master's for secondary English education. She has a B.A. in journalism.

Participant 17 is currently pursuing a dual master's degree in elementary education and secondary English education where this course is a requirement. She is currently in her second year as a permanent sub for tenth and eleventh grade. She is twenty-three years old.

Four participants of this study are currently in higher education.

Participant 18 is currently in the dental hygiene master's program. He hopes to teach dental hygiene in higher education. He received his B.S. in dental hygiene. He is not married. Participant 19 is currently a doctoral student in geology and is teaching geology courses at a university. She has a B.S. in psychology and a teaching certificate in secondary science. She is married with two children.

Participant 20 is in an education master's program. She is currently teaching on the college level. She has taught third grade for three years and is married. 
Participant 21 is taking this class because he thought it would be interesting. He finished a master's degree in communication studies in July of 2008. He is a housekeeping and laundry manager for a nursing home and teaches part time at the college level.

\section{Data Collection and Analysis}

The data that were collected and analyzed highlighted the perceptions and experiences of the participants in the online graduate course on diversity education during the fall of 2008 semester.

The researcher used deductive and inductive analysis to make sense of the archived documents within the Community of Inquiry framework while simultaneously being open to emerging patterns and themes (Patton, 2002, p. 453). A total of 1,170 archived message posts and responses on the discussion board were analyzed. Additionally, 366 archived emails, 63 cross-cultural interaction papers, and 21 final reflection papers, were reviewed and analyzed.

In order to capture the essence of the coalescence of the presences within the Community of Inquiry model, quotes from archived participant-produced documents were used. Quotes were also used to corroborate the themes which emerged from the archived documents and give voice to the participants.

Validity and reliability were met through triangulation by using inter-rater reliability, multiple sources of data, and multiple data collection methods to confirm results. Additionally, conversations with peers and other interested parties about the development, logic, and exploratory explanations of the findings were integrated with other strategies promoting validity and reliability such as critical self-reflection; sufficient immersion with the data to the point of saturation; deliberate, focused search for differences or variety within the data to make the study more germane to a greater audience; audit trail; and lastly, vivid, substantial depictions that allow 
the consumer of the research to identify with content and perspective enough to establish that the results can be transferred (Merriam, 2002, p. 31).

Possible coding limitations were tempered via inter-rater reliability through the assistance of an additional coder who reviewed the archived material through another lens and then coordinated and negotiated with the researcher until 100\% agreement was reached. The researcher and the coder each coded material separately and then met periodically over the course of several weeks to compare and negotiate coding decisions until 100\% agreement was attained. Pamela Moss (1994) writes, "most hermeneutic philosophers share a holistic and integrative approach to interpretation of human phenomena that seeks to understand the whole in light of its parts, repeatedly testing interpretations against the available evidence until each of the parts can be accounted for in a coherent interpretation of the whole" (p. 7). She also notes that "a number of philosophers of science have suggested that this 'hermeneutic circle' of initial interpretation, validation, and revised interpretation characterizes much that occurs in the natural as well as the social sciences" (p. 7).

Data was collected from the fall 2008 semester archived course documents: threaded discussions, emails, cross cultural community interactions, and final reflections. In addition to the threaded discussions, emails, cross-cultural interactions, and final reflections were analyzed in a similar manner to draw out the perceptions and experiences of the participants. This analysis answered the main research question: How do teachers' perceptions and experience in an online graduate course on diversity education evolve over time? Other questions addressed were: What light do the threaded discussions shed on the perceptions and experiences of teachers in an online graduate course on diversity education? What do the emails reveal about the perceptions and experiences of the teachers? What do the cross-cultural interactions reveal 
about their perceptions and experiences? What do the reflections reveal about the perceptions and experiences of the teachers?

\section{Threaded Discussions}

The course examined in this study, C\&I 689 (see Appendix B, p. 139) used threaded discussions to create an ongoing exchange among the participants. Each week, participants engaged with the curriculum within each session. Fourteen sessions plus a main (general information) and a final dissemination session, form the framework within which these threaded discussions occur. Participants read the required texts, visit websites, view lectures, and then synthesize their thoughts in a post under the appropriate session. A post is simply a written initial "paper" created on a word document and attached or copy and pasted onto a blank "document" under the appropriate session title, online. Other participants in the course then respond to this initial post with their thoughts in a similar manner. Posts and responses are asynchronous, meaning that participants can respond anytime, anywhere within time frame parameters.

The posts and responses in the threaded discussions of these participants were examined and analyzed to tease out perceptions and experiences. This analysis was done within the framework of the CoI. The categories of the CoI served as organizational guides for coding purposes.

Analysis of transcripts began with coding within the Community of Inquiry. Garrison, Anderson, and Archer (2000) used this template to find signs of significant learning taking place online. As explained in the review of the literature, the CoI consists of three presences, cognitive, social, and teaching presence (see Figure 1, p. 135), under which are several categories (see Table 1, p. 136) which can be used to categorize and analyze computer mediated 
communication transcripts. This template was used to categorize and analyze the data collected in this case study.

\section{Limitations}

Limitations in this study were identified and addressed by the researcher. Limitations in this study may arise from the fact that this is a qualitative case study, an in depth analysis of one course and one content area, with participants unique to that specific course during the fall of 2008, hence, not generalizable. Limitations may also arise from the fact that the researcher was also the instructor of the course and interpreter of the data. Maurino (2007) addresses the instructor perspective in her review of the literature on critical thinking in online threaded discussions and argues that "there is a need for rich, in-depth data which would call for research of a qualitative nature, particularly from the point of view of the online instructor" (p. 14).

Limitations may also arise from the inherent biases of the researcher whose personal multicultural perspective (English is her second language) and multiple philosophies (ways of looking at the world) may affect interpretation of the data. Denzin (1989) explains that "valuefree interpretive research is impossible...because every researcher brings preconceptions and interpretations to the problem being studied. The term hermeneutical circle or situation refers to this basic fact of research. All scholars are caught in the circle of interpretation" (p. 23). Patton (2002) adds, "hermeneutic researchers use qualitative methods to establish context and meaning for what people do" (p. 115). Eichelberger (1989) concludes that hermeneutists "are much clearer about the fact that they are constructing the 'reality' on the basis of their interpretations of data with the help of the participants who provided the data in the study" (p. 9). Eichelberger (1989) argues that depending on the background of the individual researcher, the methods used 
by that researcher, and the purpose of the study, various interpretations can be expected of the same data set.

Another possible limitation of this study hinges on this last statement, namely, that the parameters of the Community of Inquiry framework raised issues of interpretation and decisionmaking based on the limited set of categories and indicators which often appeared to replicate categories across the elements. For example, it was often difficult to decide whether a message fit into the personal affect category of the social presence element or the exploration or integration categories of the cognitive element since all three had indicators which made reference to personal narratives or experiences. Teasing out one category was often akin to taking the cream or sugar out of a cup of coffee. Ironically, this last limitation actually accentuated the very essence of the coalescence of the presences within the Community of Inquiry model.

This last dilemma was addressed early in the content analysis through discussion during the inter-rater reliability phase of the research. Both researchers agreed that many categories were emerging in a single message and a decision needed to be made as to how it would be handled in the analysis. Since the message was the unit that was decided upon earlier, it made sense to the researchers to designate one category under cognitive presence, namely, the highest category reached by the participant in their post or response, to represent the message as it would be inferred that the participant first went through the initial categories in order to reach the latter ones. For social presence, it was decided to include all categories found as excluding one or two of the three categories would remove valuable information necessary for the researchers and the reader to interpret the data. 


\section{CHAPTER IV}

\section{RESULTS}

This study explored the overarching question of how teachers' perceptions and experiences in an online graduate course on diversity education evolved over time. The research design was based on the following overarching research question and secondary questions: How do teachers' perceptions of and experiences in an online graduate course on diversity education evolve over time?

1. What do the emails reveal about the perceptions and experiences of the teachers?

2. What light do the threaded discussions shed on the perceptions and experiences of teachers in an online graduate course on diversity education?

3. What do the cross-cultural interactions reveal about their perceptions and experiences?

4. What do the final reflections reveal about their perceptions and experiences?

The findings are organized in the following manner. First, there will be a discussion of the findings of the emails. Next there will be a discussion of the analysis of the threaded discussions within the community of inquiry model parameters followed by the findings of the cross-cultural community interactions and the final reflections.

\section{Email Findings}

The course embedded email component served as an asynchronous communication vehicle for the course instructor and the participants. The instructor and the participants were able to communicate with the class as a whole, in groups, or individually. Teaching presence clearly found its niche in the email section of the course. Several reasons account for this: public or private feedback and support could be disseminated as needed; "how are you doing" surveys could be conducted by the instructor to mitigate any misconceptions or confusion; 
participants could be supported and encouraged privately or publicly as needed; cross-cultural community interaction papers where submitted here by the participants and feedback was given by the instructor to the participants about their experience; final reflections were submitted here. The participants in this study sent a total of 318 emails. The instructor sent a total of 333 emails. Teaching presence flowed between the email section and the discussion board concurrently until it shifted entirely to the email section of the course by session 5 . This can be explained by the instructor's perception that the participants were in command of and accountable for their learning at that point in time. This command and accountability on the part of the participants could be due in part to their professional training and education background since they are all either currently teaching or will be teaching in the near future. With such strong self-efficacy and self-regulation witnessed in the threaded discussions by the instructor, it was not difficult to allow the participants to construct meaning both cognitively and socially on their own. Had there been an occasion that required instructor input or intervention due to misconceptions or off task direction, the instructor would have stepped in to facilitate discourse in the correct direction. Threaded discussions findings will be discussed further in the next section.

Upon examination of the 318 emails received by the instructor, several patterns and themes emerged: questions about technology; assignment and grade expectations; challenges, explanations, apologies, accountability, and success. A simple initial analysis of the emails produced the following results: the lowest number of emails sent by one participant was 6 while the highest number of emails sent by another participant was $33 ; 5$ participants sent less than 10 emails, 10 participants sent between 11-15 emails, 3 participants sent between 16-20 emails, 2 participants sent between 21-25 emails, and one participant sent more than 26 emails. The mean 
was 15 emails, the median was 14, and the mode was 13 and 15. A chart of the number of emails sent by each participant can be found in Figure 3 (p. 150).

\section{Questions about technology}

The importance of counting the number of emails sent over time by the class as a whole and per participant is in the patterns and information generated to the instructor. For example, a participant who sends 8 emails within the first 10 days of class is usually confused and frightened and will require immediate and intensive support, troubleshooting, caring, and patience on the part of the instructor. This participant may be a married, female, 12 year veteran elementary education teacher (participant 1) or a young, single, male, pre-service secondary education master's student (participant 10). The instructor will need to address and adjust time management issues as they arise in cases such as this. participant 2 writes several emails attesting to the above:

\section{Where did it go?}

August 19, 2008: I've misplaced the announcement you sent telling us the username and password. (Where did it go??!) Could you please resend that information? Thanks so much!

Where are the grades?

August 24: I'm experiencing that same anxious feeling my students must feel when they just don't "get" something...I don't know where to check my grades!! I've looked all over the e-campus site, including the "assessments" and "assignments" button. I can't find them. Help? Thank you.

Where are my grades?

Later that same day: I have found the "grades" icon on the initial page, but it appears that there are none for me. You said that if I completed all assignments and responded to discussions, I would find the grades there. I believe I have done everything asked of me in Session 1...plus some! Can you tell me what I might be misunderstanding?

Thank you.

Help! 
August 25: I rechecked your assignments postings in Session 1 and, as far as I understood it, you asked us to respond to "at least two" peer discussions in the biography section. I did not see a prompt asking for a response to the multicultural or media sections. I responded to my peers four times in the bio section: once to *** on 8/19@ 6:55; twice to*** on 8/19@6:55 and on 8/24@9:08; and once to you (in my bio section). Are we also supposed to respond to all the other discussion sections? If so, how often? I see that in Session 2, you ask us to respond to 2 peer discussions re the Ayers and Loewen readings and to "some" peer media logs. Are we supposed to go beyond that? I'm confused about the assignment prompts. I thought I was doing exactly what was expected of me. (I'm a worrier and a stickler! :) Is it too late for me to go back to Session 1 and respond to more of my peers beyond the four I already did? Please help me to understand the number of responses needed to excel in this class. I've been enjoying the class so much! The readings are excellent, especially the Loewen text. I just want to do my best. Thank you.

\section{What did I do wrong?}

Six minutes later: I also responded to *** in my Media Habits section on 8/21 @ 10:36!! (Now I'm really confused! Are you not seeing on your end what I see on mine? Am I posting my responses wrong?) Thanks.

I'm still confused...

Later that afternoon: I completely agree with you about the beauty of multi-voices in a group learning situation. I enjoy reading others' responses very much. I don't mean to run this into the ground, but like I mentioned in the last e-mail, I did respond at least six times in Session 1. Is this not enough for full credit?! I do not see a grade change and...well, I'm still confused. Could you please review my posts and let me know if I need to do more? Thank you.

\section{Lightbulb!}

August 28: Yes, thank you, my lightbulb went off and now I sit red-faced. Once I understood that each section should be addressed, I responded to two "Multicultural Ed." discussions. I will respond to the Media Log discussions this evening and then begin my assignments for Session Two. Thank you for your patience with me. :) (Please let me know if I am not discussing enough or if I need to "up the quality notch" in my peer discussions. Like I said, I am enjoying this class tremendously. I am even bringing my colleagues into the course discussions!)

The issue is finally resolved on the morning of the $28^{\text {th }}$ of August. This participant not only completed the course successfully but also emerged as a leader in the threaded discussions facilitating, supporting, and encouraging the other participants in their efforts. It is also quite 
easy to see how the participant progresses through the cognitive presence cycle while infusing the social presence element and responding to the teaching presence. The coalescence of presence is clear.

\section{Assignment and Grade Expectations}

The issues brought up by this participant indicated to the instructor that perhaps the material in the curriculum needed to be clarified further for other participants as well. Participant 3 sent an email on August 28 looking for "clarification" stating "I missed the mark, but will get better..." in response to a grade that was lower than expected. In addition to questions about grades, like participant 2, participant 3 experienced technical difficulties in not being able to find an article posted under e-reserves.

These two early themes emerged across the board and are represented in the aforementioned scenarios: technical difficulties, assignment and grade expectations. As time continues, other patterns and themes began to emerge as the participants either fall in sync with the rhythm of the course or become overwhelmed by the workload and realize their time management skills need revising in order to keep up and not be left behind. Like the participants, the instructor must also be constantly assessing the workload and the time necessary to create not only a continuous, supportive and caring teaching presence but a cognitive presence as well in order to facilitate the participants' movement through the critical thinking phases necessary to achieve course outcomes.

\section{Challenges, Explanations, Apologies, Accountability, and Success}

A third theme emerges about four to five weeks into the course: challenges, explanations, and accountability. At this point in time, participants begin to feel the pressure of their commitments. Approximately half of the participants (11) that successfully completed the 
course sent emails with explanations as to their late, partial, or no work. These participants rose

to the occasion, took responsibility, and regulated their behavior accordingly successfully

completing the course. Participant 3 is one such participant and writes,

September 14: I want to appologize for pushing the deadlines on my assignments over the past two weeks. My ... had to undergo a ... this week due to some prolonged health problems. I was out of town for 3 days earlier in the week, and my priority was caring for ... and my daughter. On top of that, I had to prepare assignments for my students in my absence. Today, my ... finally started feeling better from the procedure, so I am trying hard to play catch up. I will make sure that I get everything in tomorrow. I understand the importance of getting work posted in a timely manner and will do MUCH better in future assignments.

On September 27 participant 3 sends a follow up email explaining,

September 27: I emailed you last week about my ... and ... surgery. ... has had some difficulty the past week, but is doing much better now. ... had a ... procedure where they .... On friday, ... had a post-op check, and the doctor said ... is doing much better and has now cleared ... to start doing things again. As a result, I will have alot more time to get caught up on my work. Thanks for your understanding (I too agree that family is first) and $i$ will catch up with my work as soon as possible!

A third email 6 weeks later adds,

Just wanting you to know that I am still alive! I wrote you a about 6 weeks ago regarding my ... who had to have a surgery. Thankfully, everything is going well, but it took ... a while to recover back to where ... could do her everyday activities. Add that to the fact that I had school everyday, lesson planning, participating in town council, and attending various meetings alligned with town council, and most importantly trying to spend some time with my 3 year old, and it seems that I have fallen behind really badly. However, I am going to make every effort to catch myself up over the next 10 days, including going back and doing the things that I hadnt completed, even though they are way past due and graded. By the time I was able to begin working, I was honestly lost in terms of which session/how I should go about catching up. So, im just going to start from what is current and work my way backwards to things that I havent done. I feel as though I have missed a large portion of this class due to some of the things that have been going on, I especially miss the interactions in terms of replying with my classmates because I have found those to be extra informative. Anyway, I was just going to let you know that I am still here, and i will be working dilligently to catch up!

In spite of these challenges, participant 3 rose to the occasion time and time again to successfully complete the course. In the final reflection, participant 3 writes, 
I am really happy that I have had the opportunity to take this course. As you know, there have been many things from computer malfunctions to family health problems that have thrown roadblocks in the path to completing everything in a timely manner, but I have really tried to work hard to catch up and cover everything. It is a wonderful class and I have learned a lot that will make me a better educator as a result.

Similarly, participant 8 faces challenges right out of the gate but somehow manages to stay on top of things. Emails are social, pleasant and sprinkled with emoticons.

September 4: Once again, I am a bit behind. The Labor Day Holiday really didn't allow me to get caught up on anything, it basically hindered me...but Summersville Lake was beautiful. ;-) I'm hoping to have everything turned in by Sat, but I've been a bit swamped with my Thurs evening class... which is only going to get worse. Hopefully I'll get on the ball next week with everything. I may not be late with my assignments after all, this is just a precautionary e-mail. Hope your week was great!

Four days later, participant 8 sends another email reiterating his situation but maintaining accountability for his actions:

September 8: I hope you don't think I'm a total idiot, but I was called out of town due to a slight family emergency...All is well thankfully. Unbeknownst to me, my ... computer is on the fritz. I just got back into town this morning and hope to get caught up on everything. You can certainly deduct points for my lateness...I would completely understand. So sorry for all of this.

Emails continue to pour in from participant 8:

just got my computer up and running yesterday. It has been down and out for a while and is still giving me problems. I have been pretty swamped at work as of late as well and also been totally ill with some seasonal junk. I do solemnly swear to get caught up. I promise $!=/$

Participant 8 does live up to his promise and does complete the course successfully. The 33

emails participant 8 sent throughout the semester were always upbeat, accountable, and determined regardless of the "seasonal junk" and computer problems encountered along the way.

Like the two previous participants, participant 10 encounters family related challenges.

September 20: I just wanted to appologize for getting my Cross-Cultural Comm Inter. Paper to you late. I have been in and out of hospitals and doctor offices for the last week or so for health issues of my own. And now, last night my dad went into the hospital ... in the high-risk unit. So have had a lot on my plate this past week or so. Then my mother 
is going into the hospital this coming friday for a heart procedure. I do appologize for any work that you received late. I totally understand if it is too late to get even partial credit. Just wanted to keep you in the loop with why you may receive any late work from me, it is totally out of character for me. Thanks for your understanding. Have a great day!

Participant 10 is apologetic, accountable, and pleasant in spite of the challenges faced. In another email dated September 28, participant 10 continues to show accountability and determination:

September 28: I am sorry that I submitted my CCI-Level 2 assignment about 3 minutes late (techincally) tonight. I had it typed and saved in plenty of time. I just got caught up with house chores tonight and lost track of time. I hope it is ok that it was a few minutes late. Sorry about that. I will try not to let that happen again. Thanks and have a great day!

Participant 10 sends only one more email requesting information and clarification about a grade received on November 14. The moniker, "Have a great day!" sums up her attitude and perseverance over time. Participant 10 successfully completed this course.

As the others have demonstrated, participant 15 also continued on in spite of monumental challenges. She writes:

September 18: I just got the phone call from my brother and he said my father has critical condition. I have to go to (another country) as soon as possible. And I may stay there at least 3-4weeks (I'm not sure because my mother's health is not good either) What about my grade and left over class schedule? Would you tell me what do I have to do? I'll try to do my best, but I do not want to fail this class.

Seven hours later on the same day, participant 15 writes:

I didn't finish session5, but I'll posting as much I can. and I don't think i can try to do the best next 2weeks. would you give me some credit please? but 2 weeks later, and even if i'm still stay in (another country), i'll try to read and post my work paper.

i keep try to logon e-campus and try to posting my works, but computer was not really good work at the airport... thank you 
By October 15 participant 15 is writing of returning to the United States. Participant 15 has

worked diligently in spite of emotional and geographic challenges. Participant 15 also successfully completes this course.

In spite of numerous challenges faced by the participants in C\&I 689, almost all of them faced up to and overcame whatever confronted them. Teacher presence, theme four, can account for some of this success. Numerous emails from the participants implicitly or explicitly carried phrases such as, "thank you for your help" and "thanks for understanding" or "thanks for the support" and "thanks for the encouragement - it really helps." The coalescence of presence can be seen clearly throughout the 318 emails exchanged over time.

\section{Threaded Discussions Findings}

Threaded discussions are the lifeline of most asynchronous online courses allowing for ongoing, anytime, anywhere communication to take place among the participants. Participants are often genuinely surprised at the richness of the discussions that take place over the course of the semester. For example, participant 2 writes,

Before we started, I expected the discussions to be somewhat superfluous to our coursework, but they turned out to be the fulcrum, the vehicle for understanding and analyzing all the rich material. I now believe than an online course can be superior to a face-to-face class because even slow-to-respond people like me are allowed to digest others' words and formulate a solid response in a different time frame than quick backand-forth dialogue (at which I stink!).

Social presence was virtually omnipresent as the participants displayed evidence of affect, developed group cohesion, and communicated openly throughout the threaded discussions. Emoticons, excessive punctuation, capitol letters, humor, self-disclosure, greetings, addressing classmates by name, agreeing with others, asking questions, inviting response, offering personal advice, etc. all flowed throughout the communications. Noteworthy is the fact that group cohesion was firmly established in session one as indicated by the 43 times it is found 
amongst the posts and responses. This early commitment to the group by the participants served as a solid foundation upon which the concurrent learning unfolded. Once the social bonds are established, group cohesion drops to 23 occurrences in session two. Open communication, on the other hand, predictably flip flops in the other direction. Session one understandably shows 27 occurrences as participants are getting to know each other. As the social bond of group cohesion is established, open communication more than doubles in session two at 58 occurrences. This pattern repeats itself in session three as open communication remains steady at 59 occurrences and group cohesion, now solidly entrenched, settles at 19.

Teaching presence entails more than instructor discourse and comes in many forms as shown by Table 1 on page 136. Teaching presence is comprised of 3 categories: instructional design and organization, facilitating discourse and direct instruction. Teaching presence, in the guise of instructional design and organization, serves as a constant throughout the course as participants are responding to the curriculum. Embedded within each course session are prompts, questions, and directions for the students to follow to complete their assignments. The session topic table on page 54 articulates the nuances of these sessions.

Cognitive presence remained strong throughout the semester as participants explored, integrated, and reflected upon their thoughts as they interacted with the sessions. The time afforded by the asynchronous environment allowed for deep thinking, reflecting, posting, and responding in a manner that the $\mathrm{f} 2 \mathrm{f}$ classroom does not. What is lost in immediacy is compensated by time allowed to think, feel, and reflect before posting and responding to peers.

Initial posts written in response to readings, videos, and instructor prompts, demonstrated the cognitive category flow from triggering event to exploration to integration. Most participants included references to and integrated information from the various sources the session was based 
on. For example, participant 3 begins session 3 with a response to a triggering event, namely his response to the results of the online learning inventory. He then moves into exploration and ends the post with integration of the readings. A portion of the post is presented below in the participant's own words.

I was a bit perplexed (once again) at the results of my on-line learning inventories, as both yields significantly different results! What's up with that?? At any rate, I consider myself to be a visual and tactile learner. I like to not only see, but to touch. I know I use these two senses a lot in my classroom. A picture does speak a thousand words. I do try to do a balance of the senses, although it's hard to incorporate movement....I try to be well rounded with the methodologies that I use....Lies my Teacher Told Me clearly describes how White oppression was incorporated into the new found freedoms that were fought for through internal segregation within the institution of America post Civil War. I had never heard before of the term (the niger period of 1890-1940). It goes back to the same story of how we pick and choose the American ideals that we want our children to learn through textbook. I agree with Loewen on pg. 173 in that "just as textbooks treat slavery without racism, they treat abolitionism without much idealism." What a juxtapositioning. I had no idea to what extend we had flattened the emotion, ideas, and candor that went into acts, speeches, experiences of the time...in our representation of our nation's making in our textbooks. Loewen describes textbooks that distort and select the material that best represents the perpetuation of the American Idealism that is sought through historical education in children. We are slowly turning about in learning that identity and multicultural realms can be experienced beyond a textbook.

Patterns became apparent as the participants moved through the sessions over time. Examination of the posts and responses of the participants revealed the following results interpreted within the framework of the Community of Inquiry. It became clear that the session assignments and subsequent questions and reflection activities drove the levels of the responses of the participants. The following table describes the sessions.

Session and Topic Table

\begin{tabular}{|c|l|}
\hline Session & \multicolumn{1}{|c|}{ Topic } \\
\hline Main & General Class Communication \\
\hline 1 & $\begin{aligned} \text { Multiculturalism } \\
\text { - Reflect on what multiculturalism means to you. }\end{aligned}$ \\
& - Read Dr. Jay's article and post your reaction. \\
& Post your reflection and respond to at least two of your classmates. \\
\hline
\end{tabular}




\begin{tabular}{|c|c|}
\hline 2 & $\begin{array}{l}\text { Discovering America's Forgotten Heroes } \\
\text { - Reflect on the Introduction and Chapter } 1 \text { of Loewen's Lies My Teacher Told } \\
\text { Me. Consider how his assertions resonate with your own experience learning } \\
\text { American history. Do your experiences concur or conflict with his thesis? } \\
\text { - Post your reflection and respond to at least two of your classmates. }\end{array}$ \\
\hline 3 & $\begin{array}{l}\text { Looking within Yourself } \\
\text { - Explore your personal perspectives regarding different races, ethnicities, and } \\
\text { cultures. Take the Implicit Association Test and review the Tutorial on Bias } \\
\text { after you take the test. Reflect on the following question: What do I bring to } \\
\text { this course in terms of preconceived ideas and unconscious biases related to } \\
\text { multiculturalism and culture? } \\
\text { - Using the library's database, locate and read Kailin's How White Teachers } \\
\text { Perceive the Problem of Racism in their Schools: A Case Study in 'Liberal' } \\
\text { Lakeview. Reflect on the question: Do I have expectations for my students that } \\
\text { are influenced by my personal cultural perspective? } \\
\text { - Using the library's database, locate and read Paccione's Developing a } \\
\text { Commitment to Multicultural Education. Reflect on the question: How do I } \\
\text { become a multicultural educator? } \\
\text { - Post your reflections and respond to at least one from each category. }\end{array}$ \\
\hline 4 & $\begin{array}{l}\text { The Case for Multicultural Education - Values in Action } \\
\text { - View Beverly Tatum's lecture at the University of Florida through eReserves. } \\
\text { Review the PDF chapter on white identity in her book Why Are All the Black } \\
\text { Kids Sitting Together in the Cafeteria? } \\
\text { - Read the preface and chapter one of the Bennett text, Comprehensive } \\
\text { Multicultural Education Theory and Practice. Make note of which core values } \\
\text { of multicultural education are valued in the educational environments you have } \\
\text { experienced. Which are not valued or ignored? Think of examples to illustrate } \\
\text { your answers. } \\
\text { Based on the above, consider what changes you want to see in the world. How } \\
\text { will you make this a reality versus a preference? Post your thoughts and } \\
\text { respond to at least two of your classmates. }\end{array}$ \\
\hline 5 & $\begin{array}{l}\text { Cultural Interaction Challenges } \\
\text { - After perusing the United Nations } 30 \text { articles for human rights, consider the } \\
\text { many forms of prejudice that still exist throughout the world. How are our } \\
\text { cultural interaction challenges similar to or different from the challenges of } \\
\text { cultural interaction challenges encountered in other places, if at all? How will } \\
\text { you address these very sensitive issues in the classroom, where students' ideas } \\
\text { are highly influenced by teachers, their peers, their family, the media, etc? } \\
\text { - Reflect on the above questions as you read chapters } 2 \text { and } 3 \text { in Bennett's text. } \\
\text { - Racism: During the course of your reading, consider the term reverse racism. } \\
\text { Is there such a thing as reverse racism? Have you ever been a victim of } \\
\text { racism? If so, how did it affect you? Did the experience change you in any } \\
\text { way? If you've had the good fortune never to have experienced the ignorance } \\
\text { of racism, have you ever witnessed racism? If so, how did it make you feel? } \\
\text { How did you react or intervene, if at all? }\end{array}$ \\
\hline
\end{tabular}




\begin{tabular}{|c|c|}
\hline & $\begin{array}{l}\text { - Stereotype Vulnerability: Bennett states that much of what is mistaken for } \\
\text { racial animosity in America today is really stereotype vulnerability. Do you } \\
\text { believe this is true? As a teacher how will you help educate your students in a } \\
\text { manner that will allow them to develop an appreciation for differences in an } \\
\text { optimistic manner? } \\
\text { - Reframing History: How do Loewen's chapters on American history reframe } \\
\text { your sense of the invasion of the North American continent by Europeans? } \\
\text { What emotions do you experience as you read this? Where are these feelings } \\
\text { coming from? Why? } \\
\text { We Can't Teach What We Don't Know: After reading the introduction and } \\
\text { chapter } 1 \text { in the Howard text, consider what issues his perspective raises? } \\
\text { This week's discussion should include your reflections on your readings from } \\
\text { Bennett, Loewen, and Howard. Your response should integrate and synthesize } \\
\text { all three readings and address the above questions. Respond to your peers. }\end{array}$ \\
\hline 6 & $\begin{array}{l}\text { Assimilation and Pluralism } \\
\text { - Multiculturalism and Teaching: Transforming Theory into Practice } \\
\text { - Choose one of the following: multicultural terms crossword puzzle, Professing } \\
\text { Leadership, or Discovery School; relate to culturally diverse learners. } \\
\text { - Weave Kozol, Bennett and Howard into your discussion this week. Bring in } \\
\text { the conflicting themes of assimilation and pluralism. Respond to your peers. }\end{array}$ \\
\hline 7 & $\begin{array}{l}\text { Stories of our Past Learning and Genealogy } \\
\text { - View A Place at the Table through eReserves } \\
\text { - Explore the Teaching Tolerance website } \\
\text { - Read chapters } 4 \text { \& } 5 \text { in Loewen. Consider the following question: } \\
\text { - How could you use the information in the video, the website and Loewen to } \\
\text { inform your teaching? Respond to your peers. }\end{array}$ \\
\hline 8 & $\begin{array}{l}\text { Learner Differences } \\
\text { - Read Bennett chapters } 6 \text { \& } 7 \text {. Investigate learning styles by exploring } \\
\text { Learning Styles Inventory and Multiple Intelligence Assessment online. } \\
\text { Account for how your learning style and the learning styles of students in your } \\
\text { class factor into addressing individual differences. } \\
\text { Loewen: How do these chapters on American history reframe the issues of } \\
\text { equity and social class constraints on American school children. What } \\
\text { emotions do you experience as you read this? Where are these emotions } \\
\text { coming from? Why? }\end{array}$ \\
\hline 9 & Aesthetic Reading Response \\
\hline 10 & $\begin{array}{l}\text { Individual Differences in the Classroom } \\
\text { - Research on mastery learning demonstrates that students can learn if given } \\
\text { enough time and appropriate instruction. Such instruction must emphasize } \\
\text { respect, cultural diversity and the value of lie experiences in the construction of } \\
\text { knowledge. } \\
\text { - After reading Bennett chapter } 8 \text { and Loewen chapter } 7 \text {, use your exploration of } \\
\text { multiple intelligences from the last session as a basis for exploring how } \\
\text { individual differences impact how knowledge is acquired in the classroom. }\end{array}$ \\
\hline 11 & How do we address racism? \\
\hline
\end{tabular}




\begin{tabular}{|c|c|}
\hline & $\begin{array}{l}\text { - Huck Finn, Racism and Pedagogy: Visit the PBS website and explore the } \\
\text { teaching guide and other sites related to the novel. Identify potential materials } \\
\text { and activities that would be appropriate for you to use in a future classroom. } \\
\text { Ask yourself, what adaptations would I have to make to use these activities in } \\
\text { my situation? } \\
\text { - Create a unified response to the following questions. Be sure to make } \\
\text { reference to Bennett, Loewen, Howard, and the web readings. } \\
\text { - Should racist books be eliminated from schools, including the library shelves? } \\
\text { Can books that contain profanity and ethnic dialects be used without } \\
\text { reinforcing negative stereotypes? Should they be used? }\end{array}$ \\
\hline 12 & $\begin{array}{l}\text { Should they be included? } \\
\text { - According to Loewen, textbook authors have attempted to remove the sources } \\
\text { of cognitive dissonance from textbooks, especially those experiences that } \\
\text { evoke an emotional response. He also brings in ethnocentricism. Does this } \\
\text { stance continue in today's textbooks? How will future textbooks deal with } \\
\text { emotionally charged contemporary events such as } 9 / 11 \text { ? As you read the text, } \\
\text { think of those current events that have evoked a personal emotional response. } \\
\text { How will you resolve your cognitive dissonance? } \\
\text { - Go to eReserves and view In Whose Honor. Consider the following questions: } \\
\text { - Some people say What difference does it make? What difference does it } \\
\text { make? } \\
\text { - Why can't the people who want to maintain the status quo hear the native } \\
\text { peoples perspectives? } \\
\text { - Why would a group choose to use a symbol (mascot) that mimics the spiritual } \\
\text { hino of another group? } \\
\text { other as human beings, beyond our legal obligations? } \\
\text { What's happening today at the University of Illinois regarding its mascot? }\end{array}$ \\
\hline 13 & $\begin{array}{l}\text { The new face of segregation: the digital divide } \\
\text { - The fact that you are taking this course clearly demonstrates which side of the } \\
\text { digital divide you are on. Consider those who do not have the same levels of } \\
\text { access. What does the digital divide mean for them? What issues are } \\
\text { emerging for education and society in general? } \\
\text { - Go to our library database and access Eamon's article on the digital divide. } \\
\text { - Then visit the Edutopia website and explore the promise of integrating } \\
\text { technology into the curriculum. } \\
\text { - Read One Internet, Two Nations by Henry Louis Gates Jr. } \\
\text { Begin a dialogue with your peers about the digital divide. The questions you } \\
\text { ask and the direction your group takes in exploring this issue is up to you. You } \\
\text { are encouraged to use other resources and your own experiences to supplement } \\
\text { the readings in this unit. From your readings and exploration, develop a series } \\
\text { of postings in which your group expresses their views on the impact of the } \\
\text { digital divide with respect to education and what must be done to ensure an } \\
\text { equitable future for all students. }\end{array}$ \\
\hline 14 & Teflon History \\
\hline
\end{tabular}




\begin{tabular}{|l|l|}
\hline & $\begin{array}{l}\text { Over the course of the semester you have covered a great variety of topics and } \\
\text { hopefully have gained a sense of what multicultural education is about. Now it } \\
\text { is time to think about how we use this knowledge to transform classroom } \\
\text { practice. }\end{array}$ \\
- & Visit the Southern Poverty Law Center's site for teachers. Explore the \\
resources and activities available for teachers. Identify potential materials and \\
activities that would be appropriate for you to use in a future classroom. What \\
adaptations would you have to make to use them in your situation? \\
- Convergence - In his afterword, Loewen discusses what he believes to be the \\
challenges that will confront us in the near future. After you have taken some \\
time to reflect, post your thoughts regarding the relationships that exist in the \\
final Loewen readings and the Tolerance website. Respond to your peers. \\
Dissemination Project
\end{tabular}

\section{Community of Inquiry Content Analysis Results}

A total of 1170 posts and responses in the threaded discussion of the course were analyzed and organized by session, role, type and category of presence. The sessions examined were the main and sessions 1 through 14 . Roles consisted of elementary education program participants, secondary education program participants, higher education participants and instructor. Cognitive, social, and teaching presence categories were tabulated for each role and totaled. The following sections explain the outcomes starting with analysis by presence of all of the participants, followed by breakdowns by role, e.g., instructor posts, elementary, secondary, and higher education posts, culminating with analysis of the sessions.

\section{Analysis by Presence and Participants}

\section{Cognitive presence}

Out of the 1170 posts and responses in the threaded discussions, 665 or $57 \%$ contained cognitive presence. The trigger category accounted for 28 posts $(4 \%)$, the exploration category 
accounted for 232 posts (35\%), the integration category accounted for 339 posts $(51 \%)$, and the final category, resolution, accounted for 66 posts (10\%).

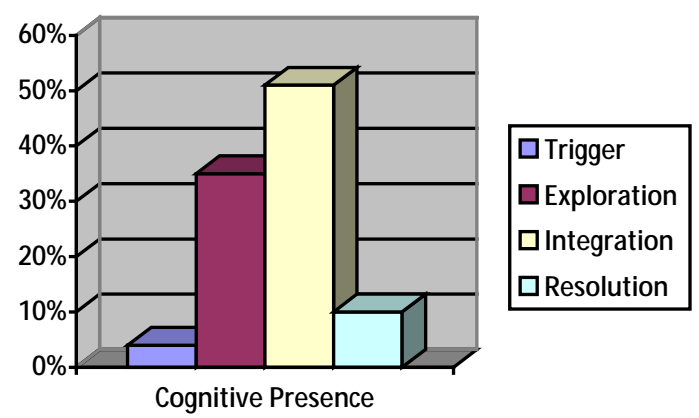

While the trigger category remained at a constant $4 \%$ for all of the roles (whole class, elementary, secondary, and higher education participants), there were some differences in the other categories. The exploration category accounted for $35 \%$ of the whole class posts, $36 \%$ of the elementary education participant posts, $29 \%$ of the secondary participant posts, and $40 \%$ of the higher education participant posts within the cognitive presence. The integration category accounted for $51 \%$ of the whole class posts, $52 \%$ of the elementary education participant posts, $54 \%$ of the secondary education participant posts, and $46 \%$ of the higher education participant posts. Lastly, the resolution category accounted for $10 \%$ of the whole class posts, $8 \%$ of the elementary education participant posts, $13 \%$ of the secondary education posts, and $10 \%$ of the higher education participant posts.

\section{Social presence}

Social presence was also noted: of the 1170 posts and responses in the threaded discussions, 665 or $57 \%$ contained evidence of personal/affect, 671 or $57 \%$ contained signs of open communication, and 310 or $27 \%$ demonstrated group cohesion. 


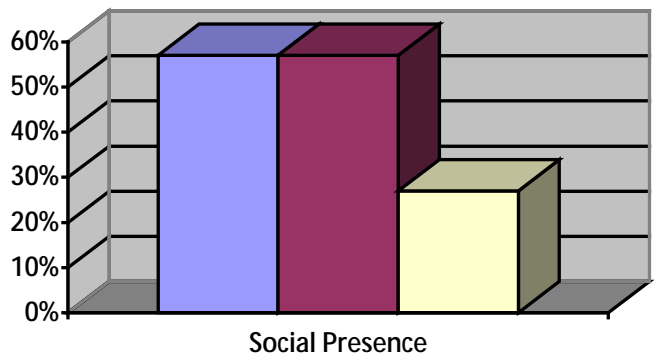

\begin{tabular}{|l|}
\hline Personal/ Affect \\
$\square$ Open Communication \\
$\square$ Group Cohesion
\end{tabular}

Instructor posts and teaching presence

Out of 1170 total posts and responses in the threaded discussions, 63 belonged to the instructor. The majority of the posts were found in the Main and session 1 (21 and 34 respectively). Session 3 included 7 posts and session 4 contained 1 post. There was no teaching presence in session 2 or in sessions 5 through 14 mostly due to the instructor's use of the Main and email to communicate to the class as a whole. Instructor posts accounted for $5.4 \%$ of the total messages posted on the discussion board. This is comparable to a mean of $4.5 \%$ per participant. The following graph shows that of the 63 posts, $21 \%$ fell into the design and organization category of teaching presence, $52 \%$ fell into facilitating discussion and $27 \%$ fell into direct instruction.

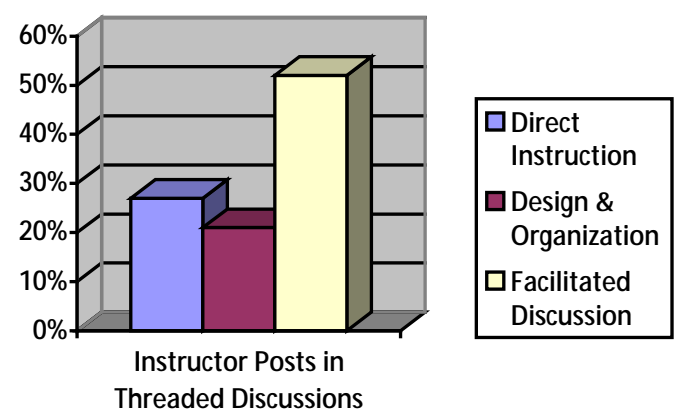




\section{Elementary Education Program Participants}

Out of the 1170 posts and responses in the threaded discussions, $563(48 \%)$ belonged to the nine elementary education program participants. Cognitive and social presence category findings are discussed in the next section.

\section{Cognitive presence}

Of the 563 posts, 315 fell into the cognitive presence. These 315 posts and responses can be further reduced into the categories that make up the cognitive presence of this community of inquiry: 13 fell into the trigger category, 115 fell into the exploration category, 163 fell into the integration category and 24 fell into the resolution category.

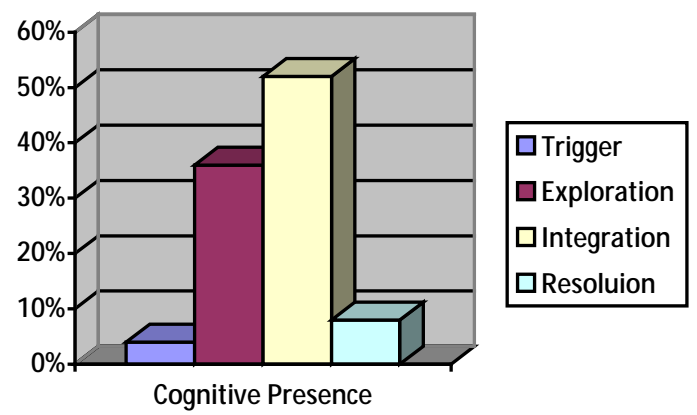

Within these 315 posts these figures translate into percentage terms as follows: $4 \%$ of the posts were categorized as trigger, $36 \%$ were exploration, $52 \%$ were interpretation, and $8 \%$ were resolution; in total, these four cognitive categories were found in $56 \%$ of the posts and responses submitted by the elementary education program participants.

\section{Social presence}

Social presence categories were made up of the following: 289 of the 563 posts $(51 \%)$ fell into the affect category, 362 of the 563 (64\%) fell into the open communication category, and $150(27 \%)$ fell into the group cohesion category. The following bar graph depicts these percentages. 


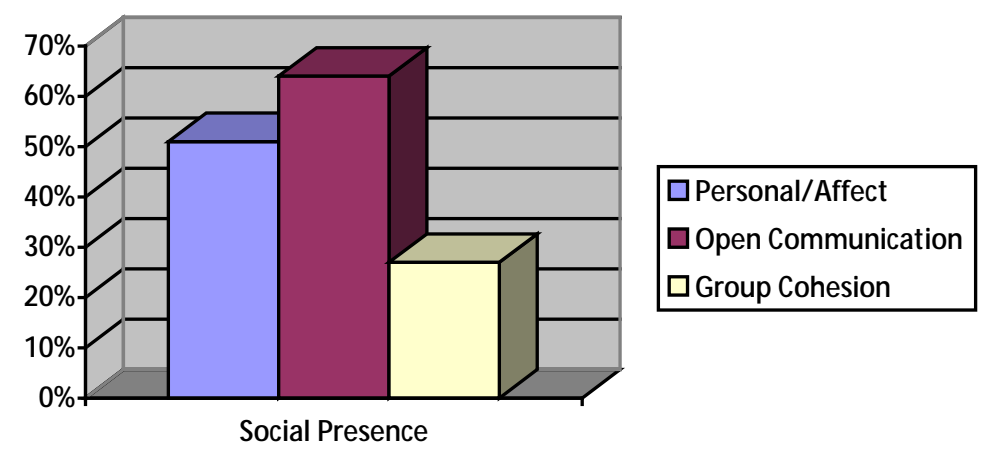

Percentage-wise these numbers will not add up to $100 \%$ as the cognitive numbers did due to the fact that more than one social presence category was often assigned to each post. As explained earlier in the research, only one cognitive presence was assigned to each post that warranted the designation due to the fact that it was decided during the inter-rater reliability calibrating period that the highest presence achieved would be noted. The researchers also agreed that more than one social presence category was repeatedly seen throughout the coding process and it would have been limiting to the understanding of what is going on in the threaded discussions from a social perspective if these categories were not all included.

\section{Secondary Education Program Participants}

Of the 1170 posts and responses in the threaded discussions, 371 belonged to the eight secondary education program participants. Cognitive and social presence category findings are discussed in the next section.

\section{Cognitive presence}

Of the 371 posts, 227 fell into the cognitive presence. These 227 posts and responses can be further reduced into the categories that make up the cognitive presence of this 
community of inquiry: 10 fell into the trigger category, 65 fell into the exploration category, 122 fell into the integration category and 30 fell into the resolution category.

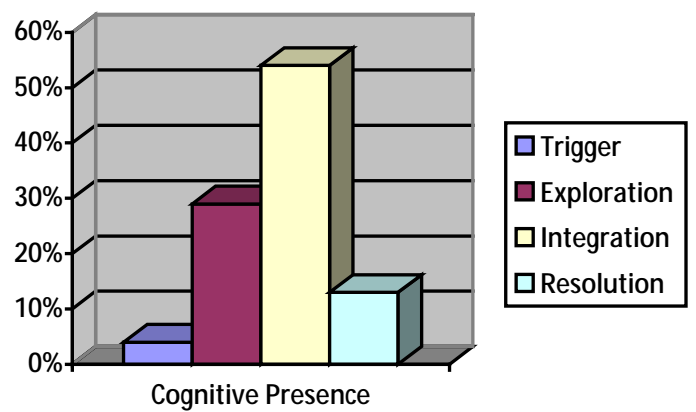

Within these 227 posts these figures translate into percentage terms as follows: $4 \%$ of the posts were categorized as trigger, $29 \%$ were exploration, $54 \%$ were interpretation, and $13 \%$ were resolution; in total, these four cognitive categories were found in $61 \%$ of the posts and responses submitted by the secondary education program participants.

\section{Social presence}

Social presence categories were made up of the following: 231 of the 371 posts $(62 \%)$ fell into the affect category, 219 of the 371 (59\%) fell into the open communication category, and $91(25 \%)$ fell into the group cohesion category.

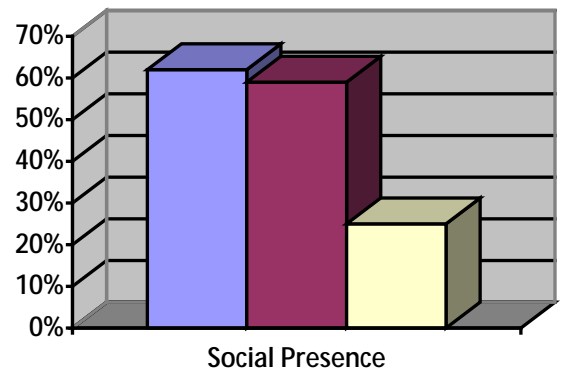

\section{$\square$ Personal/ Affect}

$\square$ Open Communication

$\square$ Group Cohesion

As noted above, more than one category was often encountered in the posts and responses. 


\section{Higher Education Program Participants}

Of the 1170 posts and responses in the threaded discussions, 196 belonged to the four higher education program participants. Cognitive and social presence category findings are discussed in the next section.

\section{Cognitive presence}

Of the 196 posts, 129 fell into the cognitive presence. These 129 posts and responses can be further reduced into the categories that make up the cognitive presence of this community of inquiry: 5 fell into the trigger category, 52 fell into the exploration category, 59 fell into the integration category and 13 fell into the resolution category.

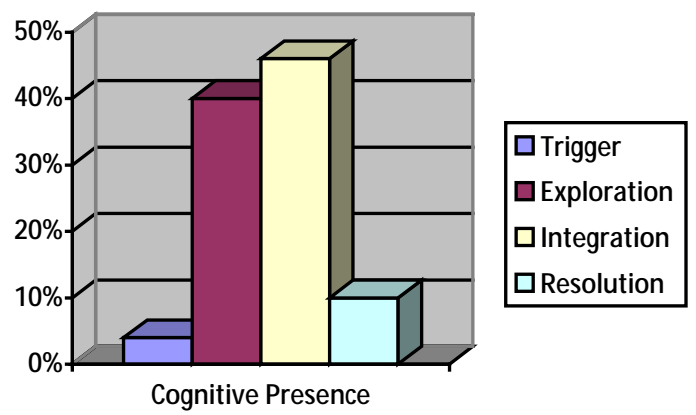

Within these 129 posts these figures translate into percentage terms as follows: $4 \%$ of the posts were categorized as trigger, $40 \%$ were exploration, $46 \%$ were interpretation, and $10 \%$ were resolution; in total, these four cognitive categories were found in $66 \%$ of the posts and responses submitted by the higher education program participants.

\section{Social presence}

Social presence categories were made up of the following: 128 of the 196 posts $(65 \%)$ fell into the affect category, 117 of the $196(60 \%)$ fell into the open communication category, and $66(34 \%)$ fell into the group cohesion category. 


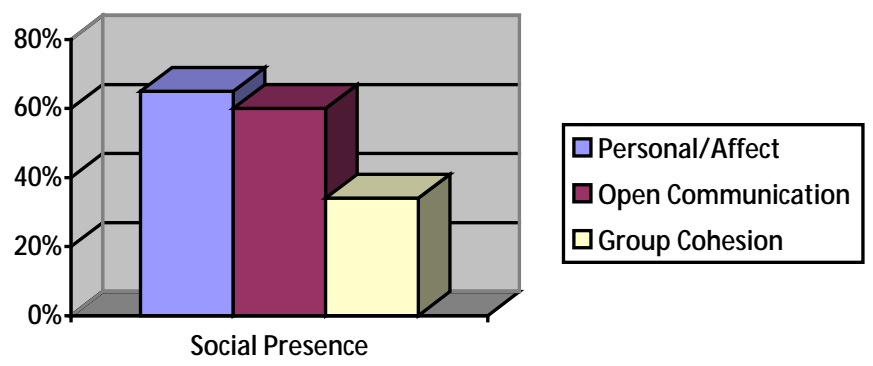

As noted above, more than one category was often encountered in the posts and responses. Analysis by Session

The vast amount of data generated by the CoI content analysis of the threaded discussions provided rich fodder to explore. Like a Russian nested doll, additional analysis of specific results yielded further insights into how learning online takes place in general and within the context of a multicultural curriculum. An examination of these results follows.

Main

The first threaded discussion opportunity on the discussion board is the main. It serves several purposes. First, it is a place where the instructor posts information. Second, it is a place where students can post questions for the instructor and/or the class as a whole. Lastly, it is a place where miscellaneous topics can be posted that may be of interest to the class. A total of 43 posts and responses were posted on the main: 15 by the instructor, 21 by the elementary education participants, 5 by the secondary education participants, 1 by a higher education participant, and 1 by a student who did not complete the course.

\section{Instructor posts}

Of the 43 posts and responses to the main, 15, or 35\% were from the instructor. These 15 instructor posts reflected the three categories of the teaching presence category: design and organization, facilitating discourse, and direct instruction. Topics of instructor posts included 
eReserve access, reminders to check email, rubrics, tips, calls for papers and upcoming

conferences, tweaks, surveys, IT, administrative, groups, request for feedback, answers to

student questions, error patterns, and positive feedback. The following examples give the flavor

of the instructor posts sent at the beginning of the semester:

August 19: eReserves - Hi everyone, eReserve appears not to be working today...I swear it WAS working yesterday J Patience is a virtue, as they say... I'll see what I can do about it. In the meantime, do what you can.

August 23: EMAIL - Hi everyone, For those of you who have sent me your information via the course email - Thank You J For those of you who have not yet visited the course email portion of our entertainment, now would be a good time J

August 23: Discussion Board Rubrics - Hi everyone, I admit that I am not a big fan of rubrics on the graduate level as I feel everyone at this point in their education should know what quality looks like. From time to time, however, I will put some tips up under the MAIN part of the discussion board on how to get the most point possible. Consider this Tip \#1: Points will be awarded in relation to how much of the session you respond to. Make sure you read each session carefully and respond thoughtfully. Don't forget to respond to your peers - I take this part of the grading VERY seriously - $50 \%$ of your session grade will be reflected in your response. Lastly, I like the " 3 before me" rule. If you have a question, ask your peers first. If no one has a clue, email me. You will see more "tips" on the MAIN as situations/questions arise. Thank you. I'm looking forward to a great semester based on what I've see so far J

August 24: Call for Papers and Upcoming Conferences - As I run across them, I will post calls for papers and upcoming conferences that relate to our course. Feel free to do the same. (The following is connected with the Civil Rights Project) National Call for Research Papers and Notice of Upcoming Conference:"Looking to the Future: Legal and Policy Options for Racially Integrated Education in the South" Deadline for Proposals: September 2, 2008 Conference date: April 2, 2009 at University of North Carolina Chapel Hill.

August 25: RESPONSES - Hi everyone, I'll be tweaking the course as we go along in response to your interpretations of the curriculum. Today's tweak is in regards to responses to your peers. As I mentioned in another post, rubrics make me kinda squeamish because I'm not a micromanager. So, instead of writing rubrics for every imaginable possible event and occurrence in an online course, I prefer to just address them as they come up. It is implicitly expected that you respond to your peers. The purpose of the discussion board is to discuss the course readings. More specifically, it is designed to discuss what you found interesting in the course readings or more specifically, to make connections to what you read and to the responses of others. Hope this clears up some of the questions you may have had about responses. 
August 30: What is Wimba? Hi everyone, As you may know by now or are soon to find out, I love surveys and love to hear how it's going with you all. I love feedback so that I can address individual and group needs. That said, my question of the day is as follows: If you had the opportunity to meet at a specific time and day in this course and actually TALK to your peers, would you be ABLE to do this? Would you WANT to do this? Would this add another desirable dimension to this course for you? Please ALL take a moment to answer the above questions. I thank you ALL for your feedbackJ

September 1: ereserves - Everyone should be able to get into ereserves at this point. If you are having trouble, please call .......... You may have locked yourself out if you tried too many combinations.

September 3: GROUPS - Hi everyone, Some of you have noticed that groups have been formed for the sessions that are coming up. I use the magic random alphabetical order system to create groups. As always, feedback is welcome as to how you feel about group vs whole class interaction. I look forward to hearing your comments and opinions :0

September 4: Searching the ... Library system - Hi all, Those of you having trouble navigating the ... Library system - do not despair - I am not too crazy about it myself! Don't spend hours getting frustrated and pulling out your hair! Call .......... And some gentle patient soul will walk you through. There's also an email address at the bottom right side of the Library page that pops up if you want to email someone instead...

September 13: Session 4 tips ... Hi everyone, Please don't forget to mention the following: 1. Tatum lecture 2. Tatum PDF 3. Core Values in Bennett 4. Ex. 5\&6 in Bennett Just a friendly reminder...

\section{Participant posts and responses}

Of the 43 posts and responses to the main part of the discussion board, 21 posts and responses were posted by the elementary education participants, 5 were posted by the secondary education participants and 1 was posted by one of the higher education participants. These figures translate into the following percentages: approximately $49 \%$ of the posts and responses came from the elementary education participants, 12 percent came from the secondary education participants, and slightly over $2 \%$ came from the higher education participants.

Breaking down these numbers further reveals that 9 of the elementary participant posts came from a female educator in the 20-30 age bracket with 3 years of teaching experience; 5 of 
the posts came from a female educator in the 31-40 age bracket with 7 years of teaching experience; 3 came from a veteran female educator in the 31-40 age bracket with 12 years of education experience; 2 came from a female educator in the 20-30 age bracket with 6 years of teaching experience; and 1 came from a new female educator in the 20-30 age bracket. Of the 5 secondary education participant posts, 2 came from a novice female educator in the 20-30 age bracket with 2 years of education experience; 2 came from a new female educator in the 20-30 age bracket; and 1 came from a Latina female educator in the 31-40 age bracket with 10 years of teaching experience. The one post from the higher education participant came from a female educator in the 20-30 age bracket with 5 years of teaching experience.

The one post from the student who did not finish the course assignments was from a preservice male in the 20-30 age bracket. In his response to the instructor's request for feedback regarding participation possibilities with Wimba, this student's reply tellingly points to time challenges that would dog him for the rest of the semester:

Meeting at a certain time of day would be very difficult for me to do. I usually work on the days I don't have classes, so it makes it hard for me to free up time on a specific day every week other than how I have it set up for classes. It would be nice to do, because I think it would help keep me on track with the course, but I just don't think I would have the time for it this semester.

Other participants voiced similar concerns. Participant 9 also responded to the Wimba interest post from the instructor. She writes:

My times schedule is already stretched pretty thin. I already have several other chat times to be online. It would be nice to do, but I don't know how realistic it is to me. I like the typed comments b/c it gives me more time to think and through my responses and entries.

Participant 5 echoes similar concerns:

I could try to meet. I am nursing, so I can only get away for a short time before my baby needs me. So it just depends if I can leave her at the appointed time and get back to her pretty quickly. 
Participant 8 also has reservations:

I also prefer the discussion boards, due to a hectic schedule. I am working fulltime, so my evenings are jam-packed with family time and paper grading.

Participant 11 notes her thoughts based on her experience with Wimba:

I think that it is always great to meet and talk to our peers. However, in my experience the technology is still not quite good to allow a fluent interaction between students. We are using Wimba in another course and when there are many students, it does not work well; things get really very slow.

Of the 6 people who responded to this instructor question, only one responded in the affirmative. Participant 4 writes:

The best time would be after 9:00 pm because the kids are all in bed.

Session One: Multicultural Education

Participant posts and responses

A total of 87 posts and responses fill the threaded discussion of session one. Of these, 18 are from the instructor, 31 are from the elementary education participants, 24 are from the secondary participants and 14 are from the higher education participants.

Session one asked the participants to first google and then reflect on what multicultural education means to them. They are then asked to post their responses on the discussion board after reading and reflecting on the following excerpt by Dr. Gregory Jay's titled Who did we learn about in school today?

Like most words, "multiculturalism" needs to be understood from both an historical and a conceptual perspective. Historically, "multiculturalism" came into wide public use during the early 1980s in the context of public school curriculum reform. Specifically, the argument was made that the content of classes in history, literature, social studies, and other areas reflected what came to be called a "Eurocentric" bias. Few if any women or people of color, or people from outside the Western European tradition, appeared prominently in the curriculums of schools in the United States. This material absence was also interpreted as a value judgment that reinforced unhealthy ethnocentric and even racist attitudes. 
Observers noted that teaching and administrative staffs in schools were also overwhelmingly white and/or male (whiteness being pervasive at the teaching level, maleness at the administrative level, reflecting the politics of gender and class as well as race in the educational system). Eventually parallel questions were raised (once more) about the ethno-racial or cultural biases of other institutions, such as legislatures, government agencies, corporations, religious groups, private clubs, etc. Each of these has in turn developed its own response and policies regarding multiculturalism. Finally, "multiculturalism" may also have become a popular term as "race" lost much of its former credibility as a concept. Scientists agree that, in terms of DNA genetics, "race" has no significant meaning as a way of categorizing human differences. Intermarried families offer the puzzle of a parent and child considered as belonging to two different races--clearly an absurd idea given that race was thought of as biologically passed from parent to offspring. Thus "culture" began to replace "race" as a term for distinguishing among distinct human groups.

Participant 2, a novice elementary school teacher, writes:

Multicultural education means integrating various cultures and ideas so students have a better understanding of the world around them. Students need to know that not everyone is like them or believes what they believe. This opens the door to both tolerance and growth as individuals. Exposing children to other cultures can truly help them get a better sense of what the entire world is like. As a child, I remember thinking everyone in the world was just like me and did the same things as me. It was interesting to learn that was not the case! Many of these students will also face students of other cultures throughout their years in the public school system. They need to be taught that it is okay to be different and that there is always something to be learned from other cultures....I see mostly females in our school system, even as administrators. You do not see many different cultures represented among teachers usually. That is not the case for the classroom though, which is why we must prepare these children for the different cultures they will encounter throughout their lives.

Participant 4, a new teacher, writes:

I think of Multicultural Education as the learning, understanding and acceptance of people differences. When I refer to people differences, this includes, race, sex, ethnicity, demographics, religion, etc. These differences directly relate to an individuals culture. We are the "meltingpot" and we all have cultural differences that we can share and learn from each other. It is us to us as individuals to educate ourselves and be accepting of others differences. Most of all, it is up to us to be accepting of the education we receive and forward our knowledge to schools and into our communities for education of multiculture to take place and be successful.

Participant 6, a pre-service teacher, voices her agreement with the others:

I think that multicultural education is so important. I agree with some of the other responses that students are overwhelmed with information and the importance of 
multicultural education has lost its bright light. I think as educators, we should help students to see that they can learn about people in history and today by the people themselves and what they have accomplished, not their gender or race.

Participant 8 , an established elementary school teacher who has been teaching for 6 years, adds

her perspective:

I would define multicultural as including different opinions and ideas. For instance, studying the impact of colonization from the European and Native American perspectives. To me, multicultural education also involved exposure to people who are different. This is not necessarily a racial difference, but could include gender or age differences.

Participant 3 offers the male perspective of a teacher who has been teaching for 4 years:

I don't feel that the term multicultural education can be given one true definition. Within each culture, I feel that there are beliefs and traditions that affect the levels at which individuals want to learn about other cultures....In a general and personal sense, I feel that multicultural education basically means the process by which we learn about individuals from other cultures and compare it with our own cultures. I am very pleased to be at a school that stresses multicultural education. Being from a region that is $98 \%$ Caucasian, there is scare opportunity to experience multicultural education by daily interaction. As a result, our school attempts to educate our students by having them participate in Chinese New Year's activities, Cinco de Mayo activities, and other various things that celebrate other cultures. With the age of technology, our world is getting smaller and we must make the efforts to educate our students to make them aware of their "neighbors" in the $21^{\text {st }}$ century.

Participant 1, a 12 year master teacher, exemplifies the coalescence of cognitive and social

presence as she weaves through the categories:

I had one of Oprah's "aha moments" when Dr. Jay brought up the idea of culture replacing race as a point of discussion, race being a moot point in discursive circles these days. Of course that makes wonderful sense! One's behavior, interests, personality, world view, etc. are not determined by genetics, as one would assume with the idea of race. It is a person's entire life context-CULTURE-that shapes her uniqueness. Besides, race is a limited scope anyway. When we speak of differences among people, we must include those having nothing to do with race: regional residence, ethnic presence, ability/disability, state of health and mind, gender identity/preference, and even socioeconomic/education status. I just read the Kinsley "last word" essay in the Aug. 25th edition of Time magazine. His subject is the push for affirmative action by social class. He brought up very interesting points about America's new focus on equalizing the playing fields in colleges and careers by addressing issues of economic status and education level. He claims that there is a movement gaining strength to allow for 
opportunities denied people because of their social class, despite their race/gender/ethnicity. Social class...one of the multi-cultures of America? Kinsley likens the movement to China's control over its citizens through massive labeling and granting/denying rights. You'll have to read his essay to see if you agree or disagree, but it brings up an interesting debate: What determines a "culture"? Perhaps the debate itself is more important than any actual answers we get. Multicultural education is the opening of dialogue, the acknowledgment of diversity, however we draw the lines in the sand. It is the awareness and acceptance of diverse thoughts and histories, the sharing of our uniquenesses that brings us to the ultimate realization: "I feared your difference at first, but I found out that you're more like me than I thought." If we can lead kids (and anyone else who'll go along for the ride) to this epiphany, what greater thing can we do as teachers?

Participant 9, a 7 year veteran teacher, also demonstrates how social presence coalesces with cognitive presence as social presence indicators of open communication, affect, and group cohesion intertwine with the cognitive triggering and exploration categories as she confronts some issues.

(Participant 14's name), Let me be honest here. I have never actually known or spoke to an athiest. What would you say to students on either side of the issues, such as religious beliefs or sexulaity issues etc.? I personally have several different beliefs and "identity" issues (for the sake of a better word) in my family and my in-laws. I find that I do not have a problem with them as people. We all make our own belief choices and lifestyle choices. I do find it difficult raising my own childrena and answering their own questions at their level (my children range from 2-5). I find it is even more difficult to try and have conversations about respect when the students come with such biases already in place from their homes or just an overall ignorance about others from lack of conversation at home. Do you find it challenging or not difficult to handle these issues having already dealt with similar ones when you were in school?

Is it harder or easier for you to keep your beliefs out of the classroom and try to teach respect for all? I find this can be tricky when I teach music. There are so mnay holidays, religious songs and games and even dances sometimes that children are not allowed to participate in.

I hope these questions make sense and do not ofend you. I am honestly curious about someone else on the opposite end of the belief spectrum deals with the same issues.

Participant 14, a novice secondary teacher, responds to Participant 9:

I LOVE talking about religous beliefs, gender inequality, sexuality, and other taboo topics. Probably why I became a social studies teacher. I love telling kids that no matter how many times they heard a lie about a certain people that we are all truley the same and deserve the same rights. I think it's easier for me to be unbiased when it comes 
to religion.. think about it. If they ask me I usually say it's a personal topic.. unless its part of a more advanced class which discusses religious beliefs. Honestly, most kids find my openness to all the diversity the planet has to offer very refreshing. I like holidays. Some people may be offended by Christ based songs but Santa really is a non-religious figure (and perhaps false idol?). But when we talk about religion or holidays in my classes we honor all traditions and heritages equally. It's much more fun because it make wayyyy more to celebrate. :) I hope my answers were okay I'm on break at work. Feel free to ask anything else, I don't get offended anymore haha.

Participant 13, a new secondary teacher, writes of the challenges faced in monocultural areas:

I think that as educators we have to be conscious of the impact that we have on the lives of our students. We spend more time with these children than their parents, and we play a huge role in their mental, social, and emotional development. I feel that we as educators must display an awareness of all individuals and their differences/similarities. And more importantly we must show our students through modeling to embrace these differences including culture differences.

Often times teachers try to shape the minds of their students to be uniform and I feel that this a terrible mistake. We as humans look at things that are "different" as a negative thing. Its human nature; "if it isn't like us, then its wrong."

Its difficult to teach your students to embrace other cultures when they aren't exposed to these other cultures. I feel that it is an uphill battle in (state name) to try to help my students see the differences as a positive aspect when they are ignorant to what the differences truly are. There needs to be some change in our ways of viewing multiculturalism. I feel that it is often taught in classrooms with mixed races or cultures, but what about those who are in a class with $90-100 \%$ caucasian its ignored. There are several issues with this but one that I see often is that this ignorance of other cultures spills out into our society because it is not taught within the classroom. These students grow up and go out as a vital member of society never understanding the importance of understanding an embracing our multicultural society.

Participant 11, a 10 year master secondary teacher originally from South America, gives a Latina perspective:

In today's society, classrooms are becoming more and more diverse. School population is nowadays a lot more heterogeneous, formed by students with different cultural backgrounds, values, beliefs, religions, etc. Multicultural education, in my view, not only recognizes cultural differences across students, but it also incorporates cultural diversity in curriculum. Multicultural education is the capacity to share with others different cultural backgrounds, share the diversity, and use this process to enhance the learning experience. In this context, it is important for teachers to be prepared to teach in a more complex environment. I am an instructor of foreign language at (school). In my class the concept of multicultural education is very relevant. By emphasizing on the issue of cultural diversity I try to set a bridge with students in order to help them understand and appreciate different cultures. It also allows them to share and find similarities with 
their own background. In my first class, I always ask the students to provide a definition of "culture". I think it is important to know what they understand about this topic. One aspect that always calls my attention is that they all tend to offer different definitions or explanations; everyone interprets multiculturalism in a different way. It is important to teach our students respect for other cultures, other traditions; respect for what is different in relation to our own experiences and backgrounds. Learning about values, beliefs, and cultural differences gives students a chance to understand the point of view of others. I liked the article by Dr. Gregory Jay. I completely agree when he mentions that most of the teachers and administrative staffs were white or male in the educational system. Today we observe a lot of diversity in the student body but it is not corresponded by a diverse group of teachers. The most common situation in school is to see white and monolingual teachers. Even thought I think there is a transformation in the educational system involving the issue of multicultural education, as teachers we have the responsibility to work together with parents and communities in order to integrate diversity in all activities of our children's life.

Participant 14, a novice secondary teacher, presents her angle:

I agree with what Dr. Jay has said about multiculturalism in schools. In social studies we constantly struggle with eurocentric, patriarchal, and nationalistic biases in our content, colleagues, students, and parents (of students). Religion based assumptions run rampant over (state)'s school systems. We need the people who inhabit our school system to mirror the ideals we claim the books are teaching. I do disagree with way the first paragraph makes this problem seem like it has past. I don't think we've even begun to scratch the surface in many parts of the US. I personally fought this demon throughout my school years as a 14 year old atheist vegetarian with somewhat radical political beliefs.. walking into high school in (City, State) was very unwelcoming place for me. I had many teachers who would show biases toward religion, political affiliations, and yes.. even race in front of their classes. I was part of the "civil rights club" and a few of my friends and I personally are responsible for it's demise. My friends I speak of were both openly gay and wanted "sexuality" added to the "protected rights" list of our charter. The principal called us in and gave us the basic good old boy bullshit about religious people and politics, but basically offered us a choice: drop the issue or lose the club. We obviously called the ACLU, but nothing was done. Point being, when I think of multiculturalism in schools and education I think of real life situations that need to be handled in ways that respect everyone's rights. I think of kids who feel unwelcome and fearful when they walk into class. I remember how overwhelming it is to feel powerless in the face of a few hundred people so different from you and wish someone, or something was saying to you that it is okay to be who you are. Because really.. it is GREAT to be who you are.

Participant 15, a 4 year secondary teacher from Korea, gives an Asian perspective:

Multicultural education is another interesting part of my work. It's not easy to meet other cultures in this small town, but it is another fun time for me and for the students. We all can have different cultures presents, and experiences when we can have 
a multicultural calls. Actually I'm from different culture, so sometimes I show them my culture, history, and my experiences. Multicultural education may ensure the highest levels of academic achievement for all students. It helps students develop a positive self concept by providing knowledge about the histories, cultures, and contributions of diverse groups. Many students try to understand or experienced other histories and cultures. Students watch movies, read books or try to talk with that different countries students of their ages online. They share their interesting ideas, curiosities, and cultures. Experience is the best teacher. It's second hand learning however this experiences gives the students huge imagination and makes the students mental vision wider. Basically, all students have to learn Native American history, it doesn't matter if African American students, Asian American students, or European American students. But all students don't learn all other cultures or histories. For that reason multicultural education is important. Multicultural education is about social change through education. It require imagination and commitment to the future. Multicultural education is not just different culture. It has different societies, different histories, different people, different families, different communities, different colors, and many different minds.

Participant 20, an established 5 year teacher in higher education, reflects on her past experiences

as a public elementary school teacher in addressing her definition of multicultural education:

I found this article rather interesting, simply because I realized that as I was reading it I was reflecting upon my past experiences as a teacher in a public elementary classroom. The population of the elementary school I worked at was very diverse in culture and race. This included students, teachers, and administrators. We had staff members who could speak several languages fluently, we celebrated "black history month" year round during learning, and our school productions included the Lunar New Year celebration and several Hindu holidays where students would wear their festive attire. Parents would bring in clothes from their culture for our principal to wear. Although I was able to have that experience, I have been in learning environments where multiculturalism was viewed as a one-dimensional concept or idea, and often only involving the race and culture of the individuals who may currently be in that room. That is why it is so important and essential for educators to be able to teach their students about various cultures and diverse backgrounds, in addition to recognizing when instructional materials are not adequately including diverse individuals and cultures. I found it interesting when the author discussed how race "has no significant meaning as a way of categorizing human differences." I have never before considered genetics as part of this issue, specifically when identifying how to appropriately differentiate human groups. I agree that culture in this aspect is more definitive as opposed to using race to address differences. I had never before thought of race in the terms offered by Dr. Jay, but after reading this I really feel that it makes a lot of sense.

Participant 19, a 10 year veteran of teaching in higher education, is triggered by something she reads in the Dr. Jay article and writes: 
Like Nancy, I did not realize that the word race was being phased out, so I looked it up in Webster. The definition is so broad as to include such phrases as: class that shares interests, habits, or characteristic; an interbreeding group within a species, and humankind that share certain distictive physical traits. I think multiculturalism has become distorted from the original attempts to recognize humanity and a collective community. We use labels such as white, black, hispanic... as ways of recognition and identifiers (both positive and negative), but they are so scrutinized by social politics and litigic fears that I think we've missed the point of a collective community that has a respect for all individuals. There is such a political influence that sometimes I think we use the pretense of race and minority to excuse and justify some of our own poor choices/and or bad behavior or lack of understanding. My upbringing did not include these identifiers to individuals, so I was not aware of social mores that surround ethnic groups until I left home. I thought everyone was equal. I concur that a "Eurocentric" bias has driven policies and dominated positions and is being challenged in curriculum through autobiographies and inclusion of women and minorities. I think textbooks are influenced by politics and norms of the area and are therefore selective in their presentation and depth of coverage to these areas to this day. I really like the thought that our communities are becoming more multicultural so that individuals have the opportunity to look beyond the identifiers we associate with persons that are different and see the common threads of humanity that we share with one another.

Participant 21, a novice, older male teacher in higher education, sums it all up in his response:

My reaction is that everyone has an opinion about multicultural education. I think that for hundreds of years Europeans have believed that this is their world. In this day and time we have to realize that we all just live on a little ball spinning in space and we should celebrate our differences and our likenesses.

\section{Instructor posts and responses}

Instructor responses to session one posts embody the teaching presence categories. For example, the following responses to participant 5 demonstrate facilitating discourse, direct instruction, and instructional design and organization:

Participant 5-you make an important distinction - "at least according to him" when you begin your discussion about the article. One of the major purposes of this course is to ask many questions - who is writing this? What are his/her credentials? Where is he/she getting this information from? What about bias? Is he/she trying to persuade you? Or inform?

Participant 5 - you actually have a point - there is a lot of research on teaching students to teach themselves to become lifelong learners and contributing democratic citizens. Learning is no longer considered a passive sport - active participation is vital. 
This goes for the teacher end to - teachers should no longer teach by simply pouring information into students heads but through authentic, real life, activities that students can relate to their own lives...

In response to participant 19 , the instructor facilitates discourse by cheering on, supporting, and praising the participant while simultaneously prompting continued dialogue from participant 19 as well as other members of the class. Creating a positive climate invites risktaking dialogue and leads to higher order thinking.

Touche' participant 19 - eloquently put and right on target! Will we ever lose the labels and live happily ever after??? How long will it take? How long has it taken already? DNA testing is already showing that we are ALL connected...

In response to participants $4,8,10$, and 1 , the instructor again draws on facilitating discourse and direct instruction as she models bringing in current diverse sources from outside the course content:

Participant 4 - you raise important questions at the end of your post. Changing the thought process of people who don't want to change is quite the challenge. We as teachers are usually so open to anything that we (I) assume everyone else is or should be. I have gleaned a lot from Covey's "Habits" books that are helpful in this regard - "Seek first to understand, then to be understood" is one of my mantras that I pull out in cases like this...

Hi Participant 8, Your post made me think of the book Encounter by Jane Yolen. You'll find it in the children's book section but it is kinda scary (to me) and can be used for all age levels to adult. It gives the perspective of Columbus landing on an island in the Caribbean from a little boy - and it is terrifying! Morning Girl by Michael Dorres is another excellent read - same historical fiction period, different perspective - this time from a girl. Island of Dolphins is the last one I'll mention that fits in this genre, also from a girl perspective. They are all fun reads and good ways to get your students thinking critically about history.

Participant 10, what are your thoughts about life before the Euros? For example, the Chinese, The Phoenicians, the Incas? If my memory serves me well, my National Geographics wrote many articles on how these ancient civilizations controlled their worlds... Why are we always focused on the Euros?

Didn't the Chinese keep meticulous records as well? I know the printing press served to cement, document, and spread the European adventures but didn't other civilizations keep records as well? I found my February 2008 National Geographic magazine which 
has on the cover "The Black Pharaohs: Conquerors of ancient Egypt." It's a pretty cool piece. It starts off with "An ignored chapter of history tells of a time when kings from deep in Africa conquered ancient Egypt." The author writes about how King Piye of Nubia (Sudan) captured Egypt in 730 BC. The author further claims that "the ancient world was devoid of racism. At the time of Piye's historic conquest of Egypt the fact that his skin was dark was irrelevant." Of course I'm asking myself how did the author know this? How did he come to this conclusion? The end of the article links to ngm.com which is where I'm heading next...

Participant 1 , your post made me think of the July 28 Newsweek with the cover story "Murder in the $8^{\text {th }}$ Grade" which describes a similar situation only the boy in this story was actually murdered in school by another classmate...Homophobia is alive and well which is disheartening.

Session one sets up a foundation upon which the rest of the course is built as the above participant and instructor posts and responses indicate. Cognitive, social, and teaching presence coalesces within the posts and responses of this session. The educational experience found at the fulcrum of the Community of Inquiry model is clearly taking place in these threaded discussions. Session Two: Discovering America's Forgotten Heroes

\section{Participant posts and responses}

A total of 83 posts and responses fill the threaded discussion of session two. Of these 38 are from the elementary education participants, 32 are from the secondary participants and 13 are from the higher education participants.

Session two asked the participants to read an d reflect on the Introduction and Chapter One of Loewen's Lies My Teacher Told Me. They are then asked to consider how his assertions resonate w ith their ow $\mathrm{n}$ experience learning A merican h istory: do their experiences concur or conflict $\mathrm{w}$ ith $\mathrm{h}$ is $\mathrm{t}$ hesis? $\mathrm{T}$ heir $\mathrm{p}$ osts an $\mathrm{d}$ responses $\mathrm{t} \mathrm{o}$ their $\mathrm{p}$ eers are $\mathrm{t}$ hen $\mathrm{p}$ osted on $\mathrm{t}$ he discussion board.

Participant 7 , a novice elementary teacher writes:

After the readings, it really makes you stop and think about the history classes and teachers you had while you were in school. I know that when I was in school and it was 
the same basic information year after year. It never changed. It was the same, here is the information learn the dates and memorize facts and then you'll be tested on it. I think there are so many interesting people and events that have occurred that just get left out. Too often our books just look at the same thing every book be fore has looked at. They are careful not to make any American figure look bad. They keep patronizing the same figures. I think our students would greatly benefit and be more interested in so may of these stories that get left out of our books. I t would be great to let them explore and research history and form their own opinions.

Participant 18 , new to teaching higher education, asks many questions:

I believe that both writers have addressed very important issues. History has been written in a manner that is to Disney. Why is it that the textbooks used in our schools today are so detail-lacking? Why is it always about individuals and not teams?

As both writers have pointed out, individuals history are the heros. How often do you read about groups working together to succesfully achieve historical significance? How much can one individual really do on their own?

Don't get me wrong... many people have completed enormously amazing feats in our history. Reading of an individual's success often causes a feeling of self-confidence in the beholder. It is the feeling of individuality that this country over-focuses on. Are we not a fend for yourself nation? Is it not every man for himself?

I agree that there are numerous historical inaccuracies that have been taught, and continue to be, in our educational systems. Educators and those being educated should assume the responsibility in researching things that are being taught. With coming from a scientific background, I have learned that one must always question presentation.

Two participants were not so enamored with the readings. Participant 5 writes:

First of all, let me say that as I began reading Loewen, I found a some topics from the Intro to the 2 nd edition to be a bit offensive, namely when the author talks about how he's tickled pink when students use this book as a "guerrilla text" and feel the need to "heckle" their teacher. Maybe it's just my loathing of spoiled brats, but these students, if they do indeed exist, sound obnoxious. Let's face it, teachers use the textbook they are instructed to use. Is this the best practice? MAybe not. Should we seek the truth? Yes. Is Lies my Teacher Told Me the gospel? I don't know. MAybe we are all being fed a bunch of lies in all subjects, or maybe the lies are confined to history class, but it's a bit much to get past the fact that the author feels a smug satisfaction that he's unearthed secret information that gives students permission to stage a revolt aimed at disrespecting teachers, many of whom work really hard for very little reward.

I have to be honest, I find the presentation of this material offensive so far. Maybe he's got all his facts straight and we've all wasted countless hours studying lies and deceptions under the guise of "History" class, but let's not take it out on teachers. 
Participant 4 responds:

I agree with you $100 \%$ I had a similar experience when I read the introduction and the first chapter. I became very defensive.... Just due to Lowen's tone it is hard for me to keep an open mind.

Rich, vivid description fills session two. The coalescence of cognitive and social

presence is found throughout the posts and responses. Session two adds another layer to the beginnings of a solid foundation of a learning experience within the Community of Inquiry.

Session Three: Looking within Yourself

Participant posts and responses

A total of 117 posts and responses fill the threaded discussion of session three. Of these, 6 are from the instructor, 57 are from the elementary education participants, 35 are from the secondary participants and 19 are from the higher education participants.

Session three asked the participants to read and reflect on two articles, one by Kailin on how white teachers pe rceive racism in their s chools and a nother by $\mathrm{P}$ accione on $\mathrm{d}$ eveloping a commitment to be coming a multicultural educator. They were then asked to take the Implicit Association Test and, after reflecting on all of the above, respond to three questions about their preconceived ideas and unc onscious biases, expectations of their s tudents, and on be coming a multicultural e ducator. Their pos ts a nd $\mathrm{r}$ esponses $\mathrm{t}$ o $t$ heir peers $\mathrm{w}$ ere then pos ted on $\mathrm{t}$ he discussion board. Session three generated the most posts and responses of all of the sessions. The s ession c ontext p roduced pa rticipant stories which w ere all un ique. For example, of the preconceived ideas and unconscious biases she brings, participant 1 , a veteran teacher writes,

Coming from a small town in northern Wisconsin, Paccione's Stage 1 and 2 were probably a slow process for me. I wasn't exposed to ethnic diversity other than the few Native Americans who moved off the reservations and into our Scandinavian immigrant towns. (Anyone listen to Garrison Keillor's Prairie Home Companion? That was us.) I did, how ever, grow up i n an e conomic minority. While most of the town was middleupper class, my family struggled to make payments on our trailer. We didn't have running 
water or a phone for many y ears. I was acu tely aw are of my peers' relative fortune in material possessions, but I did not feel like I lacked anything. I was just embarrassed a lot. Coming home from school was paradise for me because I adored my family, but to bring a friend with me was completely unthinkable. Many kids at school would whisper about my family, starting rumors...like my father's only job was trapping on our lake and that we were on welfare. I burned in anger at their ignorance and insensitivity. I think this is where I began a lifelong hostility towards the privileged, even though I now would be considered one of them. In my classroom today, I rail a gainst the insular attitude of the rich $\mathrm{s}$ uburb/subdivision dw ellers who $f$ ail to $\mathrm{s}$ ee $\mathrm{t}$ he $\mathrm{m}$ isery $\mathrm{r}$ ight out side $\mathrm{t}$ heir neighborhoods. Yes, I have a preconceived idea about the wealthy. Do I understand that not all wealthy people are selfish and insular? Of course. But that little girl still feels the anger toward a powerful majority judging her.

The Kailin and Paccione readings produce many questions in her post. She writes:

My first question upon reading the Kailin and Paccione articles was, "When were these studies d one??" I t su rprises me that in the 21 st $\mathrm{C}$. the teachers in the majority culture $\mathrm{s}$ till make $\mathrm{s}$ uch obvi ous $\mathrm{c}$ ulturally-insensitive bl unders. I wavered be tween agreeing $w$ ith $t$ he a uthors on va rious points and then becoming a ngry $w$ ith them for THEIR $i$ nherent $b$ iases a nd a gendas. M y s econd que stion $w$ as $i \mathrm{n} r$ esponse $t o$ the comment: "Ninety pe rcent of the teaching force in the US is White at a t ime when children of color will soon comprise the majority of students in public education." Well, I ask: Why i sn't it assumed that the teacher population will soon reflect the students'? If during the 70 s, $83 \%$ of the teachers $w$ ere white a nd now $90 \%$ a re white, d espite the obvious growing population of minority students, why the heck aren't more multicultural people b ecoming t eachers? W hat's goi ng on ? S oon thereafter I r ead K ailin's c omment that de tention r ooms a nd special ed cl asses ar e filled $\mathrm{w}$ ith an " inordinate $\mathrm{n}$ umber of students of c olor" a nd that i t's a re sult of $\mathrm{d}$ ifferent/inferior tre atment b y te achers of students. Later she states that 96 black students (in this "liberal Lakeview") dropped out while only 94 graduated and that blacks received five times the number of suspensions given to white students. She claims that part of it stems from teacher discrimination and part of $\mathrm{i} t \mathrm{f}$ rom $\mathrm{t}$ he $\mathrm{i}$ nability of pa rents $\mathrm{t} \mathrm{oj}$ oin in (poor $\mathrm{t}$ ransportation $\mathrm{t} o$ meetings/"superficial" nature of pa rent-teacher co nferences). W hat??! I question these assumptions. Bill Cosby would, too. This places the blame of educational failure solely on the teachers and the s ystem. W hat a bout the $\mathrm{c}$ ulture from $\mathrm{w}$ hich $\mathrm{m}$ inority students come to us, a culture in which appropriate behavior is not developed well and education is not valued?! I teach in a poor community and struggle every single day with a "home" attitude that tells the student he or she is not valued, let alone his or her education. Many of my s tudents' parents are on drugs (It's pervasive here!) or in jail. Their attitude and behavior in school, therefore, reflect that negativity to authority and mainstream "school culture."

In spite of the odds she faces, this veteran teacher write of the hope she has:

My hope is to help build movers and shakers out of our young pe ople, kids who look a $t \mathrm{t}$ he $\mathrm{w}$ orld a round $\mathrm{t}$ hem with c ompassion a nd $\mathrm{f}$ eeling of $\mathrm{r}$ esponsibility a nd brotherhood. 
As seen in sessions one and two, session three has added substantially to the educational experience of the participants in this course. Cognitive, social and teaching presence coalesce in this session as the participants explore and integrate their thoughts and feelings with those of the readings a nd the o ther pa rticipants. $T$ he $s$ ix instructor posts s erved the pu rpose of $d$ irect instruction by a sking participants to in tegrate the then current presidential election e vents in to their posts, facilitating discourse via responding to posts, and lastly, design and organization by clarifying expectations of the session.

\section{Session Four: Values in Action}

\section{Participant posts and responses}

A total of 60 posts and responses fill the threaded discussion of session four. Of these, 1 is from the instructor, 30 are from the elementary education participants, 20 are from the secondary participants and 9 are from the higher education participants. This is roughly half the number of posts generated in the previous session. One possible explanation for this digression is the departure from whole class interaction to small groups.

Session four asked the participants to view Beverly Tatum's lecture at the University of Florida through eReserves and read the PDF chapter on white identiy in her book Why are all the Black Kids Sitting Together in the Cafeteria? Additionally, they were to read and reflect on the preface and chapter one of the Bennett text while making note of which core values of multicultural education are valued in the educational environments they have experienced and which are not valued or ignored. Based on all of the above, they were to consider the changes they would like to see in the world and then describe how they would make this a reality versus a preference. Post and respond to peers. 
As noted above, session four generated half the amount of posts as the previous session.

Session four served as the first session where participants were put into groups on the discussion board. Sessions four through eight would be in this format in order to encourage small group dialogue in contrast to whole class discussion. Three groups of 7 participants each were constructed using alphabetical order. Group A contained 2 males and 4 females: 2 were higher education participants and 4 were elementary education participants. Group B contained 1 male and 6 females: 1 was a higher education participant, 1 was an elementary education participant and 5 were secondary education participants. The last group, Group C, contained 1 male and 7 females: 1 was a higher education participant, 3 were secondary education participants and 4 were elementary education participants.

In spite of the fact that there were half as many posts as the previous session, posts and responses continued to remain rich and descriptive in nature. Participant 14 , a novice secondary teacher, also brings in this notion of hope mentioned by participant 1 in session three:

Let me start by saying I just ordered 3 of Tatum's books in hopes that I enjoy them as much as her lecture and the first chapter of "Why are all the..". I thought her lecture was engaging, informative, challenging, and well spoken (I see why you selected it). Here are some points from the lecture I found especially important and wanted to discuss:

I loved that she stressed HOPE as the antidote to anxiety. I talked in previous posts of the anxiety of being different in school, and she addressed it perfectly. When we consider what can be different and start to think about putting those options into action.. we begin to believe there is hope. We also can start to take active part in being that change, and in turn being our own source of hope.

Participant 10, a male pre-service secondary teacher, echoes some of her thoughts:

I know that it sounds totally cliché, but can't we all just get along? This is always easier said than done, especially when it comes to dealing with racist undertones that invade all depths of society. If more people were aware of each others' eclectic and varied backgrounds there would be far less confusion in the world. Tatum's work and lecture really touched me deeply and opened my eyes to white privilege and its' ever-so prevalent existence. 
Not everyone agrees on all points. Participant 4, a new elementary teacher writes:

I enjoyed Beverly Tatum's lecture and believe it had several important facts. However, I did not enjoy the chapter on white identity in her book, Why Are All the Black Kids Sitting Together in the Cafeteria? It verifies my thoughts that whites seem to be blamed for the racism problem and it is up to us to fix the problem. To combat racism, we must all take fault, and quit blaming any specific race. Why should any white or black person go through a stage of being angry of their race?

Participant 4 does, however, feel that core values are being addressed in schools today:

After reading Bennett, I feel the core values are being identified in schools today. I think the core values are definitely being identified more today then 13 years ago when I attended school. In the classes that I have attended the last two semesters; the recognition of culture has been identified as an important aspect of education. All of the core values were identified in the teaching classes that I have attended so far. In one class we completed a project in going around the room and speaking of our different cultural values and our ethnicity. It really made the class more comfortable to speak openly to all classmates in all regards.

Although the posts in this session were lacking in number, they more than made up for it in rich, descriptive content which again demonstrated the coalescence of presence amongst the group members.

\section{Sessions Five through Eight}

\section{Participant posts and responses}

Sessions five through eight follow the same pattern as session four; session five generated a total of 64 posts, session 6 generated 55, session 7 generated 60 and session 8 generated 67. Likewise, participant roles followed suit. Elementary education participants generated 29 posts in session 5, 28 in session 6,28 in session 7 and 34 in session 8 . Secondary education participants generated 23 posts in session 5, 15 in session 6, 23 in session 7, and 19 in session 8. The higher education participants generated 12 posts in sessions 5 and 6,9 in session 7 and 14 in session 8 . 
From a group perspective, Group A generated 17 posts in session 5, 19 in session 6, 19 in session 7, and 25 in session 8. Group B generated 33 posts in session 5, 13 in session 6, 17 in session 7, and 17 in session 8. Likewise, Group C generated 22 in session 5, 26 in session 6, 24 in session 7, and 26 in session 8.

Mean findings show similarities as well. The elementary education participants slightly edged out the other two roles at a mean of 3.3 posts within sessions four through eight. Secondary education participants showed a mean of 2.5 and higher education participants showed a mean of 2.8. Mean findings of the groups were equally comparable. Group A had a mean of 3.3, Group B had a mean of 2.9 and Group C had a mean of 3.0.

Session 9: Aesthetic Reading Response

Participant Posts and Responses

A total of 94 posts and responses fill the threaded discussion of session nine. Of these, 48 are from the elementary education participants, 31 are from the secondary participants and 15 are from the higher education participants. This denotes an approximate $30 \%$ rise in the number of posts generated in the previous group sessions. One possible explanation for this increase is the return to whole class interaction from the small group format of sessions 4 through 8 .

Unlike the earlier sessions, session 9 asked the participants to create a personal, aesthetic response to a novel or biography written from a minority perspective highlighting cross-cultural issues. Suggestions included making a video, powerpoint, collage, or poster session. The purpose stretched beyond learning about minority perspectives in that it invited sharing learning about social and emotional implications of these perspectives.

Participant 13, a novice secondary teacher, shares her project:

With this assignment I decided to read some Maya Angelou. I remember reading excerpts from her poems in one of my literature classes then again with a women's rights 
course I took in my undergrad. I reflected back on my views at the time that I was first exposed to her. I see how much they have changed. I remember thinking that she is perpetuating the issues by addressing them in the manner that she does, but with this course I see how ignorant that way of thinking was. Which is why I took a photo of a wall on my garage. I feel like I used to be similar to the wall in that it was tough and unchanging, yet there are wholes in it that allowed some light through. Then I thought of a quote that I had read from Wilma Garcia stating "Change is not something we do, but rather something that we allow." I didn't really think about it, but that is absolutely true. We gain all of this knowledge that may oppose our prior beliefs, however, whether or not we allow that information to change our way of viewing that belief is up to us. This quote reminded me of the changing trees that we see outside this time of year.

These reflections were a result of this course along with reading this book. The book is an autobiography. Maya went through a lot; she was abandoned by her parents and she and her brother were raised by her grandparents. She experienced a lot of racism in the south during the 30's, then she moved back in with her mother and was molested by her mom's boyfriend. Because of all of this she became a delinquent and was homeless then became pregnant while she was still in high school. Somehow she overcame all of this to be a good mother and a huge inspiration (I think most have heard of Maya). I find the photo of the pine to represent Maya. Although she was faced with harshness, she remained true to beliefs, and faced adversity unchanging.

There are a lot of issues addressed in this book besides racism such as poverty, molestation, homelessness, and teen pregnancy. I find these few photos a reflection of my feelings that I gained from this book.

Participants chose a unique variety of books and presented their projects in various

mediums. Noteworthy of mention in addition to the rise in posts and responses is the $43-53 \%$ rise in open communication of social presence in session nine when compared to sessions 4 through 8. It could be surmised that this response was due to the switch back to whole class from groups and/or the aesthetic reading response activity in and of itself.

Session 10: Individual differences in the classroom

\section{Participant posts and responses}

A total of 78 posts and responses fill the threaded discussion of session ten. Of these, 38 are from the elementary education participants, 25 are from the secondary participants and 15 are from the higher education participants.

Research on mastery learning demonstrates that students can learn if given enough time and appropriate instruction. Such instruction must emphasize respect, cultural diversity and the 
value of life experiences in the construction of knowledge. Session 10 asks the participants to reflect on the readings and explore their assumptions about how individual differences impact how knowledge is acquired in the classroom.

Participant 13 , a new secondary education teacher writes:

I couldn't claim to be an educator if I didn't think that all students can grow in some way from an education. Social, emotional, intellectual, and personal growth should be one of the major goals that a teacher sets for themselves for each child. With that being said, I think it is obvious to all of us that some students grow in each of these areas faster than others.

Loewen's book discusses social status as an area that some may stereotype. It is assumed by many teachers that the poorer a child is the less likely they are to succeed. With this mindset the teacher will be less likely to invest into these students, therefore setting them up for failure. This is a touchy subject for me. I grew up in a very very poor area of the state. My mother was a single mother and she stayed at home with my sister and I. Because of this we were raised in poverty. My teachers saw something in me and invested the time and effort and I feel that this is a huge reason as to why I decided to go to college. When I took my first education course I remember the idea of SES being brought up and the at-risk behaviors associated with this. I was upset at the idea that people judge their students as inadequate learners because of their parent's income level. As I got out there in the classroom I began to see this pattern play out in front of me. When going to schools that were considered the "poorer" schools I would see a huge lack of motivation to learn and I began to believe that the statistics are true. What I, and probably many of you have figured out, is that it has nothing to do with the income level, but moreso the input from the parents. Most of them didn't graduate from high school nonetheless go to college, therefore they bring their children up to not value an education. I'm thankful for my teachers seeing potential in me and hope that I would never become a teacher who dismisses a student's potential because their family chose or perhaps circumstances chose their lifestyle for them.

Howard's book talks about kind of the same thing only pertaining to race. As educators we need to be aware of the different traditions that our students are brought up in. We want to assume that all of our students are like us. We loved school and education otherwise we wouldn't be teachers. The first step will be to recognize these differences and try to invest our time into understanding the cultures that are brought into our classroom, then we have to instruct to meet the needs of our multicultural classroom.

Participant 12 , a pre-service secondary teacher offers her slightly different viewpoint:

First of all I have to say that I have never been a teacher, so I do not have that many experiences to draw on such as some of you do. The only experiences that I have are what I have seen from observing classrooms.

I believe that all students have individual differences, as well as cultural differences. 
These differences are unfortuneately not always considered by the teachers or the school system in general. I think that in a perfect world, yes Bennett is correct in his assumption that all students are capable of growth, development, and academic success. But we all know that this is certainly no perfect world. There are too many pressures on teachers to get thru the material and move on to the next topic so that we can "teach to the test". I think that teachers are pressured into getting thru the material that is on standardized testing and often don't have the time to consider other variables like learner differences. If every child had one on one instruction and was given ample time, then yes I can see them all succeeding. But that is just not reality. Children now only have two options, keep up or fall behind. There isn't much inbetween. I think that it is important for teachers to foster intellectual, social and personal development of their students. However, there just isn't enough time in the day to do this on top of the teachers other responsibilities.

The othe issue that I have with this concept is that I do believe that students have the ability to succeed given the right circumstances. However, I do not think that every teacher has the ability to teach in ways that take into consideration learner differences.

Participant 9, a 7 year elementary education teacher, gives her perspective in this post:

I firmly believe every student can learn, but not always at the same level. Each student learns differently, has a different learning capacity and environmental and genetic circumstances they bring with them into the classroom. The environmental circumstances can be improved in a loving, caring and nurturing classroom.

Bennett discussed the idea of mastery learning that is based on the assumption that virtually all children can learn. Experiential learning engages the learner totally physically, emotionally and intellectually. These two theories help students learn at their own level and progress as they can. Their entire set of circumstances and learning capacities are reviewed and used to help the student's progress.

Howard talks about how racism affects the way teachers teach in their classrooms and the way students respond to their teachers. Many races learn differently due to the ways they were raised and the customs and traditions of their race. As teachers we need to be aware of these differences and gear our instruction in a way that fits these differences as best as possible to ensure every student is learning in some way.

Loewen discusses the American White mindset that poor students will automatically fail, the lack of analysis and discussion of social class structure and the many inequalities of education that students are not taught. Students are led to believe that this is the land of opportunity where people can easily go from rags to riches. Unfortunately this is more the exception than the rule. Students need to understand where they are and where their families have been, the struggles they have been through and how they have or have not overcome. This is not intended to put those students in their place, but to inform them of what they will face and why.

Each and every student can learn in their own way. They may not all be great scientists etc. but they can all learn. With differentiated instruction and the use of co-teachers we should be able to help students achieve their learning potential. 
Not every participant feels the same. Participant 21 comes to the conclusion that not everyone is cut out to be a teacher. He writes:

I read how Bennett says that educators should help foster the students in different areas and I am not an educator and after taking this course this semester, I now know that I never want to be an educator. I think that is something that should be talked about. I think there are a lot of teachers that really should not be in the classroom because they are there for their summers off more than for the benefit of thier students. I also agree that all children learn differently and I also think that no child will learn very well with a teacher that does not teach for the right reasons. You have to have a passion for teaching and I have been reading the responses to these postings all semester and I see educators in this group. I am just glad that I realized that I would not make a good teacher myself. After finishing the readings this week, I think that teachers are expected to be so much more than they used too and if you have 30 to 40 children in a classroom then there is just so much that you are going to be able to do, no matter how much you would like to do.

\section{Session 11: How do we address racism? Racism and Free Speech}

\section{Participant posts and responses}

A total of 77 posts and responses fill the threaded discussion of session 11. Of these, 41 are from the elementary education participants, 21 are from the secondary participants and 15 are from the higher education participants.

Session 11 addressed the topic of racism. Participants were asked to visit the PBS website and explore the teaching guide and other sites related to the Huck Finn novel. They were to identify potential materials and activities that would be appropriate for use in a future classroom and adapt them accordingly. Questions that guided this session asked if racist books should be eliminated from schools and also asked if books that contain profanity and ethnic dialects could and/or should be used without reinforcing negative stereotypes.

All of the participants agreed that books should not be banned and all had similar caveats about what should and could be done. Participant 12, an inservice secondary history teacher, writes: 
I do not believe that racist book should be eliminated from the schools or from library shelves. I do believe that if properly prepared prior to reading these stories by the teacher, the students can learn positive lessons from such books. Particularly how hatred and violence really solves nothing at all, but only begets more of the same.

Loewen states "To function adequately in civic life in our troubled times, students must learn what causes racism". I happen to believe that stories from that time period in history or perspective is definitely one way to help students understand where racism comes from and why it perpetuates. Not talking about racism and/or pretending that it doesn't exist won't fix anything. Therefore I think it is especially imperitive that we teach about racism, not only that it does exist but why and how it came to be.

I pretty much believe that same when it comes to books containing profanity and ethnic dialects. If you think that students don't know what these are, then think again. I have heard words come out of the mouths of kindergardners that you would think would only come out of convicts. Oh, they already know these words and they already use them. So we are not introducing anything new to them when it comes to profanity and ethnic dialects. The important thing to remember is that we need to prepare these students prior to reading about the context in which it was written, the author's point of view and state of affairs during that time. Students should learn both sides to a story. Keeping them in the dark is a mistake in my opinion. They need to be well informed so that they can make their own judgements. If we have done our job well, then of course they will learn what is right and what is wrong. It is equally important to learn why something is wrong as it is to recognize that it was wrong. Therefore it is important to understand the dinamics behind a situation. That is where this type of literature comes into play.

Participant 9, a master elementary school teacher agrees:

I think to remove racist books from the library shelves and classrooms of schools would be hindering freedom of speech. However, having said that I also feel that there are appropriate levels in which the materials should be used. It also needs to be used wisely with clear and purposeful lesson plans and activities. On the PBS site, I found the connections they used between articles, books and the Huck Finn book to be excellent. They thoroughly covered the issues. There are many thought-provoking discussion questions and reasons why this book is a good choice.

Bennett discussed a multicultural curriculum that addresses three "value areas: conceptions of the learner, the society and the subject matter." (p. 325). In looking at Huck Finn, the plans and activities suggested do address all three of these areas. This type of a curriculum offers guidelines and ideas for moving past controversial areas. Bennett provides many examples and ideas to use and refer to when designing activities and curriculums for our own classrooms. Eliminating racist books would ignore the issue instead of addressing the issue in its place in history and society today. As teachers, having plans and activities that move beyond the issue as controversial and into the issue as one of learning, understanding and improving the issue are worthwhile and multicultural.

Participant 19, a 10 year higher education teacher also agrees: 
I think to erase racist books from schools is to support the white idealism that is incorporated into current textbooks. By denying them, we are omitting a truthful part of history that we may not be proud in claiming. I think the inclusion of such books, accompanied by lesson plans such as those provided on PBS, will help students to understand the social climate and how stereotypes have been derived. Do we not need to challenge current conceptions or misconceptions that students have in order to break these cycles? Inclusion of these books, I think, go without merit unless we include the counter sides of racism as depicted in Lowen's reading. I think that inclusion of the opposition (KKK, White Supremacy Groups) helps to understand the fuel that goes into current social climates on all sides. I think Bennett sums it up well stating that in curriculum development, goals are to develop multiple historical perspectives, cultural consciousness, intercultural competence, state of the planet awareness, and social action skills. As well, it can help a person transition through White Identity Orientations as laid out by Howard.

Session 12: Should they be included?

Participant posts and responses

A total of 66 posts and responses fill the threaded discussion of session 12. Of these, 31 are from the elementary education participants, 28 are from the secondary participants and 7 are from the higher education participants.

Session 12 asked participants to explore the concept of cognitive dissonance and ethnocentrism in textbooks and current events in terms of the personal emotional response they evoke. They were also asked to go to eReserves and view In Whose Honor and to consider questions about minority vs. majority rights and maintaining the status quo.

Participant 7, a new elementary teacher writes,

Some people say, What difference does it make? What difference does it make? Wow! I think it makes a huge difference. I've always heard mascots names and such but never even paid attention to the true meaning behind it. I didn't even realize that there had been such controversy over mascots. Now that I actually take a minute to think about it and after seeing the stories in the video, I can completely see the other view point. The video makes a good point about the half time ceremonies and attire being sacred, religious practices of Native Americans. I have been Catholic my entire life and can't imagine going to a sporting event and having a priest come out at half time. I would be completely appalled at the ignorance. Now seeing that video it is so easy to see why there are so many people protesting the mascots of various teams and schools. I do think that it is a step in the right direction that so many schools have already changed their mascots. I 
was really surprised at how much I got from the video. It truly made you understand the viewpoint and think about it from your own perspective. As a society, we need to make sure that we do our best to respect everyone and all culture groups. If we know we are disrespecting a certain group shouldn't we do our best to fix the issue?

Participant 18, seems to start in the same direction as participant 7, but then veers in another:

Some people say, What difference does it make? What difference does it make? I beleive that those who say this are often those who are not looking at the issue from both sides of the argument. Obviously, there are insensitivities that are being addressed by the offended group. By being addressed, those offenders are being offended and are arguing, why is this all of the sudden an issue?

We must take time and look at the facts of both sides of the argument. One cannot make a riteful decision as to which side to pledge allegiance without knowing what each argument entails.

...even though I do not agree with the promotion of stereotpyes, certain stereotypes have been associated with various tribes... stereotypes that include being tough, aggressive... all attributes used in the process of intimidating one's opponent. I do not believe that these stereotypical selections of mascots were made in any effort to offend any of the represented groups. Honestly, I believe that these selections were made in an effort to celebrate the resilience and toughness of those represented groups.

...Unfortunately, $\mathrm{U}$ of I felt the pressure to also change from Fighting Illini to simply the Illini. While reading the assigned article, I couldn't help but feel as if the author was simply finding something to complain about. I know, this may offend some in this course... BUT I DONT CARE! There are things that have been done that are blatantly disrespectful to various cultural groups... naming of school mascots has not been one of them. As I stated before, these mascot selections were made to honor traditions within their respective states/regions. If these selections were made in an effort to offend, don't you think the mascots selected would have had more offensive names? I have to quit writing on this question... this one gets me fired up...........

Participant viewpoints agreed on the issue of respect but varied on what this means in reality.

Session 13: The new face of segregation: the digital divide

Participant posts and responses

A total of 86 posts and responses fill the threaded discussion of session 13. Of these, 48

are from the elementary education participants, 25 are from the secondary participants and 13 are from the higher education participants. 
Session 13 asked the participants to consider those who do not have the same levels of access as they do and what the digital divide means for them. They were then asked to reflect on issues that are emerging for education and society in general. After reading Eamon's article on the digital divide and Henry Louis Gates Jr.'s One Internet, Two Nations, and visitng the Edutopia website for ideas to integrate technology into the curriculum, they were to begin a dialogue with their peers about the digital divide on the discussion board. Lastly, they were to discuss what must be done to ensure an equitable future for all students.

Participant 13, a new secondary teacher, reflected on her student teaching experience in comparison to her hometown. She writes:

Reading the articles about the digital divide I was taken back to my student teaching experience in a middle-class community. I wanted my students to create a brochure using Microsoft Publisher, and to my surprise every single one of my students had a computer. Then I reflect to the high school in my hometown that as of last year had approximately 12 computers for student use in the entire building. How can they keep passing enforcements on teachers to incorporate technology and not provide accessible technologies to us?

I feel that this is just yet another way that our students can either be forwarded or held back. If the students get out into the real world with little to no exposure to the latest technology that is out there at the time they become instantly less qualified for a position. This is yet another way to hold back minorities and those coming from a lower income area.

The Eamon article brought up an idea that I didn't really think of before. It seems that our students are using informational technology more for pleasure rather than informational purposes, but I say we should be combining the two. Many video games are out there that are of educational purposes, but there comes a point where the responsibility needs to be shifted to the parents. I can only encourage my students to use the technology in a certain way when they are out of the school, it is up to the parents to decide what they purchase and allow their children to do with the technology.

Participant 21, a male higher education teacher in the 41-50 age bracket, writes from another

perspective:

I never used a computer until I was 34 years old and I just thought that it was the greatest thing ever but I know a lot of older people that still will not use them. My son is 9 and he knows how to use it better than I do and he will only get better at it.

Participant 20, a female higher education teacher in the 20-30 age bracket, reflects on her view: 
The entire concept of the digital divide is fascinating and possesses various multicultural perspectives and implications that I have never before considered. Due to all of the technology conferences I have been attending within the last eight months and the requirements placed upon me as an educator, I feel I have been very knowledgeable of the forms of technology available, their purposes, and the ways in which they enhance learning and communication. In all of my workshops and conferences, however, no one has ever presented or considered those groups of students who have little to limited access or knowledge regarding these technologies.

The article "Digital Divide in Computer Access and Use Between Poor and NonPoor Youth" helped to illustrate the advantages that individuals with access to technology and programs have as opposed to the disadvantages. For instance, I was aware that those with exposure to technology were able to gather information and learn new knowledge more easily, while keeping communication open for parents. However, I never considered that future employment and earnings is an important factor. Similarly, the article created by Henry Louis Gates, Jr. voices the importance of learning about technology, especially those individuals who are lacking the knowledge and experience. Technology is progressing at such a rapid rate; Gates is implying that groups of individuals will surely be left behind.

Reflecting back upon my time in the public schools as a third grade teacher, I can now notice that the minority students in my classroom were the ones who did not know how to turn a computer on, how to navigate through word processing programs that most students in my school knew since the first grade, and were the ones that were constantly behind in typing, printing, creating, or utilizing whatever program or piece of technology that was embedded within the unit or lesson. Immediately, my first inclination as I search for an immediate solution to this problem is to provide students with more opportunities within the educational setting for learning and utilizing technology. I imagine that in the future, standard PCs will be replaced with laptops, even in elementary schools and perhaps students will be given the opportunity to transport them from school to their homes. This way, parents can be just as involved in the learning process to reinforce that bridges that need to be built between our students and the greater world of technology and communication. Questions that arise when considering this topic, however, include concerns for teachers and their already hefty demands. Is it possible for teachers to continue to fulfill all obligations revolving around testing while making extra time to teach students how to use all of these new pieces of technology? Perhaps curriculum needs to be altered and that technology piece can be embedded into the learning standards.

\section{Session 14: Teflon History}

\section{Participant posts and responses}

A total of 64 posts and responses fill the threaded discussion of session 14. Of these, 27

are from the elementary education participants, 23 are from the secondary participants and 14 are from the higher education participants. 
Session 14 embodies convergence. It is time to think about how to use the knowledge gained to transform classroom practice. Participants were sent to the Southern Poverty Law Center's site for teachers where they were to explore the resources and activities available for teachers. They were to identify potential materials and activities that would be appropriate for a future classroom and make appropriate adaptations for their situations. Lastly, they were to reflect on Loewen's afterword, where he discusses what he believes to be the challenges that will confront them in the near future. Participants were then asked to post their thoughts between Loewen and the Tolerance website.

Participant 3, a male in the 20-30 age bracket who has been teaching 4 years reflects on Loewen:

There were many aspect of this reading that I really connected with. The first thing that struck me was his comment about NCLB and testing. I understand the feeling of disappointment in putting Social Studies on the back burner as a result of NCLB. I know from personal experience that there is an added emphasis placed on Math and Reading because that it what the state looks at when evaluating AYP. It is hard to teach something in a way for students to get emotional about something when teachers and school faculty do not show emotion themselves.

Participant 19, a master higher education teacher in the 31-40 age bracket, also makes the connection to emotion:

Emotion is the glue that holds history together. Every thing that I hold in remembrance has an emotional attachment. I think we have all drawn out our own identities and personas with emotional attachment in this class. As Loewen states: we do not remember detached, isolated incidents. Neither do we in our own lives.

How sad that one goes to school to learn how to not think and in becoming the good citizen one inadvertently makes improper or misguided assumptions regarding society, race, socioeconomic standing, etc...Loewen's workshop on the Vietnam War irritated me because it made me feel vulnerable and angry as to how much crap I fell for myself. I like his challenges for classroom use. Starting with the present is always a good key to the past. It makes it personal and does give perspective. Less topics are a must. I really liked the idea of picking apart chapters of a textbook to discover what was inaccurate or better yet, missing. As long as textbook authors are restrained by political correctness, teachers will have to utilize suplemental or creative ideas to expose the many sides of the story to be told. 
I'm going to miss the discussions with my group! It has been a privilege to hear your insights into these matters that we all take so seriously to heart.

Participant 14, a new secondary teacher writes of her "emo" kids:

There's a wave of kids in our classrooms that we should pay particular attention to.. "emo" kids. They dye their hair black and sing songs about their sadness and depth of feeling. They feel out of place in our classes and that we don't understand them. I totally understand why they feel this way. We never talk about how something makes us feel in a textbook. We never even talk about how the event in history effected the daily lives, beliefs, lovelifes, nationalism, or anything related to an individual *unless they were the hero or villian of the times.

Maybe this movement is backlash against our unemotional reponse to everything in society. We can laugh at racist jokes, and watch people die without sheading a tear! Most americans are numb. These kids are not. Maybe that's off the subject but it really occured to me when I thought about this.. how many of my students dress in an emo/punk look compared to when I went to school. Anyway, of course I think that history needs to be emotionally relevant to our kids. I think the way textbook companies think is inhumane and it's killing academics. I think standardized testing can't judge social/emotional development and therefore can not tell us who has learned and grown the most from their educational experience. The way teaching the truth effects our kids emotionally is that they must own the history they learn. Most Americans are diverse and do not understand the way rich white males looking out for their own economic interests. They have no relation to that way of life. They need stories about the people, about movements, about empowerment. They need the truth and the knowledge to manipulate our society to provide a better future. They need HOPE.

Final Session: Dissemination

\section{Participant posts and responses}

A total of 70 posts and responses fill the last threaded discussion session of dissemination projects. Of these, 27 are from the elementary education participants, 23 are from the secondary participants and 14 are from the higher education participants.

For the dissemination plan, participants were expected to develop a plan for school/classroom-based application of course learnings which would be based on an investigation of the needs of culturally different students and designed to affect the curriculum, classroom interactions and/or school/community environment. Many unique projects ensued. 
Participant 16, a preservice secondary teacher explains her plan:

For my dissemination project, I wanted to design a project for my students to take part in as a part of a "Heritage Week" that would be school-wide. Within the project, I wanted to give each student in my class the opportunity to present something about his/her culture. When designing this project, I had fifth graders in mind but it could easily be modified for a higher or lower grade level. I also chose to incorporate the option of having students bring in a guest speaker during his/her allotted time to help alleviate any insecurities a student might have when discussing his/her culture. I think a project like this would be great in any classroom and could stretch far beyond a "Heritage Week". When working on this project, I was inspired by Bennett's point that we must be comfortable and aware of our own cultures before we can begin to understand an other person's culture.

Participant 19, a higher education instructor, piloted her plan and described the results:

Objectives: The objective of this project is to present multicultural aspects of geologic phenomena or habits of regions into the instructional design.

Outcomes: Students can be made aware of the distribution of resources based off geologic history of a region and the interplay of how these resources are managed and distributed by power point instruction built into the daily instructional design. Opportunity: Students also have the opportunity to work in small groups to design and create a collaborative project. Twenty groups of four students will present a thematic research and poster presentation of work each of the four units of instruction through the semester. Although students are not assigned to individual groups, it is this instructor's observation that many groups form by scheduling and availability and are therefore diverse in nature. Cultural facets and relationships will be reflected within the body of their work.

Pilot study results: This dissemination project was adopted one month into the fall semester, 2008. Results indicate that the exigencies that exist within a large lecture classroom are not conducive to lengthily discuss many global issues of cultural exploitation based on geographic locality. Higher level introductory courses in Earth Science cover many geologic topics that do not include value judgments beyond the stated geologic phenomena or processes of occurrence.

Environmental topics such as groundwater, global warming, energy, and mineral and natural resources have been geologic topics where the researcher has been able to expose the students to practices that have an adverse affect on the indigenous peoples or lands within specific areas. This has been accomplished through power point slides in daily discussion. Environmental topics are easier to imbed into discussion as they are real time, problem based geologic situations that effect all populations. Although general conversations did not occur, students became aware of environmental issues that dominate the globe.

Over the course of the semester, students engage in one collaborative group project that is thematic in nature. Although this research paper and poster are geology based, the nature of the research is broad enough to include effects that may be a result of the management 
of resources in the regions they represent in writing. Students have been encouraged to research these effects and to include them in their report. Although not a mandatory part of the report, several students did accentuate details of how geologic processes influence response and management towards native individuals within studied research areas. Although there have been limitations with this project, students have been informed of issues that prevail within a global context, especially as they pertain to driving economic forces of natural resource exploitation. They are more aware of forces that are responsible for the current practices and outcomes that exist.

Participant 20, also a higher education teacher, planned a workshop for elementary teachers:

For my dissemination project I thought that it would be beneficial to create an overview of a workshop in which elementary teachers would attend. This fictional but realistic workshop encompasses three levels to integrate multicultural awareness within the classrooms; personal, teaching practices, and curriculum. I incorporated a lot of what Bennett had to offer in her book (and made her a guest speaker at the workshop) along with Loewen's ideas of re-evaluating what's being taught as part of our curriculums. As I participated in this class this semester, I realized how necessary it is for all teachers to begin making a change towards instruction and creating a classroom that incorporates and embraces every learner's differences and experiences. I really think that something like this would help to move us there.

Participant 11, a female Latina veteran teacher in the 31-40 age bracket, presents her overview:

The purpose of this project is to make the students sensitive to other cultures, mainly the Hispanic culture since this is a Spanish language course. To get students involved, I will incorporate technology. Specifically, students have to complete an assignment called a WebQuest. A WebQuest is basically a website that contains many exercises and activities that the students have to do. For instance, students may be asked to investigate about traditional foods in certain Hispanic countries. The students will then have to obtain this information by doing some online research. The WebQuest also contains different links to other websites.

I completely agree with the way Bennett describes "excellent teachers". She says "excellent teachers are those who can inspire the intellectual, social, and personal development of all their students to their highest potential". The purpose of Webquest is actually to expose my students to a different culture: my own culture. It seems to me that students learning a foreign language expect to interact with people from other countries, so I believe that exposing them to different cultures is part of the learning process.

An important point made by Howard is when he talks about own experiences. He claims that individuals who are not provided with the opportunity to expand beyond the traditions, cultures, and race that are known, lack the opportunity to fully develop a positive perception of other cultures. The Webquest, I believe, is an excellent way to enhance and learn other cultures. From Howard I would like to combine educational opportunities and activities for my students to encounter and interact with others from 
different backgrounds, heritages, and race.

I think it is essential to help guide my students through their experiences by utilizing Bennett's guidelines for considering and accepting cultural differences through verbal communication, nonverbal communication, orientation modes, social values, and intellectual modes.

To conclude, I like to implement different ways of teaching. Webquest is one way to learn. As Bennett states on page 213: "Only recently have demands been made that teachers become more flexible and use a variety of teaching styles in order to respond to the diversity of learning styles among their students." Learning about values, beliefs, and cultural differences gives students the chance to understand the point of view of others.

Clearly, this dissemination session is the place and time in the course where everyone reaches the resolution stage of the cognitive presence of the community of inquiry. While some students outline plans they hope to implement in a future class, others, such as participant 19 , actually piloted their ideas. The education experience of the community of inquiry comes together throughout the sessions as participants interact cognitively and socially with each other through the curriculum.

\section{Cross Cultural Community Interaction Findings}

Three cross-cultural community interactions were assigned over the course of the semester and were structured on three levels. The first cross-cultural community interaction at level 1 is titled "Observation and cognitive understanding." Level 2 is titled "Informationseeking through personal interviews" and Level 3 is titled "Direct participation, developing a personal relationship." Several suggestions are listed for the participants under each level. The written part of the assignment requires them to report on their interactions and respond to the following questions:

- Why did you select this experience?

- Discuss your feelings and reactions.

- What would you do differently if you were to repeat the experience? 
- What is the value of this experience to you as an educator?

These questions parallel the cognitive presence categories of the Community of Inquiry as well as the personal/affective category of the social presence and thus provided a transition framework for the participants to traverse. Thusly, each paper contained all four categories of the cognitive presence plus the personal/affective category of the social presence. The following section will provide samples of this finding.

Cross-Cultural Community Interaction Papers and the Community of Inquiry

\section{Level 1: Observation and cognitive understanding}

Suggestions for the level 1 paper included the following:

- Attend a lecture that focuses on ethnic minority and/or gender concerns

- Take a tour of an ethnic community (different from your own) observing the community's environment, housing and community services.

- Watch special programs, read popular ethnic magazines or newspapers that explore minority issues or provide insight concerning the lifestyles of ethnic minority families.

For the first cross-cultural community interaction, seven participants chose to explore a community different from their own; four participants watched a television program which explored minority issues; four participants chose to examine ethnic magazines or newspapers; one went to a conference in D.C.; one went to a science workshop for women; one reflected on an Afro-Hispanic Literature course; and one reflected on freshman year of college with an African American roommate. Of the 21 participants, 19 completed the assignment and 2 did not.

It was clear from the start that these cross-cultural community interactions captured the essence of the coalescence of the presences of the Community of Inquiry. Teaching presence materializes from the beginning within the assignment through instructional design and 
organization, direct instruction and facilitating discourse through question prompts and choices. Social Presence surfaced time and time again in the participant narrations through risk-taking open communication and emotional expression. Cognitive presence unfolded as the participants wended their way through the four categories of triggering event, exploration, integration, and resolution. participant 1 is a representative example of the group:

For level 1, participant 1 wrote about a community nearby and described it as "a fairly notorious section of the school district known for its poverty and high crime rate." The Participant explains: "I chose to explore this community for my cross-cultural experience because it serves as a stark contrast to (my) town... which caters to the rich artistic (major nearby city) weekenders." The triggering event marking cognitive presence can be recognized early in the narrative as the participant questions this "stark contrast" indicating the Participant's sense of puzzlement: "A critical eye to our community might label us as schizophrenic or at least hypocritical, considering the relative blindness (our town) has toward its 'ugly closets."' Rich, vivid descriptions follow as the participant paints picture after picture of roads that are "rife with potholes, literal and figurative" and off-limits to county school buses.

No bus could access the area and county plowing will not enter it because it's still considered a private road. I was told never to enter the town; even insurance investigators require a police escort. Judging by the number of times weekly that an illegal incident in (this town) is reported in the county newspaper (domestic batter, domestic arson, child abuse/neglect, welfare checks, stalking, even murder) and knowing how "in the family" the residents try to keep all their business, I would be crazy to go in alone, but because I have several students who live there, I trusted in the goodwill of the parent/teacher relationship.

The information exchange of the exploration category of the cognitive presence slowly

evolves into connecting ideas - the integration category of the cognitive presence element.

We discussed, as best we could despite the din, school and friends and summer, and then after hugs, I left, feeling slightly sick to have to leave them behind, wondering what awaited them in the evening with the two obviously troubled parental figures. Driving 
home, I had a renewed "counting of blessings" and felt victorious that I had accomplished something many people were afraid to try. I also felt embarrassment of riches because "there but for the grace of God" ... My reflection on this experience is definitely humbling. It helps me to see my students in a whole new light of understanding and empathy... and bonding.

Participant 1 clearly reaches the resolution category of the cognitive element category:

I will visit my kids in (this town) again. Next time, I will visit the cousins, too. I will not be nervous as I drive through the neighborhood my kids walk through every day. Next time I will bring something with which to engage the parents, something to show them that I need their help, some project that will involve them on a personal level with our school community, even if I have to pick them up and drive them to school myself.

The coalescence of presence is unmistakable in this Participant's rich, vivid narrative. All

presences were evident in all cross-cultural community interaction papers of all participants who chose to complete this assignment.

Level 2: Information-seeking through personal interviews

Suggestions for the level 2 paper included the following:

- Meet with community leaders (ministers, politicians, teachers) from an ethnic community and see what they perceive to be the needs and concerns of their community.

- Talk with students on campus or colleagues at work, who represent distinct cultures or gender perspectives which differ from your own.

- Attend a community meeting (Church, NAACP, other community organizations) and talk with some of the members attending.

For the second cross-cultural community interaction, 15 participants chose to talk with students or colleagues at work, two participants met with ethnic community members, and three participants attended community meetings. Of the 21 participants, 20 completed the assignment.

Each presence was clearly evident throughout all of the level 2 cross-cultural community interactions. Participant 13's experience and perceptions are representative of the other 
participants. Participant 13 chose to write about her experience at an African American Christian Ministry. Parallel to the level 1 interactions, this participant first experienced the trigger category of the cognitive presence and instructional design category of the teaching presence through the initial and subsequent questions of the assignment. "My friend and I are always looking for new churches to attend that differ from those that we were raised in." In her interview with one of the members, she explored their "upbringings." Participant 13 writes, "As far as discussing difficulties or differences she didn't seem too interested because as a child of Christ she said she doesn't focus on those things, she just focuses on the difference she can make in individuals lives regardless of race." Her interviewee did, however, note that children today face many issues that cause them to act differently than "they were raised in order to fit in" adding that "she sees a lot of children feeling hopelessness or shame in their heritage." Participant 13 moves into the integration phase of cognitive presence next. She writes, "After reading this week I realize that she was discussing assimilation." Participant 13 "gained a lot out of this experience" and transfers what she learned. "As an educator I can take this experience as another eye opening experience....I grew up with no exposure to different cultures and I'm still pretty ignorant. I have grown from this experience, and am truly honestly seeing a change in my thinking patterns when it comes to multiculturalism. I think everyone should have to take this course regardless of major." She has evolved into the resolution category of cognitive presence and closes with the promise to "repeat something like this for personal gain and education purposes if the opportunity presents itself." She has made decisions and found solutions to a very real problem in her and her student's lives.

Level 3: Direct participation, developing a personal relationship

Suggestions for level 3 included the following: 
- Visit with a culturally different family in their home, observing family practices, roles and customs.

- Meet socially in a public location (for lunch or coffee) with a culturally different person with whom you have established rapport. Consider the meeting an opportunity to encounter many of your feelings, attitudes, and beliefs about this particular cultural group.

- Go to a social event with a culturally different person.

- Become a genuine friend of a culturally different person. One way to do this is by participating in the Intensive English Program Conversation Partner Program. Meet with, do things with, and talk to partners throughout the semester. Help them to practice their English and to become adjusted to U.S. culture and university life.

For the third cross-cultural community interaction, 5 participants chose to visit with a culturally different family in their home, 8 choose to meet socially in a public location with a culturally different person with who they had established a rapport, 3 went to a social event and 3 sought to become a genuine friend of a culturally different person. Of the 21 participants, 19 completed the assignment.

Each presence was clearly evident throughout all of the level 3 cross-cultural community interactions. Participant 4's experience and perceptions are representative of the other Participants. Participant 4 chose to write about her visit with a culturally different family in their home, observing family practices, roles and customs. Parallel to the level 1 and 2 interactions, this participant first experienced the trigger category of the cognitive presence and instructional design category of the teaching presence through the initial and subsequent questions of the assignment. Her experience encompassed dinner at the home of an African American coworker, his Caucasian wife and their children. She had been invited to dinner many times but had never accepted the invitation "for no other reason than my busy life, I would say." She goes on to say that "maybe a small part of me just never felt comfortable around African American individuals." 
As she begins to sort out her feelings and her thinking, she moves into the exploration category of the cognitive presence. "This class made me realize it was time for me to step outside my comfort zone. In the past, I ignored individuals of different races and refrained from any kind of relationship with them....This class gave me the perfect opportunity to take him up on the offer and have dinner with his family."

The integration category of the cognitive presence comes next: "I chose this experience not only for me but for my children. I grew up in a very racist community that does not agree with biracial marriages. I was never around people of other races and in turn it made me uncomfortable to be around them. Due to this fact, it is hard for me to look at the person and not their color. I have avoided those of other cultures and races all my life. I thought it was time I stepped outside of my comfort zone. I do not want my children to feel this way towards other races."

She smoothly transitions into the resolution category of cognitive presence. "It is never comfortable to take that first step. I wish I would have taken advantage of the opportunity sooner....This semester I chose to focus on becoming more comfortable with African Americans....I believe the work that I have done this semester in the class and the cross-cultural experiences will help me to have a better understanding of not only African Americans but all races and cultures. I believe it has given me more of an open mind and understanding in regards to culture....It will help me to stop avoiding individuals of other races and be more comfortable to have a relationship."

\section{Final Reflection Findings}

The requirements of this final reflection paper ask the participants to reflect on the course, specifically, the curriculum, the materials, the instructor, their peers, what they found 
valuable or not, and anything else they may wish to add. Sixteen participants completed the final reflections.

It is no surprise that the perceptions and experiences of the participants in the end of the course reflections can ideally be described as the coalescence of the presences within the Community of Inquiry. The essence of the coalescence of the presences can be seen in the participants' rich descriptions of their perceptions and experiences in this course. Several themes emerge: enlightening, epiphany, and eye opening; benefits; appreciation (teaching presence); collaboration with and feedback from peers (social presence); cognitive transition (cognitive presence).

\section{Theme 1: Enlightening}

The word enlightening comes up time and time again in the participants' reflections. Participant 17 writes, "I found this class very interesting and enlightening." Participant 9 depicts the discussion postings as enlightening: "The discussion postings were good to voice our opinions and receive feedback as well as give feedback to others. They were enlightening." Likewise, participant 13 notes, "I thought the discussions were also enlightening and really made me question my own motives and biases." participant 5 portrays the text as enlightening:

I also found much of the information in Bennett to be enlightening, including the concepts of producing an equitable classroom culture, the various causes of educational inequality, and the promise of cooperative learning as it pertains to narrowing the achievement gap. As a special educator, I am no stranger to the fact that many of the recipients of special education are minority students. I felt like Bennett helped me to see why this is the case.

\section{Epiphany}

Participant 1 gushes about the importance of this particular text: "I experienced epiphany after epiphany and brought Loewen with me to hundreds of discussions with my family, friends, and colleagues this fall." 


\section{Eye Opening}

Similarly, many participants used the term “eye opening." Participant 7 writes: "This course has been a great eye opener. It has made me truly think of not only other people's perspectives but my student's. I have to remember that not every student has the same background as I do." Participant 7 repeats this mantra at the end of the reflection: "I learned a lot through this course and it really opened my eyes and mind to various cultures and backgrounds."

Participant 3 explains the profound effect of the course:

I feel that I have learned an immense amount of information in this course. The first aspect of this course that truly opened my eyes (and mind) was the idea that there are two histories, the one that we are taught via the book companies, and another that is much more informative, lively, and indicative of the struggles and triumphs that have helped us become the nation that we are today.

Like participant 5, participant 13 was struck by one of the texts: "I feel that Howard's book was a huge asset to me. The book was an interesting read and easy to follow, not to mention eye opening." Participant 13 was not as enamored with the third text but found it eye opening as well:

Loewen's book was a little tougher for me to follow. I always struggled in history classes to read the material due to lack of interest, and I had the same feeling about this book. With that being said I feel that the message of the text is soooooo important. Reading this text was another eye opening moment.

\section{Theme 2: Benefits}

Many participants wrote of how they benefited from their experience in this course: "I feel that this course was very beneficial to me as a future teacher and as a professional in my current career. The concepts that were learned in this course can be applied to many areas of life, making this information very valuable." Participant 12 repeats this theme and sums up: 
"Thanks again for a great semester. I really enjoyed this class and I think that it will be very

beneficial to me in the future."

Participant 11 goes further by listing the benefits.

I benefited from the course in several different ways.

- First, I believe that the subjects or topics that we studied were extremely relevant and important. I understand now much better the issue of multicultural education.

- Second, the best part of the course for me was the reflection posts. I was able through the postings to express my own opinions and share with others our points of view. It was also very interesting to assess critically other writers' opinions. Reading what other students had to say about different topics made me question my own thinking. However, it is also important to keep in mind that when it gets to multiculturalism there is not a single answer. Sometimes when somebody has a different point of view, your comments may sound rude, so you have to be careful when you write them down.

- Third, the media logs changed the way I read newspapers, watch TV, etc. I now pay a lot of attention to different practices followed in the media concerning multiculturalism.

- Fourth, I enjoyed reading the chapters of our three textbooks and articles. They offer a very interesting perspective which I had not considered before.

- Fifth, I enjoyed doing the Dissemination. I am not very good with technology, so I learned a lot from designing the WebQuest. There are many valuable ways in which we can use technology in class. The assignment was really very helpful.

- Finally, I shared this course with my whole family. It was nice to hear my daughters' opinions on several topics (for instance, we had a long and interesting debate when we discussed the issue of whether racist books should be banned from school). I was surprised many times by their points of view.

The essence of the coalescence of the presences is felt throughout participant 11's essay.

The cognitive presence categories of exploration, integration, and resolution coexist and intermingle with the social presence categories of emotional expression, open communication, and group cohesion. The element of teaching presence plays a background role surfacing time and time again as reference is made to texts, topics, perspectives and experiences.

\section{Theme 3: Appreciation (Teaching Presence)}

Teaching presence also plays a dominant role throughout the reflections with social presence categories and indicators supporting the background canvas of open communication 
and risk-free expression. Participant 8 starts the reflection assignment with the statement, "First of all, thank you for teaching this course. I have found it to be very interesting and informative." The participant continues, "I think that you did a great job, provided excellent and prompt feedback, and made the course friendly." Participant 4 writes, "I would also like to take this time to thank you for being so understanding when I had the baby. I could have never kept up without your understanding...” Participant 5, whose baby was 2 months old at the beginning of class, adds, "As for my thoughts about the instructor, it was so refreshing to be told to put my baby first. I didn't take that as a license to slack off, but I did feel a weight off my shoulders." Similarly, participant 7 affirms the feelings of participants 4 and 5: "I also wanted to thank you for a great semester. Without your understanding and help, I would never have made it through this semester with everything else I had going on.” Participant 10 also voices similar sentiments: "I also greatly appreciate you working with me on my due dates; I thoroughly apologize for being so behind. With that said I loved this course and working with you this semester. You have taught me to look beyond stigmas and stereotypes." Participant 10 continues, "All in all, you have had a great impact on my personal outlook on life and I really thank you for opening my mind to new ideas and ways of coping with the world today."

Participant 14 expresses appreciation of teacher presence: "I really appreciate that this class exists." Participant 14 adds, "I also appreciate your poignant feedback." Participant 17 mirrors these thoughts: "I appreciated your feed back; I found it useful and provoking deeper thinking." Participant 17 continues, "I would like to thank you for this semester. I appreciated the content and course lay out and would recommend this course to every educator."

Participant 1's perceptions of the course are all positive as well starting out with "this has been one of my favorite classes ever." The accolades continue: 
As an instructor you are also ideal. I really appreciated your thoughtful responses. They were individualized; they showed expertise in the course material; they were lightningquick (Any time I e-mailed you, I got an immediate response - amazing!); and they were sensitive in tone....always. It's astounding to me how you are able to keep up with everyone's discussions, considering the sheer breadth of them all. Thank you.

Participant 9 adds, "I found you to be very helpful, timely in your responses and positive in your feedback.” Participant 12 makes similar comments:

I really think that you are an excellent instructor. You always got back to me with an answer in a timely manner and I really appreciated that. I also appreciated the amount of organization you had with this course. I never had a question about what I was supposed to do or when it was due because it was all clearly laid out for us...thank you for a great semester of learning.

Participant 13 concludes, "You are obviously knowledgeable in this area, and you've been a huge facilitator in my transformation. Thanks for the experience." Participant 20 sums it all up:

"Thank you for such a wonderful learning experiencel "

\section{Theme 4: Collaboration and Feedback (Social Presence)}

It is noticeably evident from the previous participant quotes that social presence also plays a large role in the successful execution and culmination of the learning experience for each and every member of the Community of Inquiry. participants who commented on these experiences all agreed on how positive the collaboration and feedback was with their peers. Participant 13 writes,

My peers were accepting and truly a delight to share an emotional course with.... By far, one of the best parts of this class was getting to read the comments and assignments posted by my peers. In particular, I felt that (participant 9) was always so eloquent, and I learned so much from (her/him). It was amazing to get to know such an interesting and diverse group of teachers. As we come to the close of this class, I feel like I am about to lose some really good friends. Every night after I got my kids to bed, I would look forward to getting online to see what lively debate was taking place. Things are going to seem a bit flat without all these new ideas and interesting perspectives. I guess it's now up to me to take what I've learned and run with it. 
Participant 9 agrees: "I enjoyed fellow students and their comments." Participant 20 writes, "I was pleasantly surprised with the ability to get to know my classmates as well as you via online learning. You and my peers also made it easy for me to continue to participate and voice my ideas and opinions in each session.”

Like teaching presence, social presence noticeably supports dialogue and shared meaning making that, with cognitive presence, culminates in a successful learning experience for participants.

\section{Theme 5: Cognitive Transition (Cognitive Presence)}

Cognitive presence is also vividly described by the participants in their reflections often in conjunction with one or two of the other presences. Clear evidence of transition through the four categories of cognitive presence (triggering event, exploration, integration, resolution) presents itself time and time again in the participants' writing. Participant 5 provides a good example:

I have to say that I have learned more in this class than many other classes I have taken. I think this is du to the fact that I had never been exposed to the ideas of white dominance and the disadvantage that most minorities face in this country. Like Howard describes, I was wallowing in the luxury of my white ignorance. In almost every one of Howard's chapters, I would find myself furiously highlighting many of his key ideas. One particular concept that hit home is the idea that being colorblind is actually detrimental to one's journey toward becoming more culturally aware. Before taking this course, I might have identified with the ideology that "I'm so tolerant of people of other races and cultures, I'm virtually colorblind!" I now know better than to say such a thing.

participants were able to apply new ideas (resolution) throughout the course. Participant 9 says of the cross cultural interaction papers, "I got to visit with people I may not have otherwise. They took the course readings and things to learn to a different level and made them personal." Participant 12 notes, "The concepts that were learned in this course can be applied to many areas of life making this information very valuable.” Participant 20 echoes, 
The most valuable experiences were those projects in which we were given a bit of freedom to explore a particular topic in depth and depict our perceptions such as the autobiography and aesthetic representation and the dissemination project. I also found all the readings, videos, and articles to be worthwhile, in that they all helped to formulate a foundation of knowledge in dealing with multiculturalism. I especially appreciated how all of the course materials correlated with one another and helped to form a bridge to the next session... Overall, I greatly enjoyed this course and have already begun to apply concepts and ideas into the classes I teach.

Participant 1 mentions how the dynamics of the course affected her/him:

ME is set up so that there can be no fudging (without consequence) and every assignment is not only practical, it is invigoratingly challenging! ... The discussion questions require cogent analyses of the readings ... Each topic made us analyze the structure of power in politics and culture and education, and asked us to take responsibility for our part in it all. I was continually challenged by the power given to each of US as students to be paradigm shifters, to rebel actively against a faulty system, to be questioners of authority. ... This class in one semester super-charged me... reinvigorated y need to be an active agent of change.

Participant 7 subscribes to similar notions and writes that the course has "made me truly think of not only other people's perspectives but my student's. I have to remember that now every student has the same background as I do.” Participant 7 continues,

I really enjoyed the readings. I actually enjoyed completing the course readings. The authors made the information so you could relate to it. It made you sit back and think about what is really happening in our society. The assignments in the course were all inter linked and you could use each week's information in everyday life. I think that this course was about more than just memorizing ideas and facts. It was one course that you could truly establish your own ideas and views and that was okay and welcomed. I think this course is an essential part in the study of education because it helps a student learn and think about the most important thing in your classroom, your students. I will remember things I have learned in this course in my entire career of teaching. I think it is a great foundation to use to go into the classroom. ... It was fun to think about how to incorporate some course ideas into your classroom.

Clearly, the coalescence of the three presences of the Community of Inquiry materializes

in the rich, descriptive quotes of the participants. The curriculum of the teaching presence sparks

the cognitive and social presences into action and transformation resulting in the ultimate goal found at the fulcrum of the Community of Inquiry model: the education experience. Clearly, 
these final risk-taking emotion-laden reflective essays encompassing the perceptions and experiences of the participants capture the essence of the coalescence of presence in this Community of Inquiry in this course.

\section{Commonalities across the participants}

Commonalities across the participants occur in word choice, patterns and themes. All of the participants experienced personal change because of this course; words such as enlightening, eye-opening, and beneficial were found in all responses. All of the participants began many of their sentences with "I believe" or "I think" in their posts and responses. The majority of the participants were able to process through all four of the cognitive phases of the Community of Inquiry: triggering, exploration, integration, and resolution.

\section{Miscellaneous themes that occurred in several Participant data sets}

Although all participants experienced personal change, all did not experience positive perceptions and experiences. Participant 11, for example, presented conflicting views in the end of the course reflection. She writes, "I found positive and negative things during the course. The negative aspects do not have to do with the contents of the course (which I believe they are very interesting), but mostly because of the course being an online course." She gives two reasons:

First, I missed the face-to-face interaction with the professor and others students; I believe that the relationships through the computer is perhaps too impersonal. Second, I like when the professor explains the topics, we ask questions, and then we do the assignments. Sometimes understanding the explanations and the material was difficult for me.

The participant explains her challenges: "When you are not native English speaker, taking a course in other language is always a challenging experience." She then reflects on what she needs to do to meet these challenges: "I need to think, elaborate and write my ideas in another language and interact with American students. For this reason, I was very enthusiastic about 
taking this course." In conclusion, she mentions how she and her husband "had long conversations about differences that we find between the US educational system and the education we received in our country."

Participant 17 reflects on her preference of $\mathrm{f} 2 \mathrm{f}$ versus online learning: "This was only my second online course, I think that I still prefer the classroom environment versus online discussions. I think that the internet takes away from the flow of discussion. Although there are many advantages of the internet, while trying to work two jobs and go to school." She also felt that the "pace of the course in the beginning, in terms of projects and papers was more than towards the end." She suggests "spreading them out more over the semester." She notes that "other than that I have not complaints about the content or course." She concludes her reflection by saying she would "recommend this course to every educator" adding that the knowledge she gained was "invaluable."

Only one participant commented that the small group configuration was the "least favorite part" of the course. Participant 8 goes on to say,

I really like and enjoy reading everyone's posts. I know that the purpose is to foster some small group discussion, but I never felt that happen in my group. My group seemed to consist primarily of people who post at the last minute, which is fine, but does not lend itself to discussion.

Participant 21 realizes that he is not an educator and writes in Session 10, I read how Bennett says that educators should help foster the students in different areas and I am not an educator and after taking this course this semester, I now know that I never want to be an educator. I think that is something that should be talked about...You have to have a passion for teaching and I have been reading the responses to these 
postings all semester and I see educators in this group. I am just glad that I realized that I would not make a good teacher myself. After finishing the readings this week, I think that teachers are expected to be so much more than they used too and if you have 30 to 40 children in a classroom then there is just so much that you are going to be able to do, no matter how much you would like to do.

\section{Concluding Statements}

Clearly, the archived transcripts of threaded discussions, cross-cultural community interactions, emails, and final reflections of this course show a coalescence of the social, cognitive, and teaching presences throughout. Findings indicated that the course curriculum design fostered this coalescence. Texts, articles, videos, questions and reflections, carefully craft this cognitive progression into an optimal education experience. Participants repeatedly demonstrated an innate ability to transcend from the concrete to the ideological as they brainstormed, synthesized, and then applied new ideas gleaned from the curriculum and each other in their own current or future classrooms. Clearly, a Community of Inquiry has been created in this course. 


\section{CHAPTER V}

\section{CONCLUSIONS, SUMMARY, IMPLICATIONS AND RECOMMENDATIONS}

The Community of Inquiry model provided an authentic, time tested framework within which to organize and categorize the voluminous archived data collected from this fall 2008 online graduate course on diversity in the classroom. The essence of the perceptions and experiences of the teachers were captured in the coalescence of the presences within the framework of the Community of Inquiry. Additionally, themes emerging from the data of the teachers' experiences and perceptions provided rich, descriptive details which contributed to the summary of the major findings. This chapter includes responses to the research questions, implications for future practice and recommendations for future research.

\section{Responses to Research Questions}

The following questions explored the overarching question of how teachers' perceptions and experiences in an online graduate course on diversity education evolved over time. What light do the threaded discussions shed on the perceptions and experiences of teachers in an online graduate course on diversity education?

Participants' perceptions of the numerous topics came across crystal clear in the threaded discussions. Participants transitioned through the cognitive categories of the Community of Inquiry while maintaining affect through playful banter, humor, personal narratives, and serious discourse. Patterns emerged early as participants settled into the routine of posting and responding. Cognitive and social presence was found in every session on the discussion board. Teaching presence, in the form of design and organization, was also found in every session. Teaching presence, in the form of facilitating discourse and direct instruction was found in the main session and in sessions one, three and four. The Community of Inquiry framework helped 
organize and present a picture of how much presence was seen in each session. Each session portrayed a unique snapshot of the presence and its categories. Curriculum and instruction components of each session determined which presence emerged and to what extent. These components where the overarching determinant of category of cognitive presence reached by each participant in each session and amount of social presence effervescing within; the coalescence of presence was evident in the majority of the posts and responses.

Participant posts were liberally peppered with "I" statements beginning with I believe, I think, I feel, I know, and I agree, clearly identifying the cognitive and social presences at work. Because the components of the sessions were worded in such a manner requesting participants to reflect on the readings and multi-media, participants were inclined to frame their posts and responses with these powerful "I" statements giving insight to their metacognitive and social processes as captured by the Community of Inquiry framework. These processes also captured the evolution of participant perceptions over time. The omnipotent "I" statements transformed into alternative versions of I can't believe, I didn't think, I didn't know and how could I not have known. As participants closed in on understanding and experienced enlightenment, their statements also transformed to self-affirmation: I now know, I now think, I now feel, and I now believe. Lastly, the prophetic I will statements reflected that the curriculum and instruction had done its magic and that the participants intent to carry on the multicultural mission which had unfolded before them, of which they were an intricate part, will become a reality in their classrooms and in their lives. Clearly, a well-constructed online graduate education course with powerful content and reflective questioning will garner the learning experience expected of higher education. 
What do the emails reveal about the perceptions and experiences of the teachers?

While the threaded discussions centered on the Participant's learning experience, the email component of the course served as the domain of teaching presence. In this arena, the instructor articulated and facilitated course expectations and instruction. At the beginning of the course, participant generated emails harbored themes of technology and course expectation clarification. Emails then shifted into themes of challenges, explanations, apologies, accountability, and finally, success. Teacher presence was evident throughout due to the fact that the emails were addressed to the teacher. Although teacher presence was the main presence, social and cognitive presence clearly also played a role as the teacher facilitated, scaffolded and supported the participants through social and cognitive means. Evidence of the coalescence of presence was found throughout the email section of the course.

Teacher presence in the form of direct instruction, shifted to the email section from the discussion board because it was the instructor's perception that the participants were in command of and accountable for their learning. This command and accountability on the part of the participants could be due in part to their professional training and education background since they are all either currently teaching or will be teaching in the near future. With such strong self-efficacy and self-regulation witnessed in the threaded discussions by the instructor, it was not difficult to allow the participants to construct meaning both cognitively and socially on their own. Had there been an occasion that required instructor input or intervention due to misconceptions or off task direction taking, the instructor would have stepped in to facilitate discourse in the correct direction. 
What do the cross-cultural community interactions reveal about the teachers' perceptions and experiences?

The cross-cultural community interactions allowed for participants to transcend and evolve through three levels of risk. Level 1 simply asked for observation and cognitive understanding; level 2 required information-seeking through personal interviews and level 3 involved direct participation and personal relationship development. Rich, vivid, descriptive narrative provided themes of fear; getting out of their comfort zone; eye opening; I had no idea...; surprise; shock; guilt; interesting; time (not enough, wish I had more); opportunity; unique experience; will never forget; humbling; understanding; new respect; empowering; and hope. "We are all alike in more ways than I thought" participant 2 concludes. "Our differences make us unique" another writes. "We can learn from each other."

As in the themes, transformation was also evident in the realm of the cognitive presence. All four categories of the cognitive presence were evident in each cross-cultural community interaction as participants transcended from triggering to exploration to integration and finally, resolution. Social presence also marked each interaction; affective and open communication manifested itself repeatedly. The coalescence of social and cognitive presence was evident throughout the cross-cultural community interactions.

What do the final reflections reveal about the perceptions and experiences of the teachers?

The final reflections can be seen as the equivalent of the integration and resolution stages of the cognitive presence. A summary of the aforementioned themes emerged from the participants final reflections of their experience in this course: enlightening; epiphany; eye opening; benefits; appreciation of the course and the instructor; collaboration and feedback; transition and transformation. Participants voiced their opinions about what was working for 
them in this course and what was not. The coalescence of presence was again clearly apparent throughout the final reflections.

\section{Summary of the Findings}

The purpose of this study was to explore how student perceptions and experiences about learning online in a graduate course on diversity in the classroom evolve over time. Content analysis of computer-mediated communication using the Community of Inquiry framework was used to tease out and organize these perceptions and experiences. Numerous themes emerged from the various course components of which transformation was the overarching theme.

All of the participants experienced some form of transformation as they completed the course over time. As they encountered triggering events in the assignments, from their instructor, from their peers, and from their interactions with outside sources, they routinely evolved into the exploration category and then on into the integrating category. By the end of

the course, participants reached the resolution categories through their dissemination projects and their cross-cultural community interactions. Teaching presence, in the form of design and organization was transparent throughout the course. It was active in the early threaded discussions as facilitating discourse and direct instruction, and in the email components of the course as facilitating discussion and direct instruction while scaffolding and supporting the participants through their education experience. Social presence remained constant throughout the emails, threaded discussions, cross-cultural interaction papers and final reflections. All three presences of the community of inquiry coalesced throughout the course components throughout the semester.

The overarching theme of transformation flowed through the course. In the email component participants first struggled with technology and course expectations. Challenges 
were followed by explanations, apologies, accountability and finally, success. The threaded discussions were peppered with statements beginning with I believe, I think, I feel, I know, and I agree as well as their opposite components I can't believe, I didn't think, I didn't feel, I didn't know, and I don't agree. These metacognitive phrases evolved to I now believe, I now think, I now feel, I now know, as time went on. Cross-cultural community interactions and final reflections contained similar words, phrases and sentiments: I had no idea; I was surprised; I was shocked; I felt guilty; I wish I had more time; I will never forget; I have gained a new understanding; there is hope.

While all participants did experience transformation of sorts, not all participants were necessarily enamored with learning online. One participant missed the immediacy of $f 2 f$ interactions and simply had a preference for learning in that manner and environment. Another participant was not keen on the asynchronous nature of the course, instead preferring the synchronous flow associated with dialogue often found in the f2f classroom. However, this participant did acquiesce to the fact that learning online had many benefits if one was juggling a busy work and school schedule. Yet another participant felt that discussion in her group was hampered and thus limited because her peers always posted late, hence, defeated the purpose of the small group discussion. One of these late-posting participants delivered her baby in the middle of the course yet managed to complete all of her assignments and finish with an $\mathrm{A}$ in the course. Lastly, one participant's transformation led to the rejection of the career direction he had chosen before the onset of and experience with this class, realizing that he would never be able to do everything it is that teachers have to do.

In conclusion, it can be determined that eye opening experiences led to transition and transformation over time. The course readings, the types of assignments, the wording of the 
assignments, and the embedded prompts and questions along with teacher facilitation and social presence allowed for the participants to learn and grow in a supportive cognitive environment culminating in the learning experience at the fulcrum of the community of inquiry.

\section{Implications for Future Practice}

Implications for future practice in terms of course design, curriculum, and instruction begin with the course components, namely, the discussion board and email. The discussion board is designed to be a place where student discourse takes place asynchronously in response to session topics, prompts, and questions. The desired outcome of this discourse is to produce a meaningful education experience within a community of inquiry. It has been determined by this study that the questions asked determine the type of response elicited from the students. It is therefore extremely important for the course designer and instructor to carefully consider the types of questions and prompts embedded in the course material if the purpose is to draw out responses that are in the realm of higher order thinking. If the purpose of the instructor is to introduce a topic and move students through stages of development as the community of inquiry does, then questions can be designed at each category of the cognitive presence in order to facilitate the journey from trigger to resolution. Additional prompts and questions can sprinkle social presence into the mix resulting in the designed effect, namely, a significant education experience. Teaching presence, in the form of direct instruction or facilitating discourse, can scaffold the students as needed.

Students can also be called upon to self-regulate their posts and responses by identifying the level of posts or response they are creating and submitting (e.g., triggering, exploration, integration, and/or resolution). Asynchronous threaded discussions are especially conducive to this type of metacognitive approach to learning. Additionally, peers can be called upon to 
challenge or raise the level of discourse to a higher level by responding with their own question or prompt. By understanding how the community of inquiry works in an online class, students can be more involved in their own learning.

Learning style, teaching style, multiple intelligences, personality type and culture influence how students learn and subsequently respond to the classroom and curriculum, whether it is $\mathrm{f} 2 \mathrm{f}$, blended, or online. Instructional designers, course instructors and students would all be better served if they were aware of these various styles and how they can enhance outcomes. For example, if an auditory learner is in an online class that is designed for visual learners only, that auditory learner may not do as well as a visual learner and may dislike the class enough to withdraw. Likewise, a visual learner may suffer if a majority of the material was auditory as in a lecture format. Introverts may be more likely to lurk while extroverts clog the threaded discussions with their posts and responses. Being aware of style and type will allow both the student and the instructor to understand how learning takes place and plan accordingly.

Understanding what students want in an online class is another important facet for the instructor, instructional designer and institution. In this particular course, participants indicated that they want a course from which they can benefit in their future teaching, topics which they deem as important, assignments which interest and inspire them, and change the way they view the world. The readings must be enjoyable and the technology must be navigable. Feedback should be useful, clear, thought-provoking, and lightening quick. Additionally, they want an instructor who is empathetic, understanding, flexible, and above all, friendly.

Retention is a growing concern of institutions that offer online courses. Although research on this issue is in its infancy, knowledge of the existence of this problem is important for the online instructor as well as the course designer and institution. Action research and 
anecdotal evidence points to several possible reasons for student drops: time constraints, schedule conflicts with work or home, technology issues, illness of the student or family member, and other variables such as injury from car accident. Additionally, some students simply drop the course without a word of farewell or excuse. These students can be difficult to track down to find out why they dropped the course. In all of these cases, there is not much that can be done to retain the student. Focus, therefore, should be on keeping the students you do have and making sure they are enjoying and learning from their experience.

Retaining students envelops all of the above mentioned areas. Much of the research puts the responsibility on the instructor to establish and then cultivate a safe environment that is conducive to learning as the community of inquiry prescribes. The research is still at odds though, when it comes to whether or not a hands-on content expert is better than a hands-off facilitator on the sideline.

The instructor in this research has espoused the guide on the side approach for several reasons. First, it is the instructor's personal teaching philosophy. The instructor concurs with the idea of socially constructed learning vs. a banking concept of filling students' heads with a myriad of facts. Second, the students in this online graduate course are teachers and seemed to naturally follow the self-efficacy of the student/teacher role simultaneously - understanding and fulfilling the expectations of both at the same time. It appeared to be innate for them to guide and scaffold each other. Everyone brought something to the table from which the others could learn. Third, the curriculum and instruction in the sessions was designed in such a way as to model an instructor lecture with questions and prompts for the students to follow up and discuss. Hence, the questions and prompts guided the threaded discussions to the extent that instructor prodding was not necessary. Lastly, this course embodied a balance of theory and practice 
which added value in terms of providing relevant, enriching $\mathrm{f} 2 \mathrm{f}$ experiences with real people in real situations in real time through the cross-cultural community interactions. This researcher highly recommends that course designers and instructors build such opportunities into the curriculum.

This researcher realizes that this will not be the case in every online course. Only some online graduate courses contain teachers as students. Other online courses are at the undergraduate level where instructor scaffolding may be more necessary. Course subject may have additional implications for practice. For example, a finance course may produce entirely different results. Additionally, various student demographics may produce dissimilar outcomes that call for more or less direct instruction and facilitating from the instructor. This researcher believes that future research will help with the understanding and facilitation of online courses.

\section{Recommendations for Future Research}

Learning online is a new phenomenon driving the future of education. Longitudinal studies are just beginning to emerge and more are certainly needed to get a grasp on what is happening in the online learning environment. Demography is a good place to start: who are the current online learners, why are they taking courses online, and what are they looking for in an online course?

This research study tells us that several student profiles emerged. Teaching experience ranged from $0-12$ years. What they brought to the table varied considerable. For example, five of the students were pre-service teachers who had never taught before and had only been exposed to classroom situations in conjunction with other course requirements. All five were in the 20-30 age bracket. Of these five, one was in the elementary education master's program, three were in the secondary education program with content area specializations in social studies, 
history, and English, and lastly, one was preparing to teach dental hygiene at the higher education level. The backgrounds they bring to the table are as varied as their future teaching goals. More in depth demography is needed to understand who our students are, why they are taking online classes, and what they hope to find in these classes.

In addition to addressing the who question, the why must also be researched in order to have a better understanding of how institutions, instructional designers and instructors can better serve this market. Several reasons unfolded in this research. First, the elementary education master's program is online. Many of the students found this to be a convenient way to continue teaching while completing a master's degree without having to travel to a classroom in a university at a certain time every week. Other students found it to be convenient because the university was too far away to travel to on the weekly basis that the $\mathrm{f} 2 \mathrm{f}$ classes required. Finally, there were students who would have preferred to take $f 2 f$ classes but could not because the distance to the university was too far. They had no choice but to take online classes if they wanted to continue their education. These are the students that especially need support and further research needs to be conducted in how this can be done.

Interviews can add to demographic research issues as well as shed light on what students are looking for in an online course. Interviews can also illuminate student perceptions before, during, and after the online course which institutions, designers and instructors can make note of to improve their courses. For example, in this research, some students enjoyed the group work while others did not. More research is needed on what makes group work enjoyable for some and not for others in the online environment. This research could dovetail with the learning styles, multiple intelligences, personalities, and cultural attributes mentioned in the implications for practice. 
Surveys are also a popular way to conduct future research and seem to work well in collecting both quantitative and qualitative data. End of course surveys often provide effective ways to gather information on student perceptions about the course and about their perceptions about their learning outcomes. Researching, constructing and implementing survey questions that correspond to online learning are an important area where additional research is needed.

In addition to formal end of course surveys, periodic informal in-course surveys can also provide crucial feedback to the instructor about course climate as well as individual status. Information gleaned from these informal surveys can help inform the instructor on changes that need to be made. Future research focusing on informal surveys that can help instructors would help the instructor enhance the learning experience and improve course outcomes for all.

Technology is and will continue to be a quickly evolving part of all online courses on several levels. Institutions need to keep abreast of new technology and need to be able to not only implement but train their instructors as well. Instructors also need to keep pace with the technology or they will soon be out of a job. An assumption that students are experts on the current technology trends is a notion that needs to be clarified as well. In this research study alone, the technology expertise varied on the same continuum as the teaching experience did. One student, a male in the 41-50 age bracket stated in one post that he first learned how to use the computer at the age of 35 . On the other end of the continuum, a student in the 20-30 age bracket admitted that this was her first online course. Future research is needed on how technology expertise affects students' perceptions of online learning. Additional research is needed on how these students can be brought up to speed and made comfortable with the technology. 
Student expertise and comfort with technology are not the only issues that need more research. Computer interface needs to be addressed as well. While many students have access to high speed internet service, others do not. Research on how to make this resource more equitable is desperately needed. In addition to high speed internet, stability of the various platforms is still an issue as well. For example, of the 6 students in this research who responded to an informal course embedded survey, 5 students indicated that they preferred not to take advantage of the ability to have live, synchronous discussions on WIMBA. Reasons stated included being locked into time and place which conflicted with personal schedules and time resources, and, the idiosyncrasies of WIMBA which need to be researched and upgraded. The other students in the course did not even respond to the survey to indicate one way or another whether or not they wanted to make use of WIMBA. Further research, therefore, needs to be done on how students really feel about WIMBA and if they believe their learning will be enhanced by its employment in the course. Looking at this from another angle, future research may also want to investigate if students would be more inclined to take online courses if WIMBA were a major component of the course structure.

Technology and diversity in the classroom are clearly here to stay and will continue to drive future research. This study showed that it is possible to combine the two in an online classroom to create a transforming education experience within a community of inquiry.

The underlying theme of transformation throughout this course suggests another direction for future research. The writings of Ken Wilber, Don Beck and others, serve as a foundation to understand and dig deeper into this phenomenon. Yasuhiko Kimura, for example, has created curriculum and instruction intended to mainstream the idea of transformation into our postmodern society. His ideas about transformation and enlightenment are quite eloquent and 
could take a deeper look at this research on teacher perspectives and experiences in an online course on diversity to explain what is happening. Examination of the teachers' movements through the three levels of cross-cultural interactions and how they relate to other aspects of the course would also benefit from this perspective.

\section{Concluding Remarks}

As a result of this research, several changes can be made to improve practice in this course. First, questions should be reexamined to determine what category of response they are eliciting from the students. Ideally, the questions should take the students through the cognitive presence cycle of trigger, explore, integrate, and resolution. Second, focus should be turned on the social presence aspect of the curriculum to determine if more or less should or could be added to provide the right amount of social support of the cognitive presence. Lastly, teacher presence should be scrutinized to see if more instructor scaffolding is needed within the sessions or elsewhere. Additionally, more audio and/or a combination of audio and video should be created by the instructor in small clips to reach the auditory learners and to make the course friendlier. Moreover, additional research can be done on all of the above.

This course offers a plethora of research opportunities. Each session in and of itself could be a research study. Furthermore, the cross-cultural community interactions provide ample occasions for more in-depth exploration by themselves and in their connection to the course. Lastly, information gleaned from a quantitative survey with open-ended questions could provide additional information about student perspectives that could increase student satisfaction and learning in future courses.

On a broader scale, this research offers many suggestions for improving design and instruction of other online classes. Although the topics in and of themselves may not be 
transferable, some of the infrastructure and mechanics of the Community of Inquiry does offer possibilities that can be applied to other online courses. Comparisons of outcomes could yield rich results that could inform future research. 


\section{REFERENCES}

Allen, I. \& Seaman, J. (2008). Staying the course: online education in the United States, 2008. Needham, MA: The Sloan Consortium.

Akyol, A., \& Garrison, D. R. (2008). The development of a community of inquiry over time in an online course: Understanding the progression and integration of social, cognitive, and teaching presence. Journal of Asynchronous Learning Network, 12(3-4).

Anderson, T., Rourke, L., Garrison, D.R. \& Archer, W. (2001). Assessing teaching presence in a computer conferencing context. Journal of Asynchronous Learning Networks, 5(2).

Arbaugh, J. B. (2007). An empirical verification of the Community of Inquiry framework. Journal of Asynchronous Learning Network, 11(1), 73-85.

Arbaugh, J. B. \& Hwang, A. (2006). Does “teaching presence” exist in online MBA courses? The Internet and Higher Education, 9 (1), 9-21.

Arbaugh, J. B. \& Rau, B. (2007). A study of disciplinary, structural, and behavioral effects on Course outcomes in online MBA courses. Decision Sciences Journal of Innovative Education, 5(1), 63-93.

Banks, J. (2006). Cultural diversity and education. Boston: Pearson Education, Inc.

Bender, T. (2003). Discussion-based online teaching to enhance student learning: theory, practice and assessment. Sterling: Stylus Publishing, LLC.

Bennett, C. I. (2007). Comprehensive multicultural education: theory and practice. Sixth Edition. Boston: Pearson Education, Inc.

Bloom, B. (1956). Taxonomy of educational objectives, handbook 1: the cognitive domain. New York: David McKay Co., Inc.

Bullen, M. (1998). Participation and critical thinking in online university distance education. 
Journal of Distance Education, 13(2), 1-32.

Bushaw, W. and Gallup, A. (2008). Americans speak out - Are educators and policy makers listening? Phi Delta Kappan, 90(1), 9-20.

Darling-Hammond, L., Chung Wei, R., Andree, Al, Richardson, N., \& Orphanos, S. (2009). Professional learning in the learning profession: A status report on teacher development in the United States and abroad. Dallas: National Staff Development Council. Retrieved February 10, 2009, from http://www.nsdc.org/news/NSDCstudytechnicalreport2009.pdf

Denzin, N. (1989). Interpretive Interactionism. Newbury Park, CA: Sage.

Dewey, J. (1933). How We Think. A restatement of the relation of reflective thinking to the educative process. (Revised edn.), Boston: D. C. Heath.

Dewey, J. (1938). Experience and education. New York: Simon \& Schuster.

Eichelberger, R. (1989). Disciplined Inquiry: Understanding and Doing Educational Research. White Plains, NY: Longman.

Fabro, K. R., \& Garrison, D. R. (1998). Computer conferencing and higher-order learning. Indian Journal of Open Learning, 7(1), 41-54.

Freire, P. (1970). Pedagogy of the oppressed. New York: Seabury.

Gardner, H. (1993). Multiple Intelligences: The theory in practice. New York: Basic Books.

Garrison, D. R. (1991). Critical thinking and adult education: A conceptual model for developing critical thinking in adult learners. International Journal of Lifelong Education, 10(4), 287-303.

Garrison, D. R. (1997). Computer conferencing: The post-industrial age of distance education. Open Learning 12(2), 3-11. 
Garrison, D. R., Cleveland-Innes, M., Koole, M., \& Kappelman, J. (2006). Revisting methodological issues in the analysis of transcripts: Negotiated coding and reliability. The Internet and Higher Education, 9(1), 1-8.

Garrison, D. R. (2007). Online community of inquiry review: social cognitive, and teaching presence issues. Journal for Asynchronous Learning Networks, 11(1), 61-72.

Garrison, D. R., Anderson, T., \& Archer, W. (2000). Critical inquiry in a text-based environment: Computer conferencing in higher education. The Internet and Higher Education 2(2-3), 87-105.

Garrison, D. R. \& Arbaugh, J. B. (2007). Researching the community of inquiry Framework: Review, Issues, and Future Directions. The Internet and Higher Education, 10(3), $152-172$.

Gunawardena, C. N. (1991). Collaborative learning and group dynamics in computer-mediated communication networks. In Research monograph of the American center for the study of distance education (Vol. 9, pp. 14-24). University Park, PA: The Pennsylvania State University.

Gunawardena, C. N. (1995). Social presence theory and implications for interaction and collaborative learning in computer conferences. Paper presented at the $4^{\text {th }}$ International Conference on Computer Assisted Instruction. Hsinchu, Taiwan. March 1995.

Gunawardena, C. N., Lowe, C. A., \& Anderson, T. (1997). Analysis of a global online debate and the development of an interaction analysis model for examining social construction of knowledge in computer conferencing. Journal of Educational Computing Research, $17,395-429$.

Gutek, G. (2001). A biographical introduction: Historical and philosophical foundations of 
education. Upper Saddle River: Merrill Prentice Hall.

Heidegger, M. (1968). What is called thinking? New York: Harper \& Row.

Henri, F. (1992). Computer conferencing and content analysis. In A. R. Kaye (Ed.), Collaborative learning through computer conferencing: The Najaden papers (pp. 117-136). Berlin: Springer-Verlag.

Hiltz, S. R. \& Goldman, R. (2005). Learning together online: research on asynchronous learning networks. Mahwah: Lawrence Erlbaum Associates.

Hiltz, S. R., \& Turoff, M. (1993). The network nation: Human communication via computer. Cambridge, MA: MIT Press.

Howard, G. (2006). We can't teach what we don't know: White teachers, multiracial schools. New York: Teacher's College Press.

Hrastinski, S. (2008). What is online learner participation? A literature review. Computers and Education, 51(4), 1755-1765.

Hrastinski, S. (2009). A theory of online learning as online participation. Computers and Education, 52(1), 78-82.

Kanuka, H., \& Anderson, T. (1998). On-line social interchange, discord and knowledge construction. Journal of Distance Education, 13(1), 57-74.

Karpova, E., Correia, A., \& Baran, E. (2008). Learn to use and use to learn: Technology in virtual collaboration experience. Internet and Higher Education, article in press.

Kimura, Y. (2002). A philosopher of change. What is enlightenment? 22(1), 22-35.

Kuehn, S. (1993). Communication innovation on a BBS: A content analysis. Interpersonal Computing and Technology: An Electronic Journal for the $21^{\text {st }}$ Century, 1(2) (http://www.emoderators.com/ipct-j/1993/n2/kuehn.txt). Accessed 1/18/09. 
Loewen, J. (2008). Lies my teacher told me: Everything your American history textbook got wrong. New York: New Press.

Luria, A. R. (1976). Cognitive development: Its cultural and social foundations. Cambridge: Harvard University Press.

Maurino, P. (2007). Looking for critical thinking in online threaded discussions. e-Journal of Instructional Technology Science and Technology, 9(2), 1-18.

Moss, P. (1994). Can there be validity without reliability? Educational Researcher, 23(2), 5-12.

Merriam, S. (2002). Qualitative research in practice: Examples for discussion and analysis. San Francisco: Jossey-Bass.

Newman, D. R., Johnson, C., Cochrane, C. \& Webb, B. (1996). An experiment in group learning technology: Evaluating critical thinking in face-to-face and computer-supported seminars. Interpersonal Computing and Technology: An Electronic Journal for the $21^{\text {st }}$ Century, 4(1), 57-74.

Obama, B. (2007, November 3). Obama News and Speeches. Retrieved November 14, 2009, from Organizing for America: http://www.barackobama.com/2007/11/03/remarks of senator barack obam 30.php Organization for Economic Cooperation and Development (2007), Programme for International Student Assessment 2006: Science Competencies for Tomorrow's World. Paris: OECD. Retrieved March 10, 2009 from http://www.pisa.oecd.org/dataoecd/30/17/39703267.pdf

Palmer, P. (1993). To know as we are known: Education as a spiritual journey. San Francisco: Harper \& Row.

Patton, M. Q. (2002). Qualitative research \& evaluation methods. Third edition. Thousand Oaks: Sage Publications, Inc. 
Phipps, R. \& Merisotis, J. (1999). What's the difference? A review of contemporary research on the effectiveness of distance learning in higher education. Washington, DC: The Institute for Higher Education Policy.

Riis, J. (1890/1957). How the other half lives. New York: Hill and Wang.

Rubin, H. (2008). The Archer's Dilemma, or, Why the question "What will preK-12 students Need to know and be able to do in 2028?" is timely and important right now! Teachers College Record, Date Published: September 26, 2008 http://www.tcrecord.org IDNumber: 15389, Date Accessed: 11/18/2008

Schrage, M. (1990). Shared minds: The new technologies of collaboration. New York: Random House.

Schrage, M. (1995). No more teams! Mastering the dynamics of creative collaboration. Doubleday, New York.

Stake, R. E. (1995). The art of case study research. Thousand Oaks, CA: Sage Stake, R. E. (2000). Case studies. In N. K. Denzin, \& Y. S. Lincoln (Eds.), Handbook of qualitative research. ( ${ }^{\text {nd }}$ ed.) (pp. 435-454). Thousand Oaks, CA: Sage

Swan, K. (2006). Accessed February 23, 2009 5:02 PM http://www.oln.org/conferences/ODCE2006/papers/Swan_Threaded_Discussion.pdf

Tagg, A. C. \& Dickenson, J. A. (1995). Tutor messaging and its effectiveness in encouraging student participation on computer conferences. Journal of Distance Education, 10(2), $33-55$.

Teachers College Record, Date Published: January 15, 2009 http://www.tcrecord.org ID Number: 15485, Date Accessed: 3/1/2009 4:07:12 PM 
Vygostky, L. S. (1978). Mind in Society. Cambridge: Harvard University Press.

Walther, J. B. (1994). Anticipated ongoing interaction versus channel effects on relational communication in computer-mediated interaction. Human Communication Research, 20(4), 473-501. 
Figure 1: The Model of a Community of Inquiry

\section{The Model Of A Community Of Inquiry \\ Community of Inquiry}

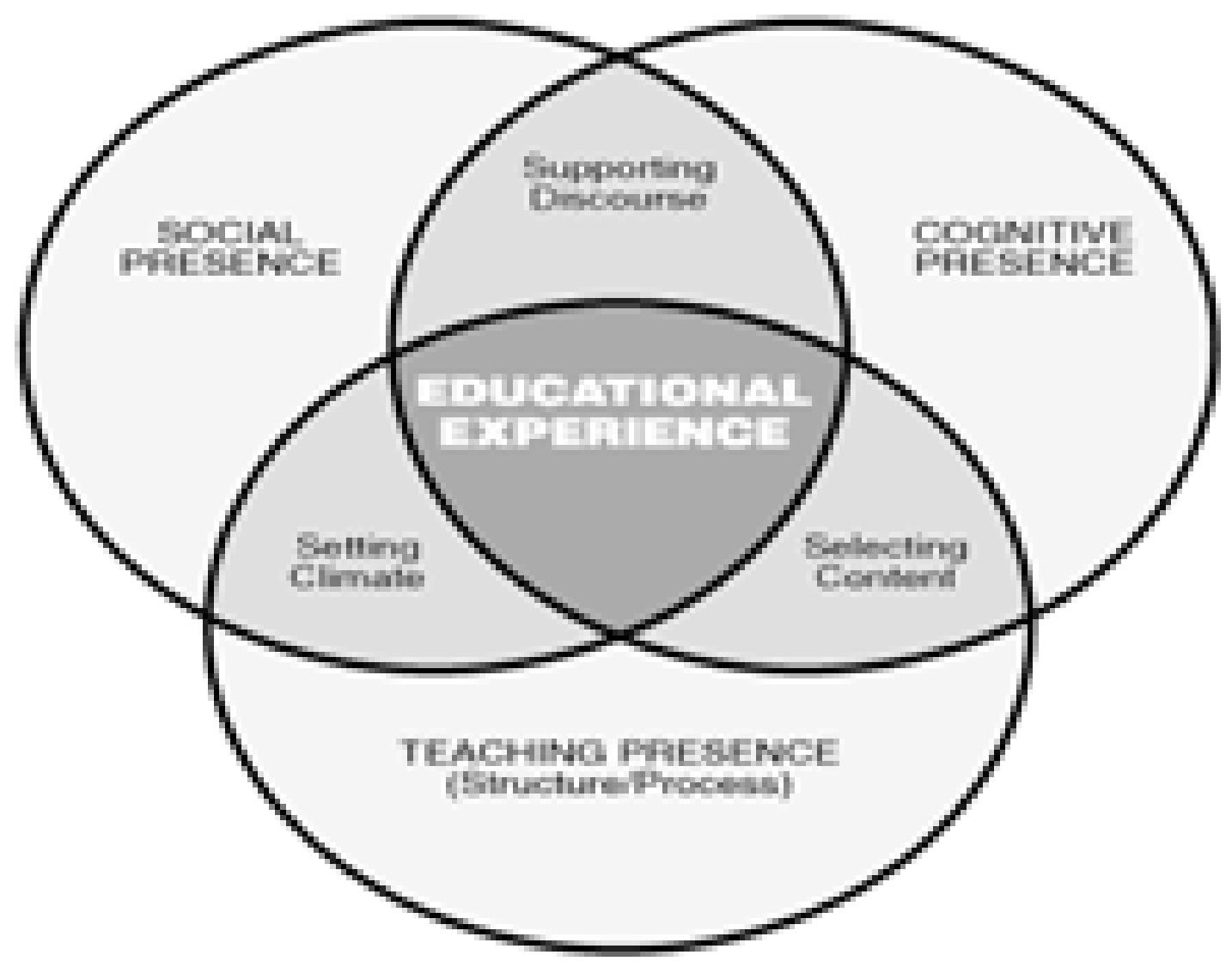

Communication Modium

Elements of an Educational Experience (Garrison, Anderson, and Archer, 2000) 
Table 1: Community of Inquiry Model Coding Template

\begin{tabular}{lll} 
Elements & Categories & Indicators (examples of) \\
\hline Cognitive Presence & Triggering Event & Sense of puzzlement \\
Exploration & Information exchange \\
Integration & Connecting ideas \\
Resolution & Apply new ideas \\
& Emotional Expression & Emotions \\
Social Presence & Open Communication & Free expression \\
& Group Cohesion & Encouraging collaboration \\
& & \\
Teaching Presence & Design \& Organization & Setting curriculum \& methods \\
& Facilitating Discourse & Sharing personal meaning \\
& Direct Instruction & Focusing discussion
\end{tabular}


Appendix A: Welcome Letter Emailed to Students

August 10, 2008

Dear C\&I 689 WEB Class Students,

Welcome to the Fall 2008 version of Cultural Diversity in the Classroom. I am teaching this class on the WEB and am looking forward to a productive and informative semester with you. Please read this letter carefully and save a copy of it for future reference.

You will not have access to C\&I 689's Web site until Monday, August 18, 2008. Please be sure to take some time to go into the course and make sure you have access early in the week, as your first assignments are due on wednesday, August 20, 2008. All of the work from every session must be completed in a timely fashion in order for the discussions to work as they are designed.

As you have noticed, we have sent this information to your MIX address. However, once class begins, all communication will occur via the course embedded e-mail system. This is NOT the same as your MIX account. It will be your responsibility to check your C\&I 689 course email daily to stay on top of the course. If, for some reason, WVU e-campus is not working properly, we will use your MIX email account to communicate with you. This will be for emergency use only, but you MUST be sure to check your MIX account regularly.

Below you will find the textbook information for C\&I 689. Since you will not be able to access the course information through WVU e-campus until August 18, we wanted you to have this information ahead of time.

Please purchase books immediately.

Books may be purchased online through your favorite book vendor. I highly recommend that you order them immediately so that you will be prepared for the first class. Books may also be available at the Brook Tower WVU Bookstore on the Evansdale Campus. If you would like to order them, you may call 293-4870.

Readings :

Bennett, Christine (2007). Comprehensive multicultural education: Theory and practice. New York: Allyn \& Bacon.

Howard, Gary (2006). We can't teach what we don't know. New York: Teachers College Press.

Loewen, James (2007). Lies my teacher told me: everything your American history textbook got wrong. New York: Simon and Schuster. 
In addition, you will need to read:

An approved novel, autobiography, or biography

Additional required readings which will be posted with various sessions in our course.

IF YOU HAVE PROBLEMS WITH THE TECHNOLOGY, CONTACT THE OIT HELP DESK. 293-4444 EXT. 1.

You will be able to access the course on Monday, August 18, 2008. It would benefit you to take a few minutes to navigate through WVU e-campus if you are not familiar with it. This will expedite the time it takes to post assignments as the semester progresses and assignments start to add up.

We believe this course is an invaluable asset to anyone currently working or soon to be working with students as it provides thought provoking yet practical information. We hope you gain as much from it as we've put into it.

Best regards for a challenging and rewarding fall semester,

Kathy Muller 
Appendix B: Course Syllabus

C\&I 689: Cultural Diversity in the Classroom

Instructor: Kathy Muller

Tel: 3046764747

e-mail: kmuller@frederick.edu

office hours: by appointment

Readings:

Bennett, Christine (2007). Comprehensive multicultural education:

Theory and practice. New York: Allyn \& Bacon.

Howard, Gary (2006). We can't teach what we don't know. New York:

Teachers College Press.

Loewen, James (2007). Lies my teacher told me: everything your American history textbook got wrong. New York: Simon and Schuster.

An approved novel, autobiography, or biography.

Additional required readings will be posted with various sessions in the e-Campus course.

You will need a digital camera (inexpensive disposables are available at many stores.)

Overview:

By definition the United States is a culturally diverse society. As its ethnic composition continues to diversify, this nation is becoming one of the more culturally pluralistic regions of the world. Yet, the struggle for open-mindedness and justice with regard to matters related to race, class, culture, and gender continues. The role of teachers, as it pertains to teaching and cultivating students' acceptance of human diversity and difference is being discussed throughout the educational arena. Culture is a powerful human quality that cannot be overlooked for its role in shaping and influencing people's conceptions and perceptions of social reality.

Every person who lives in a culturally diverse society needs to develop his or her own social vision of life as it relates to the future and the cultural realities that will accompany it. The importance of teaching multicultural education in a pluralistic society is critical. Thus, the focus of this study is to explore the existant literature, research and pedagogical strategies that will help foster an awareness and understanding of diversity and cultural pluralism in student teachers and to provide topics central to the rational and theoretical foundations of multicultural education programming in the professional 
development of educators. The sequence of readings will be augmented with a practical, hands-on application of the theories in a curriculum design project. In essence, the objective of this course will be to increase students' knowledge and awareness about issues related to multicultural education. It will provide students with socio-historical global perspectives for the study of race, ethnicity, gender, and culture in an increasingly globalized world. It will attempt to become a space for collective reflection about the multiple meanings of diversity and multiculturalism in American education.

Since classroom teachers deliver the contents of a curriculum, they have the opportunity to interpret and add their own insights about the curricula and the children they teach. The fundamental transformation that the curriculum must undergo is to serve as a guide for purposely sensitizing pupils and teachers to the multicultural realities of our nation. An important focus of multicultural education is to foster in students and teachers a sense of shared responsibility for engaging in practices appropriate for a democratic nation, which include rather than marginalize people who are a part of various cultural, ethnic, and religious groups.

The schools of the future need a vision that includes a belief in the dignity and worth of all persons. As educators we must clarify our vision in a holistic manner, taking into account the culturally pluralistic society that we live in. The future of teaching and education from a multicultural perspective should include an emphasis on cooperative learning that encourages students to develop a sense of community, that transcends competing with each other, and that also develops a sense of trust and caring between teachers and students. Including a multicultural vision in the future of education requires a strong commitment to developing a critical social consciousness that not only sensitizes students and teachers to diversity, but also empowers them to assume some responsibility for it and thus, the integrity of the nation.

Goals and Objectives:

This course is designed to familiarize educators with the impact of cultural differences based on the interactive effects of gender, race, ethnicity, and socioeconomic status in the United States. Through individual and group experiences, participants will gain a better understanding of their own and their students' differing cultural perspectives and the cross-cultural teaching methods necessary to enhance the school experience for all learners.

Course objectives are met through an applied, action-oriented curriculum aimed at the following areas: 
Awareness:

- awareness and sensitivity to one's own cultural heritage and to valuing and respecting differences

- awareness of how one's own values and biases may affect students

- awareness of institutional structures that limit access and options in schools

Knowledge :

- $\quad$ specific knowledge and information about various ethnic groups, women and low SES groups

- $\quad$ understanding of the sociopolitical system in the United States and its impact of various populations

- understanding of institutional barriers that reduce access and options in schools

- $\quad$ specific teaching strategies that will enhance learning for various groups

- $\quad$ addressing differences between teachers and students in terms of race, gender, SES, and world view

Skills:

- $\quad$ countering racism, sexism and low expectations

- making differences and similarities an explicit part of the curriculum

- $\quad$ respecting and affirming cultural differences

- $\quad$ addressing racism and discrimination in the curriculum

Requirements:

1. Online posting and participation (300 points)

Since much of the learning in this course occurs in the context of online discussion, demonstrations and practice sessions, you are expected to attend all online class sessions, participate in all online class exercises, and stay current with assignments. The instructor should be notified if you are unable to complete assignments due to illness or technical difficulties. 
Grading for this portion is as follows: no credit will be given for unexcused late assignments. It is the student's responsibility to contact the instructor to make arrangements for make-ups.

Discussion postings present a valuable opportunity to monitor your own growth, provide feedback related to course learnings and ask questions. You are required to keep a weekly notebook of personal resonance and resistance responses to assigned readings, class activities, course-related activities and cross-cultural community interactions. These notes should be edited before they are posted to your group's Discussion Board. These reflections should reveal your understanding of the readings and must include specific reference to the assigned readings for the week. They will be graded throughout the semester for quality, as well as quantity.

\section{Personal Cultural Awareness (50 points)}

In 3-5 typed pages, examine the development of your own personal values, attitudes and beliefs, family and societal influences and gender role expectations. Include aspects of your culture which contribute to your ability to attain personal goals and professional success in this society. The evaluation of this assignment will be based upon relevance to course content, not the quality of your life experiences.

\section{Cross-Cultural Community Interactions (150 points)}

These 3 papers are intended to afford you the opportunity to reflect on significant cross-cultural interactions you have over the course of the semester. Regardless of what you decide to work on, your papers must reflect the following: Why did you select the experience? Discuss your feelings and reactions. What would you do differently if you were to repeat the experience? What is the value of this experience to you as an educator? Suggestions for interaction experiences at three levels are as follows. You are to choose one from each level. See course sessions for due dates.

\section{Reading Response (150 points)}

Select a novel, autobiography, or biography that is written from an American ethnic minority perspective and highlights cross-cultural issues (elementary teachers may do several children's books.) Design a personal creative response to the cultural issues that emerged from the reading. This product may be as simple as a collage or as sophisticated as a video or web site. Use your imagination and focus on communicating feelings. If you have technical questions about how you can post your finished product, contact our technical support. 


\section{Multicultural Media Log (150 points)}

You are to keep a multicultural media log about current multicultural issues as portrayed in the media. Please remember that there are many types of media besides television and radio. (See Chapter Six in The Children Are Watching for a model of what your media log should encompass.) Post your observations and responses at least once each week on the Discussion Board. Focus on the values imbedded in these "stories" by providing a running commentary. This log should include Internet explorations as well as physical newspapers and magazines. There will be a culminating lab included in this assignment synthesizing your media log experience.

\section{Dissemination (200 points)}

You will be expected to develop a plan for school/classroom-based application of course learnings. The dissemination plan will be based on an investigation of the needs of culturally different students and will be designed to affect the curriculum, classroom interactions and/or school/community environment. This activity will be conceptualized at the beginning of the course and will be refined with instructor input during the remainder of the semester.

\section{Final Reflection}

For the last session (session 15) you will write a brief reflection of the course. Take into consideration which components of the course worked well for you and which you would change. Email your reflections to instructor.

Policy Statements

\section{Grading Policy}

Regular online attendance and participation are expected. Unexcused absences will adversely affect your grade. All assignments must be sequentially added to a word document that you will create at the beginning of class. Unless otherwise noted, all assignments must be copy and pasted from this word document into the discussion board box or into the body of an email. The purpose for this procedure is to ensure that you will have a collection of your course work and to provide you with a vehicle to save your work in case ecampus times out while you are typing in the discussion box. The quality of assignments will be based on both content and language. As such you are encouraged to pay attention to substance, clarity and coherence of thought as well as correct grammar and spelling. Assignments are due at on dates posted on our course calendar. Work turned in late will receive one letter grade lower than its quality merits, and will not be accepted more than one week after it is due. 
Regarding Academic Integrity \& Dishonesty:

Please review the WVU Graduate Catalogue for policies regarding academic integrity dishonesty: http://coursecatalog.wvu.edu/. If violations of these policies can be proven within the confines of this course an automatic $\odot$ on the assignment in question will be given. Further consequences can include an "unforgivable $F$ " in the course and/or referral to the core faculty for consideration of removal from the program.

Plagiarism (attempting to pass off the work of another as one's own) is not acceptable and will result in a grade of $\odot$ for that assignment and will be turned over to the appropriate university source for disciplinary action.

You may wish to refer to the web resource Establishing authorship by Paul C. Smith, Alverno College as a method for determining where the boundaries of academic integrity and authorship lie.

Social Justice Statement:

West Virginia University is committed to social justice. I concur with that commitment to social justice and expect to foster a nurturing learning environment based upon open communication, mutual respect, and non-discrimination. Our University does not discriminate on the basis of race, sex, age, disability, veteran status, religion, sexual orientation, color or national origin. Any suggestions as to how to further such a positive and open environment in this class will be appreciated and given serious consideration.

Students with Disabilities:

If you are already a WVU student who expects that you may have a learning disability or you have a disability and now feel you may need or may qualify for accommodations, you must make an appointment with a counselor in the Office of Disability Services at (304) 293-6700. A counselor will speak to you about your concerns and describe the nature of the Office of Disability Services as well as explain the documentation and accommodation process. A counselor will also make suggestions as to how you may obtain the necessary documentation of your disability. Identification and Documentation of a disability can take time. It is important to self-identify and seek services as soon as possible. http://Www.wvu.edu/ socjust/disability/accommodations.htm 
Days of Special Concern:

WVU recognizes the diversity of its students and the needs of those who wish to be absent from class to participate in Days of special concern, which are listed in the Schedule of courses. Students should notify their instructors by the end of the second week of classes or prior to the first Day of Special Concern, whichever is earlier, regarding Day Special Concern observances that will affect their online attendance. Further, students must abide by the online attendance policy of their instructor as stated on their syllabi. Faculty will make reasonable accommodation for assignments that a student misses as a result of observing a Day of Special Concern.

Grade Distribution:

Discussion/Participation 300

Personal Cultural Awareness 50

Cross Cultural Community Interactions 150

Reading Response 150

Multicultural Media Log 150

Dissemination Project 200

Point Distribution for Grades:

$\begin{array}{ll}900-1000 & \text { A } \\ 800-899 & \text { B } \\ 700-799 & \text { C } \\ 600-699 & \text { D } \\ \text { Below 600 } & \text { F }\end{array}$


Table 2: Demographic Data: Who Are the Participants in this Study?

\begin{tabular}{|c|c|c|c|c|}
\hline $\begin{array}{l}\text { ROLE IN } \\
\text { PROGRAM }\end{array}$ & GENDER & RACE & $\begin{array}{c}\text { AGE } \\
\text { BRACKET }\end{array}$ & $\begin{array}{l}\text { EDUCATION } \\
\text { EXPERIENCE }\end{array}$ \\
\hline 1 ELEMENTARY & $\mathrm{F}$ & W & $31-40$ & 12 \\
\hline 2 ELEMENTARY & $\mathrm{F}$ & $\mathrm{W}$ & $20-30$ & 2 \\
\hline 3 ELEMENTARY & M & W & $20-30$ & 4 \\
\hline 4 ELEMENTARY & $\mathrm{F}$ & W & $20-30$ & 1 \\
\hline 5 ELEMENTARY & $\mathrm{F}$ & W & $20-30$ & 3 \\
\hline 6 ELEMENTARY & $\mathrm{F}$ & W & $20-30$ & 0 \\
\hline 7 ELEMENTARY & $\mathrm{F}$ & W & $20-30$ & 2 \\
\hline 8 ELEMENTARY & $\mathrm{F}$ & W & $20-30$ & 6 \\
\hline 9 ELEMENTARY & $\mathrm{F}$ & $\mathrm{W}$ & $31-40$ & 7 \\
\hline 10 SECONDARY & M & W & $20-30$ & 0 \\
\hline 11 SECONDARY & $\mathrm{F}$ & W & $31-40$ & 10 \\
\hline 12 SECONDARY & $\mathrm{F}$ & W & $20-30$ & 0 \\
\hline 13 SECONDARY & $\mathrm{F}$ & W & $20-30$ & 1 \\
\hline 14 SECONDARY & $\mathrm{F}$ & W & $20-30$ & 2 \\
\hline 15 SECONDARY & $\mathrm{F}$ & W & $20-30$ & 4 \\
\hline 16 SECONDARY & $\mathrm{F}$ & W & $20-30$ & 0 \\
\hline 17 SECONDARY & $\mathrm{F}$ & W & $20-30$ & 2 \\
\hline 18 HIGHER ED & M & W & $20-30$ & 0 \\
\hline 19 HIGHER ED & $\mathrm{F}$ & W & $31-40$ & 10 \\
\hline 20 HIGHER ED & $\mathrm{F}$ & W & $20-30$ & 5 \\
\hline 21 HIGHER ED & M & W & $41-50$ & 2 \\
\hline
\end{tabular}


Table 3: Threaded Discussion Posts Sorted by Role

\begin{tabular}{|c|c|c|c|c|c|}
\hline Session & Total & Instructor & Elementary Education & Secondary Education & Higher Education \\
\hline $\mathrm{M}$ & 42 & 15 & 21 & 5 & 1 \\
\hline 1 & 87 & 18 & 31 & 24 & 14 \\
\hline 2 & 83 & 0 & 38 & 32 & 13 \\
\hline 3 & 117 & 6 & 57 & 35 & 19 \\
\hline 4 & 60 & 1 & 30 & 20 & 9 \\
\hline 5 & 64 & 0 & 29 & 23 & 12 \\
\hline 6 & 55 & 0 & 28 & 15 & 12 \\
\hline 7 & 60 & 0 & 28 & 23 & 9 \\
\hline 8 & 67 & 0 & 34 & 19 & 14 \\
\hline 9 & 94 & 0 & 48 & 31 & 15 \\
\hline 10 & 78 & 0 & 38 & 25 & 15 \\
\hline 11 & 77 & 0 & 41 & 21 & 15 \\
\hline 12 & 66 & 0 & 31 & 28 & 7 \\
\hline 13 & 86 & 0 & 48 & 25 & 13 \\
\hline 14 & 64 & 0 & 27 & 23 & 14 \\
\hline 15 & 70 & 0 & 34 & 22 & 14 \\
\hline Totals: & 1170 & 40 & 563 & 371 & 196 \\
\hline$\%$ & $100 \%$ & $3.4 \%$ & $48.1 \%$ & $31.7 \%$ & $16.8 \%$ \\
\hline Mean & & 40 & 63 & 46 & 49 \\
\hline$\%$ & & $3.4 \%$ & $5.34 \%$ & $4 \%$ & $4.2 \%$ \\
\hline
\end{tabular}


Table 4: Threaded Discussion Posts Sorted by Presence and Category

\begin{tabular}{|c|c|c|c|c|c|c|c|c|c|c|}
\hline \multicolumn{5}{|c|}{ Cognitive Presence } & \multicolumn{5}{c|}{ Social Presence } & \multicolumn{2}{|c|}{ Teaching Presence } \\
\hline Session & Trig & Exp & Int & Res & P/A & OC & GC & D\&O & Fac Di & DI \\
\hline M & 1 & 1 & 1 & 0 & 22 & 16 & 12 & 12 & 9 & 0 \\
\hline 1 & 1 & 31 & 21 & 0 & 50 & 27 & 43 & 0 & 18 & 16 \\
\hline 2 & 6 & 34 & 18 & 0 & 47 & 58 & 23 & 0 & 0 & 0 \\
\hline 3 & 3 & 31 & 28 & 3 & 71 & 59 & 19 & 1 & 5 & 1 \\
\hline 4 & 0 & 8 & 23 & 2 & 37 & 36 & 20 & 0 & 1 & 0 \\
\hline 5 & 2 & 8 & 23 & 1 & 39 & 39 & 9 & 0 & 0 & 0 \\
\hline 6 & 0 & 7 & 20 & 0 & 29 & 34 & 17 & 0 & 0 & 0 \\
\hline 7 & 0 & 13 & 19 & 3 & 39 & 32 & 10 & 0 & 0 & 0 \\
\hline 8 & 1 & 19 & 30 & 4 & 49 & 39 & 14 & 0 & 0 & 0 \\
\hline 9 & 0 & 4 & 23 & 1 & 49 & 69 & 16 & 0 & 0 & 0 \\
\hline 10 & 1 & 16 & 19 & 6 & 53 & 56 & 15 & 0 & 0 & 0 \\
\hline 11 & 0 & 17 & 25 & 10 & 44 & 48 & 9 & 0 & 0 & 0 \\
\hline 12 & 0 & 14 & 26 & 1 & 47 & 47 & 23 & 0 & 0 & 0 \\
\hline 13 & 7 & 24 & 29 & 6 & 43 & 57 & 23 & 0 & 0 & 0 \\
\hline 14 & 6 & 3 & 23 & 8 & 32 & 43 & 32 & 0 & 0 & 0 \\
\hline 15 & 0 & 2 & 11 & 22 & 54 & 55 & 26 & 0 & 0 & 0 \\
\hline Totals & 28 & 232 & 339 & 67 & 665 & 671 & 310 & 13 & 33 & 17 \\
\hline$\%$ & $2 \%$ & $20 \%$ & $29 \%$ & $6 \%$ & $57 \%$ & $57 \%$ & $27 \%$ & $1 \%$ & $3 \%$ & $1.4 \%$ \\
\hline
\end{tabular}


Figure 2: Threaded Discussion Categories of Presence over Time

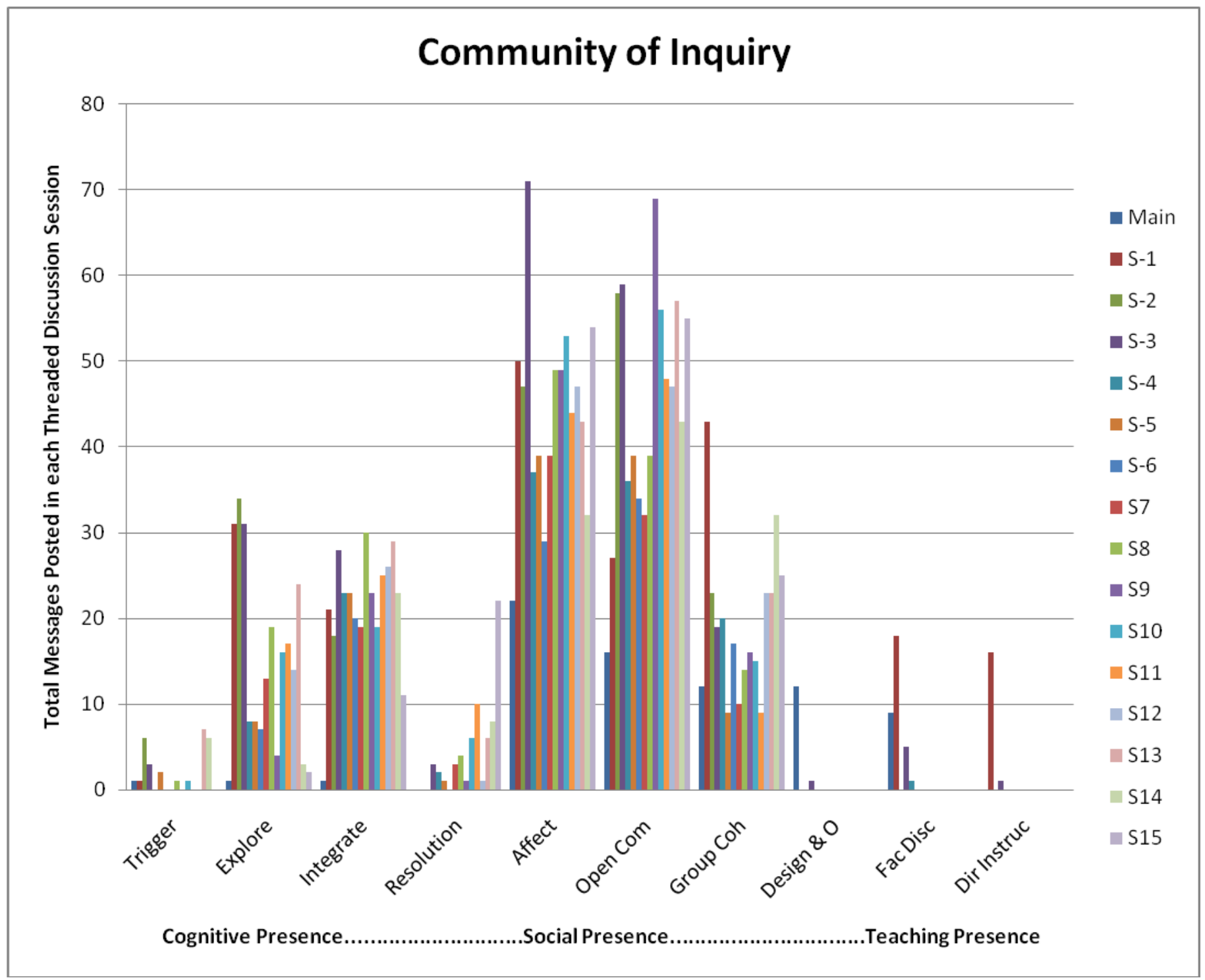

Figure 2. Plot of categories of presence found in each session of the threaded discussions over time 
Figure 3: Emails

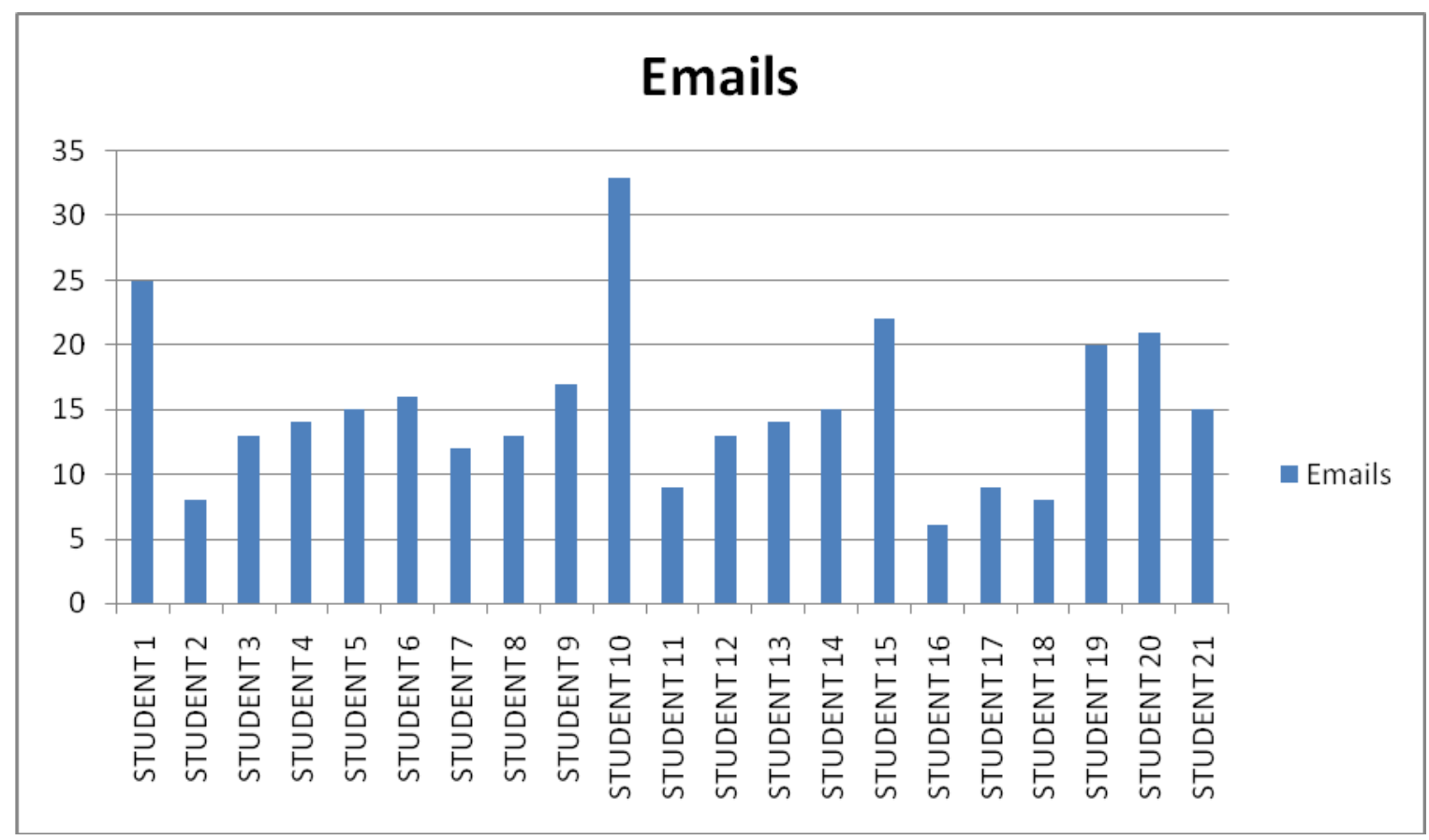

Figure 3. Emails sent by students to instructor over time 
Appendix C: $21^{\text {st }}$ Century Learners

\section{What is a 21 $1_{\text {st }}$ Century Learner?}

A 21st century learner is part of a generation that has never known a world without the Internet, without computers, without video games and without cell phones. They are digital natives who have grown up with information technology.

To these students, life without digital technologies seems alien. Their aptitudes, attitudes, expectations and learning styles reflect the stimulating environment in which they were raised. For most, instant messaging has surpassed the telephone and e-mail as the primary form of communication. Control, alt, delete is as basic to them as learning their $\mathrm{ABC}$ and $123 \mathrm{~s}$.

Twenty-first century learners are always on, always connected. They are comfortable multitasking. They sit at the computer, working on their homework while listening to an iPod. At the same time, they may have 10 different chat windows open, be playing a video game or surfing the Web while a TV blares in the background. To them, technology is only a tool that they can customize to access information and communicate.

Twenty-first century learners are multimedia oriented. Their world is Web-based. They want instant gratification. They are impatient, creative, expressive and social. They are risk-takers who thrive in less structured environments.

Constant exposure to digital media has changed not only how these students process information and learn but how they use information. Children today are fundamentally different from previous generations in the way they think, access and absorb information, and communicate in a modern world.

To cross the digital divide and reach these students, teachers must change not only what they teach, but how they teach. To do so, educators must acknowledge this digital world and educate themselves about it. To truly understand them, educators must immerse themselves in the digital landscape where the $21_{\text {st }}$ century learner lives. West Virginia's Global21 plan takes into account how students in the 21st century learn. Extensive professional development is a key element to help teachers alter their teaching techniques to better reach today's Wii generation. By changing how we teach from preschool to high school, students will be better prepared for the world that awaits them.

http://wvde.state.wv.us/global21/pdf/Global21-Learners.pdf

accessed 12:31PM June 27, 2009 


\section{What are $21_{\text {st }}$ Century Learning Skills?}

Twenty-first century learning skills can be categorized into three broad areas: Information and Communication Skills: Information processing skills include information and media literacy, visual literacy as well as communications and technology literacy, and oral, written and multimedia communication. These include using research tools, such as word processing, e-mail, presentation software and the Internet, to access, manage, integrate, create and communicate with others. Students with these skills can articulate thoughts and ideas clearly and effectively through speaking and writing. They demonstrate the ability to work well with diverse teams and exercise flexibility and willingness to be helpful in making necessary compromises to accomplish a common goal. They also assume a shared responsibility for collaborative work.

Thinking and Problem-solving Skills: These skills use problem-solving tools, such as spreadsheets, decision support and design tools, to develop critical thinking, systems thinking, problem solving, creativity and innovation. Students with these skills demonstrate originality and inventiveness in their work and develop, implement and communicate new ideas to others. They are open and responsive to new and diverse perspectives and act on creative ideas to make a tangible and useful contribution. They exercise sound reasoning in understanding and make complex choices and decisions. They understanding the interconnections among systems and ask significant questions that clarify various points of view and lead to better solutions. They frame, analyze and synthesize information to solve problems and answer questions.

Personal and Workplace Productivity Skills: These skills include interpersonal and collaboration skills, the ability to self direct, adaptability, ethical behavior, social/personal accountability, leadership, as well as project planning and development. Students who master these skills have the ability to adapt to varied roles and responsibilities, work effectively in a climate of ambiguity and changing priorities. They can monitor their own understanding and learning needs and demonstrate initiative to advance. They use time efficiently and manage workloads effectively. They also develop the ability to work productively with others of differing cultural backgrounds. They demonstrate diligence and a positive work ethic, including being punctual and reliable, as well as integrity, responsibility and ethical behavior.

http://wvde.state.wv.us/global21/pdf/Global21-Skills.pdf

accessed 12:19 PM June 27, 2009 